\title{
Structure and Mechanical Properties of Selected Protective Systems in Marine Organisms
}

\author{
Steven E. Naleway ${ }^{1, *}$, Jennifer R. A. Taylor ${ }^{2}$, Michael M. Porter ${ }^{5}$, Marc A. Meyers ${ }^{1,3,4}$, \\ Joanna McKittrick ${ }^{1,3}$ \\ ${ }^{1}$ Materials Science and Engineering Program \\ ${ }^{2}$ Scripps Institution of Oceanography, Marine Biology Research Division \\ ${ }^{3}$ Department of Mechanical and Aerospace Engineering \\ ${ }^{4}$ Department of NanoEngineering \\ University of California, San Diego, 9500 Gilman Drive, La Jolla, CA 92093, USA \\ ${ }^{5}$ Department of Mechanical Engineering, Clemson University, Clemson, SC 29634, USA \\ * Corresponding Author: snaleway@eng.ucsd.edu; tel: 1-541-255-9998; fax: 1-858-534-5698 \\ J. R. A. Taylor: j3taylor@ucsd.edu
}

M. M. Porter: mmporte@ clemson.edu

M. A. Meyers: mameyers@eng.ucsd.edu

J. McKittrick: jmckittrick@eng.ucsd.edu

\begin{abstract}
:
Marine organisms have developed a wide variety of protective strategies to thrive in their native environments. These biological materials, although formed from simple biopolymer and biomineral constituents, take on many intricate and effective designs. The specific environmental conditions that shape all marine organisms have helped modify these materials into their current forms: complete hydration, and variation in hydrostatic pressure, temperature, salinity, as well as motion from currents and swells. These conditions vary throughout the ocean, being more consistent in the pelagic and deep benthic zones while experiencing more variability in the nearshore and shallows (e.g. intertidal zones, shallow bays and lagoons, salt marshes and mangrove forests). Of note, many marine organisms are capable of migrating between these zones. In this review, the basic building blocks of these structural biological materials and a variety of protective strategies in marine organisms are discussed with a focus on their structure and mechanical properties. Finally, the bioinspired potential of these biological materials is discussed.
\end{abstract}

Keywords: Marine organisms; protective mechanisms; structural biological materials; bioinspired design 


\section{Introduction}

The study of biological materials within materials science provides the nexus where the fields of physics, engineering, chemistry and biology converge to understand and harness the vast body of knowledge that can be learned from the natural world. The findings of this research provide for better biological understanding of the complex and unique organisms and structures in nature. In addition, this knowledge provides inspiration for the peripheral fields of bioinspired materials, where synthetic structures are inspired by nature, and biomaterials, where materials and structures are designed for optimum compatibility with biological systems.

While still bound by the same physical laws, biological materials are starkly different from synthetic ones. To succinctly describe the unique qualities of biological materials, seven interrelated features have been identified (inspired by Arzt [1] and expanded by Meyers et al. and Chen et al. [2-5]). These characteristics are: self-assembly, multi-functionality, hierarchical design, hydration effects, mild synthesis conditions, evolutionary design and environmental constraints, and self-healing capability. While they apply throughout biology, marine organisms face a number of specific environmental constraints not shared by their terrestrial counterparts. These marine specific conditions include: complete hydration, and variation in hydrostatic pressure $(0.1-100 \mathrm{MPa})$, temperature $\left(-2-38^{\circ} \mathrm{C}\right)$, salinity $(34-36 \mathrm{ppt})$, as well as motion from currents and swells. These conditions vary throughout the ocean, being more consistent in the pelagic and deep benthic zones while experiencing more variability in the nearshore and shallows (e.g. intertidal zones, shallow bays and lagoons, salt marshes and mangrove forests). Of note, many marine organisms are capable of migrating between these zones, forcing them to be dynamic through many environments. Through evolution, these environmental constraints have shaped the form of all structural marine biological materials.

The combination of these qualities provides for high levels of complexity and performance within marine biological materials. This is enacted through hierarchical structural design elements [6]. The toughness of biological materials and their constituents is plotted as a function of the elastic modulus in Figure 1. The high toughness of biopolymers together with the high strength of biominerals are combined into many composite biological materials (e.g. bone and mollusk shell) [7]. When compared to engineered synthetic materials, metals and ceramics are capable of providing mechanical properties up to an order of magnitude higher than biological materials. 
However, biominerals (natural ceramics) and biopolymers (natural polymers) are mechanically comparable with many synthetic engineering composites and engineering polymers, respectively $[5]$.

Biological materials can be systematized along different classification methods. Naleway et al. [6] recently proposed eight structural design elements as a new paradigm for identifying common features in different organisms. Using a similar methodology, the organisms and structures in this manuscript can be divided into four classes based upon their biomechanical function:

1. Crushing resistant structures: found within the exoskeletons of mollusks, crustaceans, diatoms and coccolithophores, and the skeletal armor of the seahorse.

2. Flexure resistant structures: found within sea sponge spicules, the spines of sea urchins and porcupine fish.

3. Piercing resistant structures: found within the scales and scutes of fish as well as marine skeletal armors.

4. Impact resistant structures: found in the dactyl clubs of the mantis shrimp.

There are protective structures that provide effective resistance to multiple forms of stress, however here we aim to highlight the most remarkable defenses of individual organisms. We describe notable examples of organisms within each of these classes focusing primarily on systems that have a protective exoskeleton, or shell, that surrounds a soft body. The approach used here provides a valuable perspective on how the materials science methodology, connecting the structure (at various levels, from nano- to macro-) and mechanical properties, can enhance our understanding of nature and guide us to novel bioinspired designs.

Recent analysis suggests that $\sim 2.2$ million of the world's $\sim 8.7$ million eukaryotic species reside within the oceans and that $91 \%$ of these marine species have yet to be discovered and catalogued [8]. These organisms (Figure 2 shows some examples) offer an amazing array of traits and properties due to the design of their complex biological materials. The lessons learned from the structural biological materials of marine organisms have stimulated a number of bioinspired designs including high toughness materials inspired by abalone nacre [9], fiber optic wires inspired by sea sponge spicules $[10,11]$ and body armor inspired by fish scales [12,13]. Given the complex structures that have already been discovered and the immense number of organisms that have yet 
to be investigated, the study of structural biological materials of marine organisms offers much interest to the scientific community.

\section{Basic Building Blocks of Marine Organisms}

While there is a large variety of marine biological materials, the building blocks of these structures are quite simple. These consist of two basic classes: biopolymers (collagen, keratin and chitin) and biominerals (hydroxyapatite, calcium carbonate and amorphous silica being the principal ones). While these materials are simple, they are combined in a significant level of complexity. This can often allow for mechanical performance which exceeds that of the individual constituents [9]. Focusing on marine organisms, the mechanical properties of biological material constituents (Table 1) and a variety of biological materials (Table 2) are highlighted. The wide range of strengths and moduli that marine organisms employ in their biological materials in order to best thrive in their environment are shown in Tables 1 and 2.

In general, there are two basic forms of biological materials: (1) non-mineralized biological materials that consist of only biopolymers and usually take the form of directionally aligned fibers (e.g. aligned in parallel or helical patterns such as Bouligand configurations) and (2) mineralized biological materials which are composites composed of both biopolymers and biominerals arranged into hierarchical structures. In this review we focus upon protective and/or load bearing structural biological materials, most of which are mineralized.

The combination of high compressive strength of biominerals and high toughness of biopolymers is the key to incorporating these generally mutually exclusive properties (strength and toughness) [14] into many structural biological material. The balance between these properties has been

shown to relate to the mineral content where an increase relates to an increase in strength and elastic modulus with an accompanying decrease in toughness [15]. Table 3 displays the relative proportions of these phases in structural biological materials of marine organisms. Additionally, mammalian bone and human dentin are displayed for reference.

\subsection{Biopolymers}

Biopolymers make up the compliant phase in structural biological materials. In marine structural biological materials, the principal biopolymers are collagen, keratin and chitin. Collagen-based 
cartilage is also present in some marine organisms. Generally fibrous in nature, these structures can be highly anisotropic and tend to display varying mechanical properties depending upon their arrangement, alignment and organization. Additionally, they are generally stronger in tension than compression.

Collagen is one of the most important biopolymers found throughout the metazoan diversity and is the basic component in skin, tendon, bone and cartilage $[2,16]$. While there are no fewer than 29 different collagen types, the majority of collagen found in organisms ( $90 \%$ of collagen found in the human body) is type I collagen [16]. Within marine organisms, type I collagen has been extracted from the tissue of sea urchins [17, 18], octopus [19], starfish [20], jellyfish [21, 22] and a number of fish species [23-25].

Type I collagen takes the form of fibers and displays four levels of hierarchy from the molecularto macro- level (Figure 3) [16]. At the molecular level, triple helix segments (Figure 3a) assemble into tropocollagen molecules (Figure 3b) that further assemble into collagen fibrils exhibiting diameters of 50 - $200 \mathrm{~nm}$ (Figure 3c) [26] that finally agglomerate into collagen fibers with diameters of 0.5 to $3 \mu \mathrm{m}$ (Figure 3d) [16]. The offset of the tropocollagen molecules, diagramed in Figure $3 \mathrm{c}$ and imaged on collagen fibrils from a fish scale through atomic force microscopy $(A F M)$ in Figure 3e, creates a characteristic banding, periodically spaced at $67 \mathrm{~nm}$, on the collagen fibrils [3, 26-29].

Given their fibrous nature, the mechanical properties of collagen-based materials are highly anisotropic. Collagen structures tend to be highly oriented in order to provide optimized strength and mechanical properties along specific directions [7]. Collagen also often serves as a basic structural template for biomineralization [28].

Keratin is an integral element in the outer covering of many vertebrates and is commonly found in skin, hair, nails, beaks, turtle shells and hagfish slime [30-32]. There are two types of keratin: $\alpha$ keratin (Figure 4a) that forms in helices and $\beta$-keratin (Figure 4b) that forms in pleated sheets [30]. The fibrous structure of $\alpha$-keratin is similar to type I collagen as both consist of hierarchically assembled molecules, two polypeptide chains in $\alpha$-keratin (Figure 4a) and three tropocollagen molecules for type I collagen (Figure 3a). However, once the cells that produce keratin (keratinocytes) assemble, they die, resulting in a non-vascularized "dead" tissue that is in contrast 
to the extracellular "living" matrix of collagen, into which live cells are embedded [30]. Additionally, keratin can be considered a composite material, similar to synthetic semi-crystalline polymers, consisting of fibers of crystalline keratin reinforcing an amorphous keratin matrix (Figure 4c) [33]. While they have different forms, both $\alpha$-keratin and $\beta$-keratin have similar numbers of polypeptide chains, suggesting that they both originate from the same microfibril structure [34]. Within marine biological materials $\alpha$-keratin is much more common than $\beta$-keratin.

Quite similar to type I collagen, the mechanical properties of fibrous $\alpha$-keratin are highly anisotropic [35, 36]. Given this alignment, $\alpha$-keratin is capable of much higher mechanical properties parallel to the fiber direction than the more isotropic $\beta$-keratin [30]. Additionally, the composite nature of keratin results in a roughly inverse relationship between the stiffness (elastic modulus) and the volume fraction of amorphous matrix (less-crystalline composite) (i.e. as the content of the amorphous keratin increases, its stiffness decreases) [30, 37]. This relationship between crystallinity and elastic modulus is also common to semi-crystalline synthetic polymers $[38,39]$.

Chitin is found throughout a number of organisms and is the most abundant natural polysaccharide [40]. In marine biological materials it is mainly associated with the exoskeletons of marine crustaceans and mollusks and the beaks of squids and octopuses [40-42]. In squid beaks, chitin is cross-linked (also known as sclerotization or tanning) with proteins, forming a tough material despite lacking biominerals [42]. Two main varieties of chitin, $\alpha$-chitin and $\beta$-chitin (Figure 5a $5 b$ ), are commonly present in organisms, with $\alpha$-chitin being the most abundant. Specifically, $\alpha$ chitin is characteristic of crustaceans exoskeletons (Figure 5c) [28] while $\beta$-chitin is found in the pens of squid (the internal rigid structural element that supports the squid's mantle) [43] and the spines of diatoms. $\beta$-chitin is less crystalline than the more common $\alpha$-chitin and is metastable, being able to transform into stable $\alpha$-chitin if induced by the intercalation of molecules into its lattice [28]. Chitin chains are hierarchically organized into fibers of more than $1 \mu \mathrm{m}$ in diameter [28].

While chitin itself is often in a fibrous form, in most organisms it is aligned in helicoidal planes to form a twisted plywood or Bouligand structure (Figure 5d) [4, 44-47]. This structure provides for more in-plane isotropy, allowing for the use of relatively un-mineralized chitin in squid pens and crustacean exoskeletons while still maintaining strength and toughness [4]. 
Cartilage is generally an internal support structure in organisms and is comprised of a number of fibrous proteins (collagens) along with polysaccharides and peptides [48]. Cartilage can be either mineralized or non-mineralized and is most commonly associated with internal structures such as the skeletons of sharks, rays and chimaeras [49]. However, it is found within a number of mollusks, including cephalopods (e.g. squid) and gastropods (e.g. snails), generally within their fleshy tissues $[50,51]$. Mechanically, cartilage is a viscoelastic material that is highly variable in strength depending upon the level of mineralization [48].

\subsection{Biominerals}

Biominerals compose the rigid phase of structural biological materials. Biological composites are generally formed through biomineralization of biopolymer templates with minerals, primarily hydroxyapatite, calcium carbonate and silica [28]. However, magnetite $\left(\mathrm{Fe}_{3} \mathrm{O}_{4}\right)$ and iron sulfide (FeS) are also found within a select number of organisms [3].

Non-stoichiometric hydroxyapatite $\left(\mathrm{Ca}_{10}\left(\mathrm{PO}_{4}\right)_{6}(\mathrm{OH})_{2}\right)$, where 4-6\% of the phosphate groups are replaced by carbonate groups [52], constitutes the biomineral phase of bone, teeth and most fish scales [13,53-56]. Given its presence in the bones and teeth of humans, it has garnered a significant amount of research in the biomedical field, producing a number of bioinspired designs with a focus on biomedical materials and implants [9, 57-61]. Biogenic hydroxyapatite often forms around a collagen scaffold that directs growth (Figure 6a) [62]. As shown in Figure 6b - 6c for fish scales, this causes the hydroxyapatite to take on the structure of the templating constituent, in these cases type I collagen fibers [62-64]. As a result, the reactivity of the templating constituent has a significant effect on the adherence and structuring of hydroxyapatite in any biological material [65].

Calcium carbonate $\left(\mathrm{CaCO}_{3}\right)$ is the biomineral phase in many of the highly rigid marine biological structural materials such as the nacre of abalone, conch and other marine mollusks as well as urchin spines and some crustacean exoskeletons [66-69]. Amorphous $\mathrm{CaCO}_{3}$ is employed as a precursor to crystalline structures that generally take the form of aragonite (orthorhombic) or calcite (rhombohedral) depending on the growth parameters [68]. Biologically this differentiation is realized through the use of biopolymers and macromolecules as templating agents [69-71]. In structures such as mollusk nacre and sea urchin spines these crystals develop according to Kossel's 
model that states that growth occurs in a layer-by-layer fashion where new layers are started from island nucleation that grows in a plane until a new surface is completed (imaged in Figure 7a and diagramed in Figure 7b) [68], which results in faceted crystal structures (Figure 7c). This is due to the fact that growth occurs preferentially along surfaces with steps where more than one attachment is ensured, thus lowering the total energy of each atomic attachment event. Additionally, in many marine organisms (e.g. sea urchins, corals and crabs) other minerals such as magnesium and bromine are incorporated into $\mathrm{CaCO}_{3}$ crystal structures to improve the mechanical strength [72$75]$.

Silica $\left(\mathrm{SiO}_{2}\right)$ is most commonly expressed within the biological materials of sponges and diatoms [76-81], and is generally found in its amorphous form [76-79]. The biomineralization of $\mathrm{SiO}_{2}$ follows different processes in different organisms. In sponges and diatoms the biomineralization of $\mathrm{SiO}_{2}$ occurs similarly to hydroxyapatite and $\mathrm{CaCO}_{3}$ by forming an essential skeleton to provide both structure and mechanical strength $[4,79,82]$. Given its amorphous nature, and unlike $\mathrm{CaCO}_{3}$ and hydroxyapatite, there is no dominant structure of biological $\mathrm{SiO}_{2}$ with it appearing in multiple forms (e.g. spicules, Figure 8) in a single organism [76, 83]. These silica structures are templated by biopolymers into the structural elements of many marine organisms.

Magnetite $\left(\mathrm{Fe}_{3} \mathrm{O}_{4}\right)$ is found within a number of marine bacteria $[84,85]$ as well as sea turtles $[86$, 87] and some crustaceans [88]. $\mathrm{Fe}_{3} \mathrm{O}_{4}$ is rarely employed as a broad structural material in organisms, but rather within individual organs for a specific function. However, it is present as a structural material in the teeth of chitons, where it is employed in order to increase hardness [89]. Given the magnetic properties of $\mathrm{Fe}_{3} \mathrm{O}_{4}$, it is most often employed as a bio-compass allowing marine organisms such as lobsters and sea turtles to orient themselves to the earth's magnetic field and travel without other sensory cues $[84,85,88,90]$.

Though uncommon, iron sulfide $(\mathrm{FeS})$ is found within deep sea organisms: commonly bacteria, tube worms and a few gastropods, where the FeS is made available by deep sea vents [91, 92]. It is often deposited on or absorbed into organisms and incorporated into their dermis to create an outer FeS shell [92].

While the biominerals described above are the most common, there are around sixty currently described minerals in biological materials. These include carbonates (e.g. vaterite), phosphates 
(e.g. struvite, francolite), halides (e.g. fluorite), sulfates (e.g. gypsum, barite), oxides and hydroxides (e.g. goethite, ferrihydrite) and sulfides (e.g. pyrite) [4].

\section{Crushing Resistant Structures}

\subsection{Mollusk Shells}

Many mollusks protect themselves from predators with hard external shells composed of a brittle external calcite layer and a tough internal layer composed of aragonite, chitin and proteins, also known as nacre or mother-of-pearl (shown in Figure 9a for the example case of abalone) [67, 9395]. These shells forfeit all flexibility in favor of high strength, which is reflected in the relative proportions of rigid biomineral to ductile biopolymer found in the shells of red abalone (19:1) [96], where biomineral severely outweighs biopolymer. In spite of this, many of these shells manage to provide optimized toughness, much higher than pure calcium carbonate [7, 67, 93]. This is realized through the brick-and-mortar structure of nacre (Figure 9b) [67, 93, 94].

In order to grow this tough microstructure, mollusks employ complex assembly techniques. In the example case of abalone, growth is mediated by an organic interlayer comprised of chitin, an organic silk and acidic proteins in such a manner that successive layers of calcium carbonate (aragonite) tablets are deposited (Figure 10a) [95, 97-100]. Naturally, the growth of aragonite crystals is highly anisotropic, with the $C$ direction in the orthorhombic cell (normal to the largest surface) having a much greater velocity than either of the orthogonal $A$ or $B$ directions. This would lead to the formation of needle-like structures without mediation. In order to regulate the growth, the epithelial layer of the organism generates a porous chitin-based membrane and deposits it on the growth surface. The sequence shown in Figure 10a (progressing from top to bottom) shows the deposition of one such layer and the manner by which it alters the growth. The $C$-growth direction is slowed down, while growth in directions $A$ and $B$ proceeds normally as the $\mathrm{Ca}^{+2}$ and $\mathrm{CO}_{3}{ }^{-2}$ ions traverse the membrane. The resulting shape of the crystal is changed from a needle to a hexagonal prism. Lateral growth continues until the tablets (tiles) abut each other. In this manner, terraced cones (also called "Christmas trees") are created. Figure 10b shows a scanning electron microscopy (SEM) image of the growth surface. This results in growth of a lamellar, brick-andmortar structure with $\mathrm{CaCO}_{3}$ tablets (tiles) held together by an organic mortar and mineral bridges 
$[95,97]$. This growth has been shown to depend strongly on both nutrient availability and ambient environmental conditions [101].

At quasi-static loading rates in compression, the shells of abalone [66, 97, 102, 103], conch [104, 105] and giant clam [96] employ a variety of toughening mechanisms, realized through the brickand-mortar structure of their nacre, including crack deflection and microbuckling of the calcium carbonate plates to induce a gradual "graceful failure." These toughening mechanisms are imaged in Figure 9c-9d. Within brittle materials, where there is limited plastic deformation to absorb energy, fracture toughness is increased by toughening mechanisms such as the ones listed above that force a crack to propagate through a long and tortuous path [106, 107]. A more tortuous crack path requires that additional surface area is created to induce catastrophic failure, thereby increasing the toughness.

The brick-and-mortar structure of nacre provides a highly tortuous crack path, redirecting the crack front at angles near $90^{\circ}$ (as shown in Figure 9c). Of additional importance, in the cases of abalone and conch, both show an increase in strength of $\sim 50 \%$ at high strain rates that are more representative of the crushing bites of predators $[102,104]$. Given the success of this system in the natural world, it has led to bioinspired designs of ceramics with toughness that surpasses that of their monolithic equivalents [9, 108].

Beyond the toughened shells of abalone, conch and clams, there are a number of other marine mollusks that provide intriguing mechanical properties and bioinspired potential. An example is the deep sea scaly-foot gastropod Crysomallon squamiferum (Figure 11), which employs an outer layer of FeS and a calcified inner layer that are separated by a relatively thick organic layer [92, $109,110]$. FeS is deposited on the surface of the mollusk by the deep sea vents in its natural habitat and incorporated into its structure $[92,110]$. These FeS deposits are referred to as "sclerites," or elements of deposited mineral that are held together by a matrix (in this case the thick organic layer) in order to form a protective coating [92].

Another intriguing marine mollusk is the chiton. Chitons have one of the more complicated shell structures of any mollusk despite being reported to be the most phylogenetically primitive. They are often referred to as "living fossils," since their appearance has not changed much in over 500 million years [111]. There are eight overlapping plates (valves) on their dorsal surface that are 
surrounded by a tough, leathery organic substance called a girdle, which often has mineralized scales or spicules [112]. This configuration allows the animal considerable flexibility compared to other mollusks. They can bend either upward for movement or downward to curl up into a ball for defensive purposes. Figure 12a shows photographs of the valves and of the animal curled up. From the dorsal to ventral surfaces, six layers in mid-section valves were identified that have granular, prismatic or crossed-lamellar microstructures of aragonite crystals [113]. The interconnection between the valves was described as an actuating sandwich structure consisting of two valves separated by compliant muscles that operate to provide motion [113]. Of additional interest, the chiton Cryptochiton stelleri has adapted to produce extremely hard and wear-resistant teeth of $\mathrm{Fe}_{3} \mathrm{O}_{4}$ and $\alpha$-chitin to scrape algae off of rocks (Figure 12b) [89, 114, 115]. The teeth themselves mineralize in a four-step process: (1) forming a pure chitin scaffold tooth, (2) precipitating crystals of an intermediate and metastable iron oxide (ferrihydrite), (3) transforming the ferrihydrate into $\mathrm{Fe}_{3} \mathrm{O}_{4}$ and (4) allowing for $\mathrm{Fe}_{3} \mathrm{O}_{4}$ crystal growth $[89,116]$. This mineralization process is driven by acidic macromolecules that pattern the chitin scaffold [116].

\subsection{Diatom and Coccolithophore Exoskeletons}

Diatoms and coccolithophores are both unicellular phytoplankton (algae). Diatoms, commonly found throughout the ocean, produce rigid external cell walls (or exoskeletons) formed from hydrated amorphous silica and range in diameters from 10 - $150 \mu \mathrm{m}[117,118]$. Despite their often microscopic size, the sheer biomass of diatoms causes them to account for $40 \%$ of the primary production of carbon [119] and the majority of biogenic silica (silica transformed from dissolved silicate into skeletal material) [120] in the oceans. While diatoms often exhibit simple geometric profiles (Figure 13a), their surfaces (called "frustules") are adorned with complex structures (an example is shown in Figure 13b). Both of these length scales provide structural protection. The geometric profiles provide strength against engulfing and crushing attacks from larger predators (e.g. crustacean zooplankton) while the frustule provides protection from the attacks of smaller predators (e.g. parasitoid and ingesting protists) [121]. As there is an immense number of different profiles [122], it has been theorized that diatom species have evolved to defend against specific local predators [121]. The strength of the frustule itself varies by up to an order of magnitude along the diatom surface with the maximum strength approaching that of pure silica [123-125]. This variation has been associated with different regions of the exoskeleton's growth, with the highest 
strength region running along the center of the body, effectively creating a load-bearing beam of harder material (Figure 13c) [124].

The complex frustules of diatoms are often researched because they manage to rapidly create complex structures of silica at or near room temperature [126]. This is achieved through the deposition of micro- and nano-spheres of amorphous silica by species-specific polyamines in a specialized membrane called the silica deposition vesicle (Figure 14a - 14b) [126, 127]. The complex structures themselves have been proposed to be the result of a continuous phase separation process where a silica phase is constantly deposited at the edges of a water phase in order to create increasingly smaller patterns (Figure 14c) [128]. The structure of the diatom exoskeleton is controlled by the availability of the necessary nutrient: silicic acid (the naturally available silica precursor in the oceans), causing both the strength and structure to diminish when depleted [117].

Coccolithophores have a spherical shell composed of over 30 calcium carbonate plates (diameters $2-10 \mu \mathrm{m}$ ) called coccoliths (Figure 15a). Similar to diatoms in that they possess strikingly beautiful periodic shells, they tend to be smaller, having overall diameters between $5-100 \mu \mathrm{m}$. The shells are thought to protect the cell from osmotic, chemical and physical shocks and from UV light [129]. There are over 100 species of coccolithophores and they are the only organisms that produce mineralized materials intracellularly [130]. There are two types: heterococcoliths, which have crystal elements with different sizes and morphologies (Figure 15a), and the less common holococcoliths, which are composed of identical single crystal elements (Figure 15b). In the heterococcoliths, most of the elements in the plate are single crystal rhombohedral calcite, which has a different morphology than inorganic calcite [131]. These organisms are thought to be an important indicator of ocean acidification, as they decrease the $\mathrm{pCO}_{2}$ in the upper euphotic zone through photosynthetic fixation of $\mathrm{CO}_{2}$ into organic molecules [132].

\subsection{Crustacean Exoskeletons}

The crustacean exoskeleton is a multi-layered, multi-functional cuticle that affords favorable mechanical properties in a lightweight structure. The calcified cuticle is made up of chitin fibers mineralized with calcium carbonate [133], although some crustaceans employ other elements as reinforcing agents (e.g. magnesium, bromine). The cuticle is comprised of four distinct layers that 
differ in structure, composition, and mechanical properties. The outermost layer is the epicuticle, which is thin and mineralized [134]. As this is the outermost layer, one of its primary functions is a barrier to the external environment. Beneath the epicuticle lies the procuticle, subdivided into the exocuticle and endocuticle, which serve as the load bearing layers. Both the exocuticle and endocuticle are composed of a chitin-protein matrix embedded with mineral. The epicuticle, exocuticle and endocuticle are displayed in Figure 16a. Chitin and protein bundles are arranged in horizontal planes, or lamellae, that are stacked into a helicoid, or Bouligand, structure (highlighted in Figure 16b) [135]. A series of pore canals traverse the lamellae of both the exocuticle and endocuticle, creating a honeycomb-like structure that contributes to the strong, lightweight design [136]. Generally, the endocuticle is the thickest and most variable layer. The fourth, innermost membranous layer is a non-mineralized matrix, which is present in only some crustaceans and is not thought to contribute to the cuticle mechanical properties.

Although the load bearing layers have the same architecture, they differ in stacking density and crystallinity, affording a gradient of mechanical properties. Typically, the exocuticle lamellae are denser than those of the endocuticle $[133,137]$. The crystallinity of the exocuticle not only differs from the endocuticle, but it also exhibits a gradient within it; amorphous calcium carbonate occurs in the proximal end, near the interface with the endocuticle, and transitions to calcite at the distal end $[138,139]$. In contrast, the endocuticle contains magnesium calcite and amorphous calcium carbonate [139]. These differences result in the exocuticle being both harder and stiffer than the endocuticle [133, 137, 140-142]. As the exocuticle increases in hardness toward the interface with the endocuticle, there is an abrupt change in both hardness and stiffness of more than an order of magnitude between these two layers [137].

Despite the cuticle being brittle and prone to delamination [133, 143, 144], the Bouligand structure of the procuticle layers affords some toughness by crack deflection and bridging, which force cracks to propagate in a tortuous, stepwise fashion [142]. The ductile pore canal tubules are also thought to enhance toughness, as necking is observed during tensile testing normal to the cuticle surface [133].

Crustaceans exhibit variation in cuticle mineralization and structure (e.g. layer thickness, stacking density) across species and across functional regions within an individual. For example, appendage joints contain non-calcified arthrodial membranes that must remain soft and flexible to permit 
rotation [145]. There are also great differences between the cuticle of the carapace, which protects internal organs and resists compression, the walking legs, which primarily resist muscle contraction forces, and the claws, which function as weapons and prey capture devices. In crab claws, for example, the exocuticle is 3-4 times harder than the walking leg exocuticle, and this is primarily due to its greater mineral content [133]. The effectiveness of claws in securing prey depends not only on their hardness, but also on their resistance to cracking and abrasion. In some crabs, such as stone crabs, the claw tips are darkly pigmented and even harder and tougher than non-pigmented areas, possibly due to the increased cross-linking associated with tanning and reduced porosity [146]. Other crabs, such as shore crabs, enhance their claws by adding bromine rich tips that can afford an order of magnitude increase in fracture resistance compared to calcified tips $[74,75]$.

The intricacy and variability of the crustacean cuticle is even more impressive considering that, unlike mollusk shells that form by accretion, crustaceans repeatedly shed and secrete a whole new cuticle during the process of molting. The secretion of matrix to form the cuticle layers and the subsequent deposition of mineral occur rapidly, over the course of days, and as frequently as once per week in small juveniles. Cuticle formation is a conserved and intricate process, but can be affected by environmental conditions such as ocean carbon chemistry.

\subsection{Seahorse Skeleton}

Seahorses (Hippocampus) have plated skeletons that cover their bodies and prehensile tails (Figure 17a). Unlike most fish, seahorses swim upright, utilizing their dorsal fin for propulsion and two pectoral fins for maneuverability, resulting in slow swimming velocities [147-149]. Thus, they use their prehensile tails for stability, gripping and holding onto objects such as sea grasses, mangrove roots, and coral reefs [147]. The tail skeleton is composed of several articulating segments arranged into cross-sectional squares, each composed of four bony plates that surround a central vertebra (Figure 17b) [147-154]. These plates are connected by overlapping joints that allow them sufficient flexibility for grasping as well as added strength for armored protection [154]. In grasping, the square structure of the tail provides more surface contact and a mechanism for maintaining organization of the articulating plates [154]. When the tail (of a deceased seahorse) is crushed, it can be compressed up to nearly $50 \%$ of its original width before fracture of the vertebral column (Figure 17c) [150]. This unique energy absorption mechanism provides seahorses protection 
against predators, many of whom attack by crushing (e.g. claws of crabs, beaks of sea turtles and birds) [155].

\section{Flexure Resistant Structures}

\subsection{Sea Sponge Spicules}

Sea sponges produce a rigid skeleton to provide both structure and protection from predators. This skeleton is made up of needle-like spicules of amorphous silica, templated by axial collagen fibers $[10,11,82,156-158]$ that are encased in a collagen net $[10,156]$. The structure is diagramed in Figure 18a. Of particular interest, silica is not necessary for growth of the sponge as it has been shown that, when deprived of silica, the silicatein (protein) axial filaments will continue to grow [159]. The structure (Figure 18b - 18c) consists of concentric rings (similar to tree rings), which surround the axial filament. While not to the extent found in mollusk shells, sea sponge skeletons are highly mineralized (3:1 biomineral to biopolymer [82]). These rings are held together with a "mortar" of silicatein $[2,82,157,158,160]$. The sea sponge employs the toughening mechanism

of crack deflection (Figure 18d - 18e) to create an elongated and more tortuous crack path [161], thus increasing the fracture toughness significantly over that of its pure constituent, silica glass (Figure 18f) [161].

While the microstructural toughening mechanisms of sea sponges provide for a strong biological structural material, certain species employ additional hierarchical mechanisms as well. Euplectella aspergillum employs a complex macrostructure skeleton in order to provide high bending and flexural strength while minimizing material volume (Figure 19a) [157, 158]. It utilizes a lattice of longitudinal, transverse and diagonal struts (each comprised of a bundle of spicules) in order to resist forces in a wide range of directions (Figure 19b - 19d). Around the exterior, spiraling ridges are aligned at an angle of $\sim 45^{\circ}$ in order to resist the maximum structural torsion and bending forces (Figure 19b). Reinforcements such as these (set at $45^{\circ}$ ) have been shown to best resist torsional forces in composite structures [162].

\subsection{Sea Urchin Spines}

Sea urchins belong to the phylum Echinodermata, which also include sea cucumbers, starfish and sand dollars. Urchins are characterized by having five-fold symmetry, a collagenous dermis 
overlying an endoskeleton (test) formed by fusion of calcite ossicles (plates) and spines that radiate from the test. An example of an urchin (Paracentrotus lividus) and its test are shown in Figure $20 a-20 b$.

Urchins are highly diverse, ranging throughout every marine environment from polar to tropical temperatures and down to depths of $5000 \mathrm{~m}$. Most of their spines are long and pointed, since they function as protection from predators. Spines can range up to $30 \mathrm{~cm}$ in length and up to $1 \mathrm{~cm}$ in diameter [163]. Figure 20c shows a spine fracture surface imaged by SEM from Paracentrotus lividus, illustrating 20 plates that radiate from a central core. The spines are porous crystals of a highly $\mathrm{Mg}$-substituted calcite, $\mathrm{Mg}_{\mathrm{x}} \mathrm{Ca}_{1-\mathrm{x}} \mathrm{CO}_{3}(0.02 \leq \mathrm{x} \leq 0.15)$. Substitution of $\mathrm{Mg}$ into the calcite structure results in a harder material. Figure 21 shows SEM micrographs of a Heterocentrotus mammillatus spine, revealing a radial sequence of porous and dense layers that are attributed to growth rings. There is a gradient in porosity, with porosity increasing substantially from $\sim 10 \%$ on the surface and in the growth rings to $\sim 60 \%$ in the medullary core. These spines are a model for biologically controlled crystal growth and consist of a mesocrystal [164, 165]. Originally thought to be a single crystal $[166,167]$, it has recently been shown that the structure consists of periodic and uniform nanocrystals, 30 - $50 \mathrm{~nm}$ in diameter, with parallel crystallographic alignment (Figure $22 \mathrm{a}-22 \mathrm{~b}$ ) [68, 163-165]. These nanocrystals are held together with layers of amino acids (mainly aspartic and glutamic acid) with a thickness of several hundred nanometers [165-167]. This results in a structure that fractures in a manner similar to a glass (Figure 22c) but presents the diffraction pattern of a single crystal [164].

Mechanically, the spines have been shown to preferentially fail at the proximal end when tested in a bending mode, which was found to be associated with the relatively higher concentration of magnesium at the base of the spine [168]. This, coupled with the fact that sea urchins are capable of repairing and regenerating spines that have been damaged or completely severed [169, 170], suggests that the spines themselves are designed to fracture when stressed, potentially remaining within a predator to deter further attack. Figure 23 shows a sketch of the cross section, an X-ray computer tomography micrograph along the length of a Heterocentrotus mammillatus spine and compressive force-displacement data [163]. The compressive force-displacement curve displays a graceful failure instead of a catastrophic failure typified of monolithic ceramics. The forcedisplacement curve resembles that of a classical cellular solid, as described by Gibson and Ashby 
[171]. The peak stress is related to the strength of the dense outer sheath, whereas the subsequent plateau region relates to the failure of the highly porous region, dependent on the density and other elastic properties of the solid material. This value is similar to the bending strength of spines of another species (Heterocentrotus trigonarius), which contained $80 \mathrm{~nm}$ protein inclusions [172]. Furthermore, it was pointed out that the strength to weight ratio of the spines is greater than that of mollusk shells and calcareous rocks, indicating the animals use calcite with high efficiency [173].

Though not a protective structure, the teeth of the sea urchin have garnered a significant amount of interest for their complex self-sharpening and self-assembly mechanisms. These teeth, despite being composed primarily of calcite, are able to grind through rocks of a similar composition [174176]. This is achieved by highly aligned and continuous growth of $\mathrm{Mg}$-reinforced calcite that results in self-sharpening grinding tips $[174,176]$. The $\mathrm{Mg}$ concentration increases towards the distal end of the teeth resulting in strengthened tips that can grind away calcite rocks.

\subsection{Porcupine Fish Spines}

Within the order (Tetraodontiformes) [177], the spines of Diodontidae (porcupine fish) (Figure 24) have developed to provide an active form of defense. These long spines are embedded within the skin of the fish and can, in many species, become erect as the fish inflates [178] and similarly to the spines of the sea urchin, must be capable of resisting bending and flexure in order to provide effective defense. These spines are controlled by arrays of collagen fibers that wrap around the base [178]. In spite of this inventive protective mechanism, there is a current lack of knowledge concerning the mechanical and material properties of these spines.

\section{Piercing Resistant Structures}

\subsection{Overlapping Fish Scales}

Fish scales provide protection from a variety of predators by integrating highly ordered type I collagen fibers with hydroxyapatite biomineral [13, 179, 180]. Scales are composites that are composed of multiple layers. These generally include mineralized collagen and enamel-like (or bony) layers (examples shown in Figure 25a) [13, 180-182]. When a collagen layer is formed, it often has a Bouligand-like structure in order to provide increased toughness and strength in many 
directions [44, 183]. Scales are most commonly arranged in overlapping sheets that allow for smooth motion of the body for locomotion while ensuring full coverage for protection from predators $[13,180]$. This overlapping pattern minimizes drag to ease swimming by regulating wave propagation about the body [184-186]. While scales can vary greatly in size, shape and arrangement from species to species, they have been classified into three relevant general groups: placoid, elasmoid (with two sub-groups: cycloid and ctenoid) and cosmoid [13, 180]. A fourth group, ganoid scales, are rare and only reported in predominantly freshwater fish such as gars [187] and bichirs [181] and, as a result, will not be discussed here. Finally, a fifth group, scutes, will be discussed later.

Placoid scales (Figure 25b) are found on many cartilaginous fish, including sharks and rays. In shark species, they are specified as odontodes, where they display a "tooth-like" appearance [188]. They consist of an outer layer with large vascular spaces and a lamellar inner layer [189]. As these are cartilaginous fish and are without bone, the same applies to their scales. Placoid scales are specifically designed to have a surface structure that generates small-scale vorticities in water, thereby decreasing drag.

Elasmoid scales can be subdivided into cycloid and ctenoid scales (ctenoid scale imaged in Figure $25 \mathrm{c})$. They are found in teleosts, a major group of marine and freshwater fish that includes more than 26,000 species within 40 orders and 448 families; the majority of living fishes are members of this group, including the striped bass (Morone saxatilis) $[180,190,191]$ and sea bream (Pagrus major) [64]. Cycloid scales, found mainly in soft fin ray fish, such as salmon, carp and eels, have a smooth margin. In contrast, ctenoid scales, found mostly in spiny fin ray fish such as perch, grunion and swordfish, have a comb-like scale with teeth or serrations on the margin. Through the cross-section, the ctenoid scales of the striped bass have a bony outer layer and a collagen inner layer with the same thickness [180]. The collagen layer is formed from 4-5 $\mu \mathrm{m}$ thick collagen lamellae, which are oriented in a Bouligand arrangement that varies from species to species [180]. These collagen fibrils are mineralized at the scale's smallest length-scale, forming a staggered array with nanoplatelets of hydroxyapatite between the heads and tails of the molecules.

Latimeria (coelacanth) (Figure 26a) are one of very few extant species, others include certain Neoceratodus (lungfish), known to exhibit cosmoid scales (Figure 26b). The first live coelacanth, long considered extinct, was caught on the east coast of South Africa in 1938. The scales consist 
of isopedine (dense lamellar bone), spongy bone and cosmine (similar to dentin) layers [189, 192194]. Given their scarcity, the exact structure of cosmoid scales is of debate. Smith et al. [192] found that the isopedine layer consists of densely packed collagen fibers and only the most superficial portion of the scale is mineralized, while some other investigators [193-195] contrarily held the opinion that the entire scale was mineralized. New research has been able to clarify this discrepancy and has shown that the scales consist of a highly mineralized surface and less mineralized base [196]. Similar to elasmoid scales, this collagen base is formed from lamellae of collagen fibers, however, these cosmoid scales also exhibit struts that connect adjacent lamellae and provide additional rigidity (Figure 26c) [196].

Fish scales are generally designed to defend against the bites of piscivorous predators. Mechanically, this can be translated to piercing forces applied by sharp and/or jagged objects with a small surface area (i.e. teeth) $[25,197,198]$. This requires a composite with a surface strong enough and hard enough to withstand the high stresses and piercing nature of teeth without fracture and a base with enough toughness and ductility to absorb the compressive force of jaws and distribute it over a broader area. All fish scales achieve both of these goals with a heavily mineralized outer layer made of ganoid or hydroxyapatite-based coatings and a tough base usually made of bone or collagen fibers. This has been experimentally shown on the scales of the sea bass [191] where the hardness decreases through the thickness of the scale towards the proximal surface $[181,198]$. Of note, this collagen base has been shown to be amongst the toughest biological materials known [199]. In addition to the mechanical properties of the fish scale layers, there are specific design qualities that dictate the ability of scales to provide protection while still maintaining mobility and minimizing weight. These include the amount of overlap or imbrication, the ratio of the scale length to thickness and the ratio of the scale length to the overall fish length.

\subsection{Marine Scutes and Skeletal Armors}

While most fish scales are overlapping, the examples of both fish scutes and skeletal armors provide alternative modes of protection. Similar to fish scales, both are composites that consist of hydroxyapatite and collagen. While still providing effective protection against predators, these armors do so in very different and distinct ways. 
Sea turtles are an organism that employs plated skeletal armor. These armors are formed from individual osteoderms, the bone-like reptilian counterpart to scales [13, 200]. These exhibit a cellular sandwich structure consisting of a porous interior and dense exterior allowing for weight savings while maintaining stiffness. The leatherback sea turtle (Figure 27a, Dermochelys coriacea) is of particular interest as it is capable of diving to depths in excess of $1200 \mathrm{~m}$ [201]. This is made possible by sutured interfaces between the osteoderms of its shell (Figure 27b - 27c), allowing it some flexibility (up to $\sim 15^{\circ}$ of rotation) in order to accommodate the severe hydrostatic pressures of the turtle's deep ocean environment, which can reach as high as $\sim 10 \mathrm{MPa}$ (at $1200 \mathrm{~m}$ of depth) $[13,200]$. Specifically, the sutured interface employs a gap between the osteoderms (Figure 27d) along with an array of tridimensional suture teeth (Figure 27e) that enable this flexibility.

The scutes of boxfish (Ostraciidae) provide a very different mechanism for protection than fish with overlapping scales. These scutes are composed of a rigid mineral surface (hydroxyapatitebased) and a compliant collagen base (type I collagen) (Figure 28a) [12, 202]. While these constituents are similar to other fish scales, the way that they are implemented is quite different, with non-overlapping scutes that connect with sutured interfaces. The ratio of biomineral to biopolymer in the scutes is $1: 2$ [12] which is in stark contrast to many other dermal armors such as the seahorse $(\sim 2: 1)$ [150] and alligator $(\sim 2: 1)$ [203]. This suggests an armor based primarily in collagen as opposed to more common mineral-based armor. Of additional interest, when mechanically tested, the mineral surface remains intact while the collagen base deforms significantly (Figure 28b - 28c) [12]. While this likely lowers the overall strength, it ensures that failure occurs in a predictable and controlled manner.

\section{Impact Resistant Structures}

\subsection{Mantis Shrimp Dactyl Club}

The mandible of the mantis shrimp (highlighted in Figure 29a) is perhaps the most remarkable adaptation of the crustacean cuticle. It must resist tremendous impact forces as they rapidly unfurl to strike hard-shelled prey. The impact surface of the smashing mantis shrimp species, the dactyl club, changes in structure from an inner bulk area of chitin fibers to an outer, heavily calcified impact surface, with the highest degree of crystallinity at the impact surface (Figure 29b) [204, 205]. The bulk area primarily contains amorphous calcium carbonate that transitions to amorphous 
calcium phosphate $[205,206]$ and then ultimately a hyper-mineralized fluorapatite with calcium phosphate at the surface [204]. These changes in crystallinity and mineral result in increasing stiffness and hardness toward the impact surface, with hardness six times greater in the impact region [204-206]. Similar to other regions of cuticle, the impact region is toughened with chitin that absorbs energy and limits crack propagation. In the dactyl club, cracks typically nucleate in the bulk region and are deflected in the impact region due to a modulus mismatch, which contains them mostly within the bulk region [205]. In this region, cracks propagate in a helicoidal pattern, creating a larger crack surface area, and are stopped quickly when traversing the helicoid trajectory by an oscillation in stiffness [205]. In addition, this structure has been shown to effectively disperse the stress pulse waves generated during impact [207]. Combining a hard outer layer with an inner, energy dispersive matrix is reminiscent of human-made impact resistant armor.

\section{Bioinspired Materials Potential}

The study of protective marine biological materials is leading to significant bioinspired materials and designs. These allow for the lessons learned from marine biological materials to affect and improve everyday life. Though not an extensive list, we provide a few examples here as an introduction to the materials and research provided by bioinspiration.

- Crush resistant, high toughness ceramics based upon the tough and highly mineralized shells of abalone [9, 108]: the nacre-inspired brick-and-mortar structure of these ceramics are fabricated through an ice templating process called "freeze casting" [57] followed by compression and infiltration with a second phase. They can be infiltrated with polymers or metals to form composites whose toughness is significantly greater than that of their base constituents.

- Flexure resistant fiber optics based on strong and tough silica spicules of sponges [10, 11]: the structure of the spicules is comprised of three sections: a core with a high refractive index, a low refractive index cylindrical tube and an outer portion with a progressively increasing refractive index [10]. These properties allow for effective light transmission. More importantly, the layered structure provides enhanced toughness.

- Pierce resistant body armor based upon the overlapping protection of fish scales [56]: perhaps the most common marine organism bioinspiration source, these armors date back to the scaled armor of the Roman Empire, the "Lorica Squamata" (Figure 30a) [48]. This 
armor consisted of individual, overlapping metal scales (called "squamae") set over a leather shirt, thus providing both a hard penetration resistant surface and a tough energy absorbent base. Modern examples of fish inspired armor include the recently developed "Dragon Skin" armor that consists of circular, ceramic, bulletproof plates oriented in overlapping arrays within a wearable vest (Figure 30b) [13, 48].

- Impact resistant fiber composites based upon the dactyl club of the mantis shrimp [208]: these carbon fiber-epoxy composites are fabricated to mimic the helical structural design of the dactyl club. Similar to the mantis shrimp itself, when impacted, these bioinspired composites can reduce the through-thickness damage propagation.

Given the specific environments that marine organisms have evolved in, there is still much room for bioinspiration in fields such as high pressure applications (deep sea organisms), filtration (gills) and high strength wet-adhesives (organisms in tidal zones that must adhere and resist the force of waves). Additionally, with $91 \%$ of marine organisms yet to be discovered and classified [8], the wealth of knowledge to provide bioinspiration will only continue to grow.

\section{Conclusions}

From the wide range of marine organisms covered within this review, it is possible to make some conclusions on the qualities that contribute to specific forms of defense:

1. Crushing resistant structures: The majority of organisms that focus on crushing resistance opt for relatively high mineral content within their defenses in order to increase strength. Given this, ingenious methods are employed to increase ductility and/or toughness, including the brick-and-mortar structure of mollusk nacre, the helical fiber arrangement in crustacean exoskeletons, the geometric macrostructures of diatoms and the sliding plates of the seahorse.

2. Flexure resistant structures: Organisms that aim to provide flexure resistance tend to still require high strength and therefore often place a focus on strategic allocation of material, as is the case in the precisely aligned spicules of the sea sponge and the porous/dense layers in the spines of sea urchins.

3. Piercing resistant structures: Structures focused upon pierce resistance must provide both hardness to halt penetration and toughness to absorb the force of a bite. In most cases this is 
achieved through a layered structure, as is found in many fish scales, scutes and marine skeletal armors, with a rigid surface plate supported by a tough base.

4. Impact resistant structures: The impact resistant dactyl clubs of the mantis shrimp employ a rigid outer layer and a helical energy absorbent inner layer. The gradient in mechanical properties between these two layers is, itself an effective mechanism to absorb energy and deflect cracks.

The oceans offer unique challenges to their inhabitants. From the inky darkness and extreme pressures of the ocean floor to the immense forces of crashing waves at the shorelines, organisms have evolved different strategies to survive and thrive under these extreme conditions. In contrast to terrestrial organisms, marine organisms have adapted different protective mechanisms, shaped by the specific effects of hydrostatic pressure, local temperature and salinity, motion from currents and swells and complete hydration. These defensive mechanisms take on many different forms with both passive (e.g. diatom exoskeletons and mollusk shells) and active (e.g. porcupine fish and sea urchin spines) mechanisms represented. As with all biological materials, the sheer complexity of structures that are formed from relatively simple constituents of biominerals (carbonated hydroxyapatite, calcium carbonate, amorphous silica, magnetite and iron sulfide) and biopolymers (collagen, keratin, chitin and cartilage) is astounding. Additionally, these complex structures provide for all manner of bioinspired designs, from fiber optics to body armor, which have realworld impact. While this review has served as an introduction to many marine biological materials that have been studied, there are still many material secrets of marine life yet to be cracked.

\section{Acknowledgements}

This work is supported by a Multi-University Research Initiative through the Air Force Office of Scientific Research (AFOSR-FA9550-15-1-0009) (S.E.N., M.A.M. and J.M.), Scripps Institution of Oceanography (J.R.A.T.) and the Department of Mechanical Engineering, Clemson University (M.M.P.). The authors wish to thank Prof. Lisa Levin and Kirk Sato of Scripps Institution of Oceanography as well as Michael Frank of the University of California, San Diego for their input on Echinodermata, Frances Su and Esther Cory of the University of California, San Diego for their input on Diodontidae, Haochan Quan of the Unviersity of California, San Diego for his input on the coelacanth, Dr. James Tyler of the Smithsonian Institute for his input on fish scutes and spines, Prof. Phil Hastings of the Scripps Institution of Oceanography for his input on marine biology and 
Prof. Cheryl Hayashi of the University of California, Riverside for her input on biological classifications. 


\section{References}

[1] Arzt E. Biological and artificial attachment devices: Lessons for materials scientists from flies and geckos Materials Science and Engineering C 2006;26:1245-50.

[2] Meyers MA, McKittrick J, Chen P-Y. Structural biological materials: Critical mechanicsmaterials connections. Science 2013;339:773-9.

[3] Meyers MA, Chen P-Y, Lopez MI, Seki Y, Lin AYM. Biological materials: A materials science approach. Journal of the Mechanical Behavior of Biomedical Materials 2011;4:626-57.

[4] Meyers MA, Chen P-Y, Lin AYM, Seki Y. Biological materials: Structure and mechanical properties. Progress in Materials Science 2008;53:1-206.

[5] Chen P-Y, McKittrick J, Meyers MA. Biological materials: Functional adaptations and bioinspired designs. Progress in Materials Science 2012;57:1492-704.

[6] Naleway SE, Porter MM, McKittrick J, Meyers MA. Structural design elements in biological materials: Application to bioinspiration. Advanced Materials 2015:published online.

[7] Wegst UGK, Ashby MF. The mechanical efficiency of natural materials. Philosophical Magazine 2004;84:2167-81.

[8] Mora C, Tittensor DP, Adl S, Simpson AGB, Worm B. How many species are there on earth and in the ocean? PLOS one 2011;9:e1001127.

[9] Munch E, Launey ME, Alsem DH, Saiz E, Tomsia AP, Ritchie RO. Tough, bio-inspired hybrid materials. Science 2008;322:1516-20.

[10] Müller WEG, Wang XH, Cui FZ, Jochum KP, Tremel W, Bill J, Schroder HC, Natalio F, Schlossmacher U, Wiens M. Sponge spicules as blueprints for the biofabrication of inorganic-organic composites and biomaterials. Applied Microbiology and Biotechnology 2009;83:397-413.

[11] Aizenberg J, Sundar VC, Yablon AD, Weaver JC, Chen G. Biological glass fibers: Correlation between optical and structural properties. Proceedings of the National Academy of Sciences 2004;101:3358-63.

[12] Yang W, Naleway SE, Porter MM, Meyers MA, McKittrick J. The armored carapace of the boxfish. Acta Biomaterialia 2015;23:1-10. 
[13] Yang W, Chen IH, Gludovatz B, Zimmermann EA, Ritchie RO, Meyers MA. Natural flexible dermal armor. Advanced Materials 2013;25:31-48.

[14] Ritchie RO. The conflicts between strength and toughness. Nature Materials 2011;10:817-22.

[15] Currey JD, Brear K. Hardness, young's modulus and yield stress in mammalian mineralized tissues. Journal of Materials Science-Materials in Medicine 1990;1:14-20.

[16] Parenteau-Bareil R, Gauvin R, Berthod F. Collagen-based biomaterials for tissue engineering applications. Materials 2010;3:1863-87.

[17] Omura Y, Urano N, Kimura S. Occurrence of fibrillar collagen with structure of $($ alpha(1))(2) alpha(2) in the test of sea urchin Asthenosoma ijimai. Comparative Biochemistry and Physiology B 1996;115:63-8.

[18] Nagai T, Suzuki N. Partial characterization of collagen from purple sea urchin (Anthocidaris crassispina) test. International Journal of Food Science and Technology 2000;35:497-501.

[19] Kimura S, Takema Y, Kubota M. Octopus skin collagen - Isolation and characterization of collagen comprising two distinct a chains. Journal of Biological Chemistry $1981 ; 256: 3230-4$.

[20] Kimura S, Omura Y, Ishida M, Shirai H. Molecular characterization of fibrillar collagen from the body wall of starfish Asterias amurenis. Comparative Biochemistry and Physiology B 1993;104:663-8.

[21] Kimura S, Miura S, Park YH. Collagen as the major edible component of jellyfish (Stomolophus nomural). Journal of Food Science 1983;48:1758-60.

[22] Miura S, Kimura S. Jellyfish mesogloea collagen. Characterization of molecules as a1a2a3 heterotrimers. Journal of Biological Chemistry 1985;260:5352-6.

[23] Kimura S, Zhu XP, Matsui R, Shijoh M, Takamizawa S. Characterization of fish muscle type-I collagen. Journal of Food Science 1988;53:1315-8.

[24] Nagai T, Araki Y, Suzuki N. Collagen of the skin of ocellate puffer fish (Takifugu rubripes). Food Chemistry 2002;78:173-7.

[25] Meyers MA, Lin YS, Olevsky EA, Chen P-Y. Battle in the Amazon: Arapaima versus piranha. Advanced Biomaterials 2012;14:B279-B88. 
[26] Wenger MPE, Bozec L, Horton MA, Masquida P. Mechanical properties of collagen fibrils. Biophysical Journal 2007;93:1255-63.

[27] Graham JS, Vomund AN, Phillips CL, Grandbois M. Structural changes in human type I collagen fibrils investigated by force spectroscopy. Experimental Cell Research 2004;299:335-42.

[28] Ehrlich H. Chitin and collagen as universal and alternative templates in biomineralization. International Geology Review 2010;52:661-99.

[29] Yang W, Sherman VR, Gludovatz B, Mackey M, Zimmermann EA, Chang EH, Schaible E, Qin Z, Buehler MJ, Ritchie RO, Meyers MA. Protective role of Arapaima gigas fish scales: Structure and mechanical behavior. Acta Biomaterialia 2014;10:3599-614.

[30] McKittrick J, Chen P-Y, Bodde SG, Yang W, Novitskaya EE, Meyers MA. The structure, functions, and mechanical properties of keratin. JOM 2012;64:449-68.

[31] Rouse JG, Van Dyke ME. A review of keratin-based biomaterials for biomedical applications. Materials 2010;3:999-1014.

[32] Koch EA, Spitzer RH, Pithawalla RB, Castillos FA. Hagfish biopolymer: A type I/type II homologue of epidermal keratin intermediate filaments. International Journal of Biological Macromolecules 1995;17:283-92.

[33] Feughelman M. Structural features of keratin suggested by its mechanical properties. Biochimica et Biophysica Acta 1959;32:596-7.

[34] Fraser RDB, MacRae TP, Parry DAD, Suzuki E. Structure of beta-keratin. Polymer 1969;10:810-\&.

[35] Trim MW, Horstemeyer MF, Rhee H, Le Kadiri H, Williams LN, Liao J, Walters KB, McKittrick J, Park SJ. The effects of water and microstructure on the mechanical properties of bighorn sheep (Ovis canadensis) horn keratin Acta Biomaterialia 2011;7:1228-40.

[36] Tombolato L, Novitskaya EE, Chen P-Y, Sheppard FA, McKittrick J. Microstructure, elastic properties and deformation mechanisms of horn keratin. Acta Biomaterialia 2010;6:319-30.

[37] Zahn H, Fohles J, Nienhaus M, Schwan A, Spel M. Wool as a biological composite structure. Industrial \& Engineering Chemistry Product Research and Development 1980;19:496-501. 
[38] Rosen SL. Fundamental principles of polymeric materials. 2nd ed. New York: John Wiley \& Sons Inc.; 1993.

[39] Kennedy MA, Peacock AJ, Mandelkern L. Tensile properties of crystalline polymers linear polyethylene. Macromolecules 1994;27:5297-310.

[40] Kumar MNVR. A review of chitin and chitosan applications. Reactive \& Functional Polymers 2000;46:1-27.

[41] Rinaudo M. Chitin and chitosan: Properties and applications. Progress in Polymer Science 2006;31:603-32.

[42] Miserez A, Rubin D, Waite JH. Cross-linking chemistry of squid beak. Journal of Biological Chemistry 2010;285:38115-24.

[43] Rudall KM, Kenchington W. The chitin system. Biological Reviews 1973;48:597-633.

[44] Bouligand Y. Twisted fiberous arrangements in biological materials and cholesteric mesophases. Tissue \& Cell 1972;4:189-217.

[45] Giraud-Guille MM. Fine structure of the chitin protein system in the crab cuticle. Tissue \& Cell 1984;16:75-92.

[46] Giraud-Guille MM, Chanzy H, Vuong R. Chitin crystals in arthropod cuticles revealed by diffraction contrast transmission electron-microscopy. Journal of Structural Biology 1990;103:232-40.

[47] Giraud-Guille MM. Plywood structures in nature. Current Opinion in Solid State \& Materials Science 1998;3:221-7.

[48] Ehrlich H. Biological Materials of Marine Origin: Springer; 2015.

[49] Dean MN, Summers AP. Mineralized cartilage in the skeleton of chondrichthyan fishes. Zoology 2006;109:164-8.

[50] Cole AG, Hall BK. Cartilage differentiation in cephalopod molluscs. Zoology 2009;112:2-15.

[51] Cole AG, Hall BK. The nature and significance of invertebrate cartilages revisited: Distribution and histology of cartilage and cartilage-like tissues within the Metazoa. Zoology 2004; 107:261-73.

[52] Chen P-Y, Toroian D, Price PA, McKittrick J. Minerals form a continuum phase in mature cancellous bone. Calcified Tissue International 2011;88:351-61. 
[53] Dorozhkin SV. Calcium orthophosphates in nature, biology and medicine. Materials 2009;2:399-498.

[54] Weiner S, Wangner HD. The material bone: Structure mechanical function relations. Annual Review of Materials Science 1998;28:271-98.

[55] Novitskaya EE, Chen P-Y, Lee S, Castro-Cesena AB, Hirata GA, Lubarda VA, McKittrick J. Anisotropy in the compressive mechanical properties of bovine cortical bone and the mineral and protein constituents. Acta Biomaterialia 2011;7:3170-7.

[56] Yang W, Chen IH, McKittrick J, Meyers MA. Flexible dermal armor in nature. JOM 2012;64:475-85.

[57] Porter MM, McKittrick J, Meyers MA. Biomimetic materials by freeze casting. JOM 2013;65:720-7.

[58] Vallet-Regi M, Gonzalez-Calbet JM. Calcium phosphates as substitution of bone tissues. Progress in Solid State Chemistry 2004;32:1-31.

[59] Hench LL. Bioceramics - from concept to clinic. Journal of the American Ceramic Society 1991;74:1487-510.

[60] Hench LL. Bioceramics. Journal of the American Ceramic Society 1998;81:1705-28.

[61] Deville S, Saiz E, Nalla RK, Tomsia AP. Freezing as a path to build complex composites. Science 2006;311:515-8.

[62] Olszta MJ, Cheng XG, Jee SS, Kumar R, Kim YY, Kaufman MJ, Douglas EP, Gower LB. Bone structure and formation: A new perspective. Materials Science and Engineering R 2007;58:77-116.

[63] Nudelman F, Pieterse K, George A, Bomans PHH, Friedrich H, Brylka LJ, Hilbers PAJ, de With G, Sommerdijk NAJM. The role of collagen in bone apatite formation in the presence of hydroxyapatite nucleation inhibitors. Nature Materials 2010;9:1004-9.

[64] Ikoma T, Kobayashi H, Tanaka J, Walsh D, Mann S. Microstructure, mechanical, and biomimetic properties of fish scales from Pagrus major. Journal of Structural Biology 2003;142:327-33.

[65] Ducheyne P, Qiu Q. Bioactive ceramics: The effect of surface reactivity on bone formation and bone cell function. Biomaterials 1999;20:2287-303.

[66] Mayer G. Rigid biological systems as models for synthetic composites. Science 2005;310:1144-7. 
[67] Blank S, Arnoldi M, Khoshnavaz S, Treccani L, Kuntz M, Mann K, Grathwohl G, Fritz M. The nacre protein perlucin nucleates growth of calcium carbonate crystals. Journal of Microscopy-Oxford 2003;212:280-91.

[68] Meldrum FC, Colfen H. Controlling mineral morphologies and structures in biological and synthetic systems. Chemical Reviews 2008;108:4332-432.

[69] Wolf G, Konigsberger E, Schmidt HG, Konigsberger LC, Gamsjager H. Thermodynamic aspects of the vaterite-calcite phase transition. Journal of Thermal Analysis and Calorimetry 2000;60:463-72.

[70] Falini G, Albeck S, Weiner S, Addadi L. Control of aragonite or calcite polymorphism by mollusk shell macromolecules. Science 1996;271:67-9.

[71] Belcher AM, Wu XH, Christensen RJ, Hansma PK, Stucky GD, Morse DE. Control of crystal phase switching and orientation by soluble mollusc-shell proteins. Nature 1996;381:56-8.

[72] Long X, Ma YR, Qi LM. Biogenic and synthetic high magnesium calcite - A review. Journal of Structural Biology 2014;185:1-14.

[73] Falini G, Fermani S, Gazzano M, Ripamonti A. Biomimetic crystallization of calcium carbonate polymorphs by means of collagenous matrices. Chemistry-A European Journal 1997;3:1807-14.

[74] Schofield RMS, Niedbala JC, Nesson MH, Tao Y, Shokes JE, Scott RA, Latimer MJ. Brrich tips of calcified crab claws are less hard but more fracture resistant: A comparison of mineralized and heavy-element biological materials. Journal of Structural Biology 2009;166:272-87.

[75] Cribb BW, Rathmell A, Charters R, Rasch R, Huang H, Tibbetts IR. Structure, composition and properties of naturally occurring non-calcified crustacean cuticle. Arthopod Structure \& Development 2009;38:173-8.

[76] Perry CC, Keeling-Tucker T. Biosilicification: The role of the organic matrix in structure control. Journal of Biological Inorganic Chemistry 2000;5:537-50.

[77] Epstein E. Silicon: Its manifold roles in plants. Annals of Applied Biology 2009;155:15560.

[78] Lucas PW, Turner IM, Dominy NJ, Yamashita N. Mechanical defences to herbivory. Annals of Botany 2000;86:913-20. 
[79] Gebeshuber IC, Kindt JH, Thompson JB, Del Amo Y, Stachelberger H, Brzezinski MA, Stucky GD, Morse DE, Hansma PK. Atomic force microscopy study of living diatoms in ambient conditions. Journal of Microscopy-Oxford 2003;212:292-9.

[80] Garcia AP, Pugno N, Buehler MJ. Superductile, wavy silica nanostructures inspired by diatom algae. Advanced Engineering Materials 2011;13:B405-B14.

[81] Epstein E. Silicon. Annual Review of Plant Physiology and Plant Molecular Biology 1999;50:641-64.

[82] Shimizu K, Cha J, Stucky GD, Morse DE. Silicatein alpha: Cathepsin L-like protein in sponge biosilica. Proceedings of the National Academy of Sciences of the United States of America 1998;95:6234-8.

[83] Xia L, Liu Y, Li ZB. Biosilicification templated by amphiphilic block copolypeptide assemblies. Macromolecular Bioscience 2010;10:1566-75.

[84] Schuler D, Frankel RB. Bacterial magnetosomes: Microbiology, biomineralization and biotechnological applications. Applied Microbiology and Biotechnology 1999;52:464-73.

[85] Lefevre CT, Viloria N, Schmidt ML, Posfai M, Frankel RB, Bazylinski DA. Novel magnetite-producing magnetotactic bacteria belonging to the Gammaproteobacteria. ISME Journal 2012;6:440-50.

[86] Lohmann KJ. Magnetic orientation by hatchling loggerheasd sea-turtles (Caretta caretta). Journal of Experimental Biology 1991;155:37-49.

[87] Lohmann KJ, Lohmann CMF. Detection of magnetic field intensity by sea turtles. Nature 1996;380:59-61.

[88] Boles LC, Lohmann KJ. True navigation and magnetic maps in spiny lobsters. Nature 2003;421:60-3.

[89] Wang QQ, Nemoto M, Li DS, Weaver JC, Weden B, Stegemeier J, Bozhilov KN, Wood LR, Milliron GW, Kim CS, DiMasi E, Kisailus D. Phase transformations and structural developments in the radular teeth of Cryptochiton stelleri. Advanced Functional Materials 2013;23:2908-17.

[90] Greene SE, Komeili A. Biogenesis and subcellular organization of the magnetosome organelles of magnetotactic bacteria. Current Opinion in Cell Biology 2012;24:490-5.

[91] Luther GW, Rozan TF, Taillefert M, Nuzzio DB, Di Meo C, Shank TM, Lutz RA, Cary SC. Chemical speciation drives hydrothermal vent ecology. Nature 2001;410:813-6. 
[92] Suzuki Y, Kopp RE, Kogure T, Suga A, Takai K, Tsuchida S, Ozaki N, Endo K, Hashimoto J, Kato Y, Mizota C, Hirata T, Chiba H, Nealson KH, Horikoshi K, Kirschvink JL. Sclerite formation in the hydrothermal-vent "scaly-foot" gastropod possible control of iron sulfide biomineralization by the animal. Earth and Planetary Science Letters 2006;242:39-50.

[93] Barthelat F, Tang H, Zavattieri PD, Li CM, Espinosa HD. On the mechanics of motherof-pearl: A key feature in the material hierarchical structure. Journal of the Mechanics and Physics of Solids 2007;55:306-37.

[94] Espinosa HD, Juster AL, Latourte FJ, Loh OY, Gregoire D, Zavattieri PD. Tablet-level origin of toughening in abalone shells and translation to synthetic composite materials. Nature Communications 2011;2.

[95] Addadi L, Joester D, Nudelman F, Weiner S. Mollusk shell formation: A source of new concepts for understanding biomineralization processes. Chemistry 2006;12:980-7.

[96] Lin AYM, Meyers MA, Vecchio KS. Mechanical properties and structure of Strombus gigas, Tridacna gigas, and Haliotis rufescens sea shells: A comparative study. Materials Science and Engineering C 2006;26:1380-9.

[97] Lin AYM, Chen P-Y, Meyers MA. The growth of nacre in the abalone shell. Acta Biomaterialia 2008;4:131-8.

[98] Lin A, Meyers MA. Growth and structure in abalone shell. Materials Science and Engineering A 2005;390:27-41.

[99] Meyers MA, Lim CT, Li A, Nizam BRH, Tan EPS, Seki Y, McKittrick J. The role of organic intertile layer in abalone nacre. Materials Science and Engineering $\mathrm{C}$ 2009;29:2398-410.

[100] Lopez MI, Martinez PEM, Meyers MA. Organic interlamellar layers, mesolayers and mineral nanobridges: Contribution to strength in abalone (Haliotis rufescence) nacre. Acta Biomaterialia 2014;10:2056-64.

[101] Lopez MI, Chen P-Y, McKittrick J, Meyers MA. Growth of nacre in abalone: Seasonal and feeding effects Materials Science and Engineering C 2011;31:238-45.

[102] Menig R, Meyers MH, Meyers MA, Vecchio KS. Quasi-static and dynamic mechanical response of Haliotis rufescens (abalone) shells Acta Materialia 2000;48:2383-93. 
[103] Salinas C, Kisailus D. Fracture mitigation strategies in gastropod shells. JOM 2013;65:473-80.

[104] Menig R, Meyers MH, Meyers MA, Vecchio KS. Quasi-static and dynamic mechanical response of Strombus gigas (conch) shells Materials Science and Engineering A 2001;297:203-11.

[105] Kamat S, Su X, Ballarini R, Heuer AH. Structural basis for the fracture toughness of the shell of the conch Strombus gigas. Nature 2000;405:1036-40.

[106] Ritchie RO. Mechanisms of fatigue crack-propagation in metals, ceramics and composites - Role of crack tip sheilding. Materials Science and Engineering A 1988;103:15-28.

[107] Ritchie RO. Mechanisms of fatigue-crack propagation in ductile and brittle solids. International Journal of Fracture 1999;100:55-83.

[108] Bouville F, Maire E, Meille S, Van de Moortele B, Stevenson AJ, Deville S. Strong, tough and stiff bioinspired ceramics from brittle constituents Nature Materials 2014;13:508-14.

[109] Yao HM, Dao M, Imholt T, Huang JM, Wheeler K, Bonilla A, Suresh S, Ortiz C. Protection mechanisms of the iron-plated armor of a deep-sea hydrothermal vent gastropod. PNAS 2010;107:987-92.

[110] Waren A, Bengtson S, Goffredi SK, Van Dover CL. A hot-vent gastropod with iron sulfide dermal sclerites Science 2003;302:1007-.

[111] Vendrasco MJ, Wood TE, Runnegar BN. Articulated Palaeozoic fossil with 17 plates greatly expands disparity of early chitons. Nature 2004;429:288-91.

[112] Treves K, Traub W, Weiner S, Addadi L. Aragonite formation in the chiton (Mollusca) girdle. Helvetica Chimica Acta 2003;86:1101-12.

[113] Connors MJ, Ehrlich H, Hog M, Godeffroy C, Araya S, Kallai I, Gazit D, Boyce M, Ortiz C. Three-dimensional structure of the shell plate assembly of the chiton Tonicella marmorea and its biomechanical consequences. Journal of Structural Biology 2012;177:314.

[114] Nemoto M, Wang QQ, Li DS, Pan SQ, Matsunaga T, Kisailus D. Proteomic analysis from the mineralized radular teeth of the giant Pacific chiton, Cryptochiton stelleri (Mollusca). Proteomics 2012;12:2890-4. 
[115] Towe KM, Lowensta HA. Ultrastructure and development of iron mineralization in radular teeth of Cryptochiton stelleri (mollusca) Journal of Ultrastructure Research 1967;17:1-13.

[116] Gordon LM, Roman JK, Everly RM, Cohen MJ, Wilker JJ, Joester D. Selective formation of metastable ferrihydrite in the chiton tooth. Angewandte Chemie 2014;53:11506-9.

[117] Martin-Jezequel V, Hildebrand M, Brzezinski MA. Silicon metabolism in diatoms: Implications for growth. Journal of Phycology 2000;36:821-40.

[118] Hildebrand M. Diatoms, biomineralization processes, and genomics. Chemical Reviews 2008;108:4855-74.

[119] Sarthou G, Timmermans KR, Blain S, Treguer P. Growth physiology and fate of diatoms in the ocean: A review. Journal of Sea Research 2005;53:25-42.

[120] Treguer P, Nelson DM, Van Beenekom AJ, DeMaster DJ, Leynaert A, Queguiner B. The silica balance in the world ocean: A reestimate. Science 1995;268:375-9.

[121] Hamm CE, Merkel R, Springer O, Jurkojc P, Maier C, Prechtel K, Smetacek V. Architecture and material properties of diatom shells provide effective mechanical protection. Nature 2003;421:841-3.

[122] Hildebrand H, Durselen CD, Kirschtel D, Pollingher U, Zohary T. Biovolume calculation for pelagic and benthic microalgae. Journal of Phycology 1999;35:403-24.

[123] Losic D, Short K, Mitchell JG, Lal R, Voelcker NH. AFM nanoindentations of diatom biosilica surfaces. Langmuir 2007;23:5014-21.

[124] Almqvist N, Delamo Y, Smith BL, Thomson NH, Bartholdson A, Lal R, Brzezinski M, Hansma PK. Micromechanical and structural properties of a pennate diatom investigated by atomic force microscopy. Journal of Microscopy 2001;202:518-32.

[125] Francius G, Tesson B, Dague E, Martin-Jezequel V, Dufrene YF. Nanostructure and nanomechanics of live Phaeodactylum tricornutum morphotypes. Environmental Microbiology 2008;10:1344-56.

[126] Kroger N, Deutzmann R, Bergsdorf C, Sumper M. Species-specific polyamines from diatoms control silica morphology. PNAS 2000;97:14133-8.

[127] Kroger N, Deutzmann R, Sumper M. Polycationic peptides from diatom biosilica that direct silica nanosphere formation. Science 1999;286:1129-32. 
[128] Sumper M. A phase separation model for the nanopatterning of diatom biosilica. Science 2002;295:2430-3.

[129] Young JR. Functions of coccoliths. In: Siesser WG, Winter A, editors. Coccolithophores. Cambridge, UK: Cambridge University Press; 1994. p. 63-82.

[130] Smith BL, Paloczi GT, Hansma PK, Levine RP. Discerning nature's mechanism for making complex biocomposite crystals. Journal of Crystal Growth 2000;211:116-21.

[131] Mann S, Sparks NHC. Single crystal nature of coccolith elements of the marine alga Emiliania huxleyi as determined by electron diffraction and high resolution electron microscopy. Proceedings of the Royal Society B 1988;234:441-53.

[132] Marsh ME. Regulation of $\mathrm{CaCO}_{3}$ formation in coccolithophores. Comparative Biochemistry and Physiology B 2003;136:743-54.

[133] Chen P-Y, Lin AYM, McKittrick J, Meyers MA. Structure and mechanical properties of crab exoskeletons. Acta Biomaterialia 2008;4:587-96.

[134] Travis DF. The molting cycle of the spiny lobster, Panulirus argus-Latreille. II. Preecdysial histological and histochemical changes in the hepatopancreas and integumental tissues. Biological Bulletin 1955;108:88-112.

[135] Bouligand Y. Aspects ultrastructuraux de la calcification chez les Crabes. Septieme Congres Internationale de Microscopie Electronique. Gernoble, France1970. p. 105-6.

[136] Fabritius HO, Sachs C, Triguero PR, Raabe D. Influence of structural principles on the mechanics of a biological fiber-based composite material with hierarchical organization: The exoskeleton of the lobster Homarus americanus. Advanced Materials 2009;21:391400.

[137] Raabe D, Sachs C, Romano P. The crustacean exoskeleton as an example of a structurally and mechanically graded biological nanocomposite material. Acta Materialia 2005;53:4281-92.

[138] Dillaman R, Hequembourg S, Gay M. Early pattern of calcification in the dorsal carapace of the blue crab, Callinectes sapidus. Journal of Microscopy 2005;263:356-74.

[139] Fabritius HO, Karsten ES, Balasundaram K, Hild S, Huemer K, Raabe D. Correlation of structure, composition and local mechanical properties in the dorsal carapace of the edible crab Cancer pagurus Zeitschrift für Kristallographie-Crystalline Materials 2012;227:766-76. 
[140] Raabe D, Romano P, Sachs C, Fabritius H, Al-Sawalmih A, Yi S, Servos G, Hartwig HG. Microstructure and crystallographic texture of the chitin-protein network in the biological composite material of the exoskeleton of the lobster Homarus americanus. Materials Science and Engineering A 2006;421:143-53.

[141] Cheng L, Wang LY, Karlsson AM. Image analyses of two crustacean exoskeletons and implications of the exoskeletal microstructure on the mechanical behavior Journal of Materials Research 2008;23:2854-72.

[142] Sachs C, Fabritius H, Raabe D. Experimental investigation of the elastic-plastic deformation of mineralized lobster cuticle by digital image correlation Journal of Structural Biology 2006;155:409-25.

[143] Hepburn HR, Joffe I, Green N, Nelson KJ. Mechanical-properties of a crab shell. Comparative Biochemistry and Physiology 1975;50:551-4.

[144] Joffe I, Hepburn HR, Nelson KJ, Green N. Mechanical-properties of a crustacean exoskelton. Comparative Biochemistry and Physiology 1975;50:545-9.

[145] Williams CL, Dillaman RM, Elliott EA, Gay DM. Formation of the arthrodial membrane in the blue crab, Callinectes sapidus. Journal of Morphology 2003;256:260-9.

[146] Melnick CA, Chen Z, Mecholsky JJ. Hardness and toughness of exoskeleton material in the stone crab, Menippe mercenaria. Journal of Materials Research 1996;11:2903-7.

[147] Foster SJ, Vincent ACJ. Life history and ecology of seahorses: implications for conservation and management. Journal of Fish Biology 2004;65:1-61.

[148] Consi TR, Seifert PA, Triantafyllou MS, Edelman ER. The dorsal fin engine of the seahorse (Hippocampus sp.). 248 2001;1.

[149] Ashley-Ross MA. Mechanical properties of the dorsal fin muscle of seahorse (Hippocampus) and pipefish (Syngnathus). Journal of Experimental Zoology 2002;293:561-77.

[150] Porter MM, Novitskaya EE, Castro-Cesena AB, Meyers MA, McKittrick J. Highly deformable bones: Unusual deformation mechanisms of seahorse armor. Acta Biomaterialia 2013;9:6763-70.

[151] Hale ME. Functional morphology of ventral tail bending and prehensile abilities of the seahorse, Hippocampus kuda. Journal of Morphology 1996;227:51-65. 
[152] Praet T, Adriaens D, Van Cauter S, Masschaele B, De Beule M, Verhegghe B. Inspiration from nature: dynamic modelling of the musculoskeletal structure of the seahorse tail. International Journal for Numerical Methods in Biomedical Engineering 2012;28:102842.

[153] Neutens C, Adriaens D, Christiaens J, De Kegel B, Dierick M, Boistel R, Van Hoorebeke L. Grasping convergent evolution in syngnathids: A unique tale of tails. Journal of Anatomy 2014;224:710-23.

[154] Porter MM, Adriaens D, Hatton RL, Meyers MA, McKittrick J. Why the seahorse tail is square. Science 2015;349:aaa6683.

[155] Kleiber D, Blight LK, Caldwell IR, Vincent ACJ. The importance of seahorses and pipefishes in the diet of marine animals. Reviews in Fish Biology and Fisheries 2011;21:205-23.

[156] Müller WEG, Wang XH, Kropf K, Ushijima H, Geurtsen W, Eckert C, Tahir MN, Tremel W, Boreiko A, Schloßmacher U, Li JH, Schröder HC. Bioorganic/inorganic hybrid composition of sponge spicules: Matrix of the giant spicules and of the comitalia of the deep sea hexactinellid Monorhaphis. Journal of Structural Biology 2008;161:188203.

[157] Weaver JC, Aizenberg J, Fantner GE, Kisailus D, Woesz A, Allen P, Fields K, Porter MJ, Zok FW, Hansma PK, Fratzl P, Morse DE. Hierarchical assembly of the siliceous skeletal lattice of the hexactinellid sponge Euplectella aspergillum. Journal of Structural Biology 2007;158:93-106.

[158] Aizenberg J, Weaver JC, Thanawala MS, Sundar VC, Morse DE, Fratzl P. Skeleton of Euplectella sp.: Structural hierarchy from the nanoscale to the macroscale. Science 2005;309:275-8.

[159] Imsiecke G, Steffen RT, Custodio M, Borojevic R, Muller W. Formation of spicules by sclerocytes from the freshwater sponge Ephydatia muelleri in short-term cultures in vitro. In Vitro Cellular \& Developmental Biology - Animal 1995;31:528-35.

[160] Cha JN, Shimizu K, Zhou Y, Christiansen SC, Chmelka BF, Stucky GD, Morse DE. Silicatein filaments and subunits from a marine sponge direct the polymerization of silica and silicones in vitro. Proceedings of the National Academy of Sciences of the United States of America 1999;96:361-5. 
[161] Woesz A, Weaver JC, Kazanci M, Dauphin Y, Aizenberg J, Morse DE, Fratzl P. Micromechanical properties of biological silica in skeletons of deep-sea sponges. Journal of Materials Research 2006;21:2068-78.

[162] Porter MM, Meraz L, Calderon A, Choi H, Chouhan A, Wang L, Meyers MA, McKittrick J. Torsional properties of helix-reinforced composites fabricated by magnetic freeze casting. Composite Structures 2015;119:174-84.

[163] Presser V, Schultheiss S, Berthold C, Nickel KG. Sea urchin spines as a model-system for permeable, light-weight ceramics with graceful failure behavior. Part I. Mechanical behavior of sea urchin spines under compression. Journal of Bionic Engineering 2009;6:203-13.

[164] Seto J, Ma YR, Davis SA, Meldrum F, Gourrier A, Kim YY, Schilde U, Sztucki M, Burghammer M, Maltsev S, Jager C, Colfen H. Structure-property relationships of a biological mesocrystal in the adult sea urchin spine. PNAS 2012;109:3699-704.

[165] Oaki Y, Imai H. Nanoengineering in echinoderms: The emergence of morphology from nanobricks. Small 2006;2:66-70.

[166] Aizenberg J, Hanson J, Koetzle TF, Weiner S, Addadi L. Control of macromolecule distribution within synthetic and biogenic single calcite crystals. Journal of the American Chemical Society 1997;119:881-6.

[167] Politi Y, Arad T, Klein E, Weiner S, Addadi L. Sea urchin spine calcite forms via a transient amorphous calcium carbonate phase. Science 2004;306:1161-4.

[168] Moureaux C, Perez-Huerta A, Compere P, Zhu W, Leloup T, Cusack M, Dubois P. Structure, composition and mechanical relations to function in sea urchin spine. Journal of Structural Biology 2010;170:41-9.

[169] Edwards PB, Ebert TA. Plastic responses to limited food availability and spine damage in the sea urchin Strongylocentrotus purpuratus (Stimpson). Journal of Experimental Marine Biology and Ecology 1991;145:205-20.

[170] Dubois P, Ameye L. Regeneration of spines and pedicellariae in echinoderms: A review. Microscopy Research and Technique 2001;55:427-37.

[171] Gibson LJ, Ashby MF. Cellular Solids: Structure and Properties: Cambridge University Press; 1999. 
[172] Su X, Kamat S, Heuer AH. The structure of sea urchin spines, large biogenic single crystals of calcite. Journal of Materials Science 2000;35:5545-51.

[173] Weber J, Greer R, Voight B, White E, Roy R. Unusual strength properties of echinoderm calcite. Journal of Ultrastructure Research 1969;26:355-66.

[174] Ma Y, Aichmayer B, Paris O, Fratzl P, Meibom A, Metzler RA, Politi Y, Addadi L, Gilbert PUPA, Weiner S. The grinding tip of the sea urchin tooth exhibits exquisite control over calcite crystal orientation and Mg distribution. PNAS 2009;106:6048-53.

[175] Ma Y, Cohen SR, Addadi L, Weiner S. Sea urchin tooth design: An “'all-calcite”, polycrystalline reinforced fiber composite for grinding rocks. Advanced Materials 2008;20:1555-9.

[176] Killian CE, Metzler RA, Gong Y, Churchill TH, Olson IC, Trubetskoy V, Christensen MB, Fournelle JH, De Carlo F, Cohen S, Mahamid J, Scholl A, Young A, Doran A, Wilt FH, Coppersmith SN, Gilbert PUPA. Self-sharpening mechanism of the sea urchin tooth. Advanced Functional Materials 2011;21:682-90.

[177] Tyler JC, Santini F. Review and reconstructions of the tetraodonitform fishes from the Eocene of Monte Bolca, Italy, with comments on related tertiary taxa. Studi e Ricerche sui Giacimenti Terziari di Bolca, Museo Civico di Storia Naturale di Verona 2002;9:47119.

[178] Brainerd EL. Puffer inflation: Functional morphology of postcranial structures in Diodon holocanthus (Tetraodontiformes). Journal of Morphology 1994;220:243-61.

[179] Ikoma T, Kobayashi H, Tanaka J, Walsh D, Mann S. Physical properties of type I collagen extracted from fish scales of Pagrus major and Oreochromis niloticas. International Journal of Biological Macromolecules 2003;32:199-204.

[180] Zhu D, Ortega CF, Motamedi R, Szewciw L, Vernerey F, Barthelat F. Structure and mechanical performance of a "modern" fish scale. Advanced Engineering Materials 2012;14:B185-B94.

[181] Bruet BJF, Song JH, Boyce MC, Ortiz C. Materials design principles of ancient fish armour. Nature Materials 2008;7:748-56.

[182] Song JH, Ortiz C, Boyce MC. Threat-protection mechanics of an armored fish. Journal of the Mechanical Behavior of Biomedical Materials 2011;4:699-712. 
[183] Zimmermann EA, Gludovatz B, Schaible E, Dave NKN, Yang W, Meyers MA, Ritchie RO. Mechanical adaptability of the Bouligand-type structure in natural dermal armour. Nature Communications 2013;4:2634.

[184] Long JH, Hale ME, McHenry MJ, Westneat MW. Functions of fish skin: Flexural stiffness and steady swimming of longnose gar Lepisosteus osseus. Journal of Experimental Biology 1996;199:2139-51.

[185] Long JH, Adcock B, Root RG. Force transmission via axial tendons in undulating fish: A dynamic analysis. Comparative Biochemistry and Physiology A 2002;133:911-29.

[186] Long JH, Koob TJ, Irving K, Combie K, Engel V, Livingston N, Lammert A, Schumacher J. Biomimetic evolutionary analysis: Testing the adaptive value of vertebrate tail stiffness in autonomous swimming robots. Journal of Experimental Biology 2006;209:4732-46.

[187] Yang W, Gludovatz B, Zimmermann EA, Bale HA, Ritchie RO, Meyers MA. Structure and fracture resistance of alligator gar (Atractosteus spatula) armored fish scales. Acta Biomaterialia 2013;9:5876-89.

[188] Sire JY, Huysseune A. Formation of dermal skeletal and dental tissues in fish: A comparative and evolutionary approach. Biological Reviews 2003;78:219-49.

[189] Goodrich ES. On the scales of fish living and extinct, and then importance in classification. Proceedings of the Zoological Society of London 1907;77:751-74.

[190] Vernerey FJ, Barthelat F. Skin and scales of teleost fish: Simple structure but high performance and multiple functions Journal of the Mechanics and Physics of Solids 2014;68:66-76.

[191] Zhu DJ, Szewciw L, Vernerey F, Barthelat F. Puncture resistance of the scaled skin from striped bass: Collective mechanisms and inspiration for new flexible armor designs Journal of the Mechanical Behavior of Biomedical Materials 2013;24:30-40.

[192] Smith MM, Hobdell MH, Miller WA. Structure of scales of Latimeria chalumnae. Journal of Zoology 1972;167:501-9.

[193] Orvig TOR. Paleohistological notes I. On the structure of the bone tissue in the scales of certain Palaeonisciformes. Arkiv Zool 1957;10:481-90.

[194] Roux GH. The microscopic anatomy of the Latimeria scale. The South African Journal of Medical Sciences 1942;7:1-18. 
[195] Jarvik E. On some osteolepiform crossopterygians from the Upper Old Red Sandstone of Scotland. K Svenska Vetenskapsakad Handl 1950;2:1-35.

[196] Sherman VR, Yang W, Meyers MA. The materials science of collagen. Journal of the Mechanical Behavior of Biomedical Materials 2015:in press.

[197] Grubich JR, Huskey S, Crofts S, Orti G, Porto J. Mega-bites: Extreme jaw forces of living and extinct piranhas (Serrasalmidae). Scientific Reports2012.

[198] Chen P-Y, Schirer J, Simpson A, Nay R, Lin Y-S, Yang W, Lopez MI, Li J, Olevsky EA, Meyers MA. Predation versus protection: Fish teeth and scales evaluated by nanoindentation. Journal of Materials Research 2012;27:100-12.

[199] Dastjerdi AK, Barthelat F. Teleost fish scales amongst the toughest collagenous materials. Journal of the Mechanical Behavior of Biomedical Materials 2015:in press.

[200] Chen IH, Yang W, Meyers MA. Leatherback sea turtle shell: A tough and flexible biological design. Acta Biomaterialia 2015:in review.

[201] Houghton JDR, Doyle TK, Davenport J, Wilson RP, Hays GC. The role of infrequent and extraordinary deep dives in leatherback turtles (Dermochelys coriacea). Journal of Experimental Biology 2008;211:2566-75.

[202] Besseau L, Bouligand Y. The twisted collagen network of the box-fish scutes. Tissue \& Cell 1998;30:251-60.

[203] Sun C-Y, Chen P-Y. Structural design and mechanical behavior of alligator (Alligator mississippiensis) osteoderms. Acta Biomaterialia 2013;9:9049-64.

[204] Amini S, Masic A, Bertinetti L, Teguh JS, Herrin JS, Zhu X, Su HB, Miserez A. Textured fluorapatite bonded to calcium sulphate strengthen stomatopod raptorial appendages Nature Communications 2014;5.

[205] Weaver JC, Milliron GW, Miserez A, Evans-Lutterodt K, Herrera S, Gallana I, Mershon WJ, Swanson B, Zavattieri P, DiMasi E, Kisailus D. The stomatopod dactyl club: A formidable damage-tolerant biological hammer. Science 2012;336:1275-80.

[206] Currey JD, Nash A, Bonfield W. Calcified cuticle in the stomatopod smashing limb. Journal of Materials Science 1982;17:1939-44.

[207] Guarín-Zapata N, Gomez J, Yaraghi N, Kisailus D, Zavattieri PD. Shear wave filtering in naturally-occurring Bouligand structures. Acta Biomaterialia 2015;23:11-20. 
[208] Grunenfelder LK, Suksangpanya N, Salinas C, Milliron G, Yaraghi N, Herrera S, EvansLutterodt K, Nutt SR, Zavattieri P, Kisailus D. Bio-inspired impact-resistant composites. Acta Biomaterialia 2014;10:3997-4008.

[209] Parry DAD, North ACT. Hard alpha-keratin intermediate filament chains: Substructure of the $\mathrm{N}$ - and $\mathrm{C}$-terminal domains and the predicted structure and function of the C-terminal domains of Type I and Type II chains. Journal of Structural Biology 1998;122:67-75.

[210] McKittrick J, Chen P-Y, Tombolato L, Novitskaya EE, Trim MW, Hirata GA, Olevsky EA, Horstemeyer MF, Meyers MA. Energy absorbent natural materials and bioinspired design strategies: A review. Materials Science and Engineering C 2010;30:331-42.

[211] Raabe D, Al-Sawalmih A, Yi SB, Fabritius H. Preferred crystallographic texture of alpha-chitin as a microscopic and macroscopic design principle of the exoskeleton of the lobster Homarus americanus. Acta Biomaterialia 2007;3:882-95.

[212] Han YS, Hadiko G, Fuji M, Takahashi M. Factors affecting the phase and morphology of $\mathrm{CaCO} 3$ prepared by a bubbling method. Journal of the European Ceramic Society 2006;26:843-7.

[213] Lopez MI, Meyers MA. The organic interlamellar layer in abalone nacre: formation and mechanical response. Materials Science and Engineering C 2015:in review.

[214] Young JR, Geisen M, Cros L, Kleijne A, Probert I, Ostergaard JB. A guide to extant coccolithophore taxonomy. Journal of Nanoplankton Research 2003;1:1-132.

[215] Mayer G, Sarikaya M. Rigid biological composite materials: Structural examples for biomimetic design. Experimental Mechanics 2002;42:395-403.

[216] Weiner S, Addadi L. Design strategies in mineralized biological materials. Journal of Materials Chemistry 1997;7:689-702.

[217] Ji BH, Gao HJ. Mechanical properties of nanostructure of biological materials. Journal of the Mechanics and Physics of Solids 2004;52:1963-90.

[218] Jager I, Fratzl P. Mineralized collagen fibrils: A mechanical model with a staggered arrangement of mineral particles. Biophysical Journal 2000;79:1737-46.

[219] Vincent JFV, Wegst UGK. Design and mechanical properties of insect cuticle. Arthopod Structure \& Development 2004;33:187-99. 
[220] De With G, Van Dijk HJA, Hattu N, Prijs K. Preparation, microstructure and mechanical properties of dense polycrystalline hydroxy apatite. Journal of Materials Science 1981;16:1592-8.

[221] Levi C, Barton JL, Guillemet C, Lebras E, Lehuede P. A remarkably strong natural glassy rod - the anchoring spicule of the monorhaphis sponge. Journal of Materials Science Letters 1989;8:337-9.

[222] Sarikaya M, Fong H, Sunderland N, Flinn BD, Mayer G, Mescher A, Gaino E. Biomimetic model of a sponge-spicular optical fiber - mechanical properties and structure. Journal of Materials Research 2001;16:1420-8.

[223] Chen P-Y, Lin AYM, Stokes AG, Seki Y, Bodde SG, McKittrick J, Meyers MA. Structural biological materials: Overview of current research. JOM 2008;60:23-32.

[224] Jackson AP, Vincent JFV, Turner RM. The mechanical design of nacre. Proceedings of the Royal Society B 1988;234.

[225] Fudge DS, Gosline JM. Molecular design of the alpha-keratin composite: Insights from a matrix-free model, hagfish slime threads. Proceedings of the Royal Society B 2004;271:291-9.

[226] Hayes DK, Armstrong WD. Distribution of mineral material in calcified carapace and claw shell of the American lobster, Homarus americanus, evaluated by means of microroentgenograms. Biological Bulletin 1961;121:307-15.

[227] Mkukuma LD, Skakle JMS, Gibson IR, Imrie CT, Aspden RM, Hukins DWL. Effect of the proportion of organic material in bone on thermal decomposition of bone mineral: An investigation of a variety of bones from different species using thermogravimetric analysis coupled to mass spectrometry, high-temperature X-ray diffraction, and Fourier transform infrared spectroscopy. Calcified Tissue International 2004;75:321-8.

[228] Sankar S, Sekar S, Mohan R, Rani S, Sundaraseelan J, Sastry TR. Preparation and partial characterization of collagen sheet from fish (Lates calcarifer) scales. International Journal of Biological Macromolecules 2008;42:6-9. 


\section{List of Table Captions}

Table 1. Mechanical properties of marine biological material constituents.

Table 2. Mechanical properties of selected marine biological materials tested in a quasi-static, hydrated state.

Table 3. Relative weight proportions of biomineral and biopolymer constituents for marine organisms. 


\section{List of Figure Captions}

Figure 1. Toughness as a function of elastic modulus for biological materials. Adapted from [7].

Figure 2. Examples of some spectacular marine organisms. (a) Odontodactylus (mantis shrimp); (b) Hippocampus (seahorse); (c) Farrea (honeycomb glass sponge); (d) Haliotis (abalone). Adapted from: (a) - (c) nationalgeographic.com, (d) wikipedia.com.

Figure 3. Diagram of the hierarchical structure of collagen fibers. (a) triple helix segments; (b) Tropocollagen molecules; (c) Assembled collagen fibrils with the characteristic periodic $67 \mathrm{~nm}$ spacing highlighted; (d) Collagen fibers assembled from multiple collagen fibrils; (e) Atomic force micrograph of a collagen fibril from fish scales with the characteristic spacing highlighted. Adapted from: (a) - (d) [16], (e) [29].

Figure 4. Structure of keratin. (a) Hierarchy of $\alpha$-keratin showing the assembly from two polypeptide chains (i) to a fibrous structure (iv); (b) $\beta$-keratin that shows a pleated sheet shape that consists of antiparallel chains with R-groups that extend between sheets; (c) TEM micrograph of $\alpha$-keratin from a sheep horn that displays the composite structure of a crystalline keratin core within an amorphous keratin matrix. Adapted from: (a) [30, 209], (b) [30], (c) [30, 210].

Figure 5. Diagram of the structure of chitin. (a) The molecular structure of $\alpha$-chitin viewed from three different directions; (b) The molecular structure of $\beta$-chitin viewed from three different directions; (c) Aligned microstructure of mineralized $\alpha$-chitin fibers from the exoskeleton of a lobster; (d) Diagram of the helical Bouligand structure of many chitin materials, such as crustacean exoskeletons. Adapted from: (a) and (b) [41], (c) [211], (d) [4].

Figure 6. Growth and structure of hydroxyapatite and, in the case of bone, carbonated hydroxyapatite. (a) A diagram of the biomineralization of hydroxyapatite where collagen (or other biopolymer) fibrils template hydroxyapatite crystal growth; Deproteinized tissue (by heating at 1473 K, images of tissue from a sea bream, (Pagrus major) at (b) low and (c) high magnification. While these samples consist of only mineral, they still show a preferential orientation to their original collagen template. Adapted from: (a) [62], (b) and (c) [64].

Figure 7. Crystalline calcium carbonate structure. (a) Calcite showing the characteristic layered structure of crystallized calcium carbonate. Layers are colored coordinated with (b); (b) This 
characteristic structure is caused by layer-by-layer growth as dictated by the diagramed Kossel model; (c) Particles of calcium carbonate (calcite) showing a faceted structure. Adapted from: (a) and (b) [68], (c) [212].

Figure 8. Example spicule structures of amorphous silica employed in sponges and diatoms. Adapted from [82].

Figure 9. Structure and toughening mechanisms of marine mollusk nacre (imaged species: Haliotis Rufescens and Strombus gigas). (a) Cross-section of the abalone shell displaying the calcitic and aragonitic (nacre) layers; (b) The brick-and-mortar structure of nacre displaying calcium carbonate plates with mortar-like chitin layers; (c) Crack deflection toughening mechanism that causes a more tortuous crack path; (d) Microbuckling toughening mechanism of the calcium carbonate plates that creates significant additional surface area. Adapted from: (a) [213], (b) [93, 102], (c) [96], (d) [102].

Figure 10. Process of nacre growth in the shell of abalone (Haliotis rufescens). (a) Diagram of the process of nacre growth (progressing from top to bottom) where calcium carbonate mineral shelves assemble through an organic membrane. Growth occurs laterally ( $A$ and $B$ directions) while it is retarded longitudinally ( $C$ direction) by deposition of a porous organic layer (dashed lines); (b) SEM image of nacre displaying the growth peaks. Adapted from: (a) [97], (b) [99].

Figure 11. Deep sea scaly-foot gastropod (Crysomallon squamiferum) that employs a three part shell with an iron-sulfide based outer layer (FeS), an organic intermediate layer (Organic) and an aragonite inner layer (Calcified Layer). Adapted from [109].

Figure 12. (a) Side-view photographs of a chiton (Tonicella marmorea) showing the eight plates that can curl up into a defensive position; (b) Another chiton species (Cryptochiton stelleri) displaying their characteristic mineralized teeth that are made of magnetite at the leading and trailing edges and iron-phosphate in the core. Adapted from: (a) [113], (b) [89].

Figure 13. (a) Diatoms displaying a wide variety in exoskeleton shape (scale bars range from 1 $50 \mu \mathrm{m}$ ); (b) Example of the intricate designs of diatom frustules; (c) Elastic modulus results of atomic force microscopy mapping of a diatom exoskeleton showing the beam-like formation of 
stronger material (circled) that runs along the center of the body. Adapted from: (a) [118], (b) [79], (c) $[124]$.

Figure 14. (a) Diatom (Cylindrotheca fusiformis); (b) Cross-section of the diatom showing the silica spheres (marked with arrows) being deposited on the surface of the diatom; (c) The proposed mechanism for the formation of the frustule of diatoms through continuous segregation of a silica phase (light grey) from a water phase (dark grey), steps diagramed (top) and in scanning electron imagery (bottom). Adapted from: (a) and (b) [127], (c) [128].

Figure 15. Scanning electron microscopy images of coccolithophores. (a) Heterococcolith (Emiliania huxleyi). The unicellular organism is surrounded by calcite plates whose elements are composed of single crystals; (b) Holococcolith (Syracosphaera pulchra). The unicellular organism is surrounded by a shell composed of small, uniform single crystals. Adapted from [214].

Figure 16. Crustacean exoskeletons (Pachygrapsus crassipes). Images are scanning electron microscopy micrographs showing fractured cross-sections of crab cuticle: (a) The epicuticle, exocuticle and endocuticle of the cross section. There is a change in stacking density of the Bouligand layer at the interface between the exocuticle and endocuticle. The exocuticle has a greater stacking density; (b) Magnified view of Bouligand layer of the endocuticle. Vertical line depicts single Bouligand layers, black arrows indicate pore canals. Unpublished works provided by Jennifer Taylor.

Figure 17. (a) A micro-computed tomography image of the skeletal system of a seahorse (imaged species: Hippocampus reidi and Hippocampus kuda); (b) A micro-computed tomography image of the square seahorse tail displaying four overlapping bony segments and the central vertebrae; (c) The tail cross-section subjected to compression. The skeletal armor buckles and deforms to protect the central vertebral column. Adapted from [154].

Figure 18. (a) Diagram of the structure of a sea sponge (imaged species: Euplectella aspergillum and Monorhaphis chuni) spicule showing the axial filament (silicatein), the surrounding silica shells and exterior collagen net; (b) Etched microstructure of a sea sponge spicule showing the concentric silica rings (shells); (c) Transverse cross-section of a silica spicule showing the concentric tree-like rings; (d) Fracture of a spicule showing significant deflection of a crack passing through the silica rings; (e) Magnified fracture displaying the thin layer of silicatein 
(protein) between the silica rings; (f) Mechanical data displaying the significant increase in toughness of a sponge spicule over a sample of similar geometry made up of the spicule's main constituent, silica glass. Adapted from: (a) [156], (b) - (d) [161], (e) [158] (f) [215].

Figure 19. (a) Hierarchical skeleton macrostructure of the Venus' flower basket sponge (Euplectella aspergillum). Examples of the complex structure of struts that Euplectella aspergillum employs with diagrams, optical microscopy and scanning electron microscopy images: (b) Exterior spiraling ridges; (c) Horizontal and vertical struts where the horizontal struts are predominately on the interior of the lattice and the vertical struts are predominately on the exterior of the lattice; (d) Diagonal struts. Adapted from: (a) [158], (b) - (d) [157].

Figure 20. (a) Photographs of a common sea urchin (Paracentrotus lividus); (b) the sea urchin test; (c) SEM image of the fracture surface of a spine. Adapted from: (a) www.puntacampanella.org, (b) www. aeonwebtechnology.com, (c) [216].

Figure 21. Scanning electron micrographs at varying magnifications of a cross-section from a spine from the sea urchin, Heterocentrotus mammillatus, displaying the porous bulk and dense growth rings. The growth rings likely result from former exoskeleton surfaces. Adapted from [163].

Figure 22. Structural features of sea urchin (imaged species: Echinometra mathaei, Anthocidaris crassispina and Authoeidaris erassispina) spines. (a) Transmission electron microscopy image of the nanocrystals from spines; (b) Etched transmission electron microscopy image of the mesocrystal structure of spines; (c) Scanning electron microscopy image of the spine fracture surface displaying a similar structure to glass fracture surfaces. Adapted from: (a) and (c) [165], (b) [164].

Figure 23. Force-deflection curve for a spine from the slate pencil urchin (Heterocentrotus mammillatus) showing a graceful failure mode. Top left image is a diagram showing the growth rings and porous interior (sterom). Top right image is an X-ray computed tomography image showing higher (lighter) and lower (darker) density regions. Adapted from [163]. 
Figure 24. Micro computed tomography image of a porcupine fish (Diodon holocanthus) displaying the long spines embedded within the skin of the fish. Unpublished works provided by Frances Su (UCSD).

Figure 25. Marine fish scales. (a) Cross section of an elasmoid scale (from a striped sea bass, Morone saxatilis) displaying bone and collagen layers. Major marine fish scale groups: (b) Scanning electron microscopy image and diagram of a placoid scale (from a catshark, Scyliorhinus canicula); (c) Image and diagram of an elasmoid scale (ctenoid, from a striped sea bass). Adapted from: (a) [180], (b) [13, 188], (c) [13].

Figure 26. Cosmoid scales from a coelacanth (Latimeria chalumnae). (a) Coelacanth; (b) Cosmoid scale; (c) Micrograph of the cross-section of the cosmoid scale displaying the distinctive struts that bridge between collagen lamellae and provide additional strength. (a) is unpublished work provided by Haochan Quan (UCSD), (b) - (c) are adapted from [196].

Figure 27. Carapace of the leatherback sea turtle (Dermochelys coriacea). (a) Leatherback sea turtle; (b) A section of carapace displaying osteoderms connected by sutured interfaces; (c) Scanning electron microscopy micrograph of the sutured interface of two osteoderms; (d) Microcomputed tomography image displaying a highly random porous morphology and gap between osteoderms that enable flexing; (e) Micro-computed tomography image of a single osteoderm showing a 3D arrangement of sutures. Adapted from: (a) - (c) [13], (d) and (e) [200].

Figure 28. (a) Structure of the lateral scutes of the boxfish (Lactoria cornuta), the external surface is mineralized and rigid, but if removed, a base of aligned collagen fibers is revealed; (b) Fracture of a scute tested in a punching mode by a hexagonal punch (highlighted); (c) Fracture of the surrounding scutes. In both cases, the facture occurs primarily within the collagen base while the mineral remains relatively intact. Adapted from [12].

Figure 29. Mantis shrimp (Gonodactylus chiragra) dactyl club. (a) A mantis shrimp with the dactyl clubs circled; (b) Diagram of the cross-section of the dactyl club showing the heavily calcified surface, the fibrous chitin in the interior and soft tissue at the core. (a) adapted from [205], (b) adapted from [4]. 
Figure 30. Bioinspired armor designs based upon fish scales. (a) Ancient Roman "Lorica Squamata" armor designed with metal overlapping scales over a leather shirt; (b) Modern "Dragon Skin" armor designed with ceramic, bulletproof and overlapping plates. Adapted from [48]. 
Tables

Table 1. Mechanical properties of marine biological material constituents.

\begin{tabular}{|c|c|c|c|c|c|}
\hline Material & $\begin{array}{c}\text { Elastic Modulus }(E) \\
(\mathbf{G P a})\end{array}$ & $\begin{array}{c}U C S^{1} \\
(\mathbf{M P a})\end{array}$ & $\begin{array}{c}U T S^{2} \\
(\mathbf{M P a})\end{array}$ & $\begin{array}{c}\text { Example } \\
\text { Biological } \\
\text { Organisms } \\
\end{array}$ & Reference \\
\hline \multicolumn{6}{|c|}{ Biopolymer Constituents } \\
\hline $\begin{array}{l}\text { Type I } \\
\text { Collagen }\end{array}$ & $0.05-1$ & & $20-100$ & Fish scales & $\begin{array}{c}{[30,217} \\
218]\end{array}$ \\
\hline Chitin & $1-20$ & & 200 & $\begin{array}{l}\text { Mollusk and } \\
\text { crab } \\
\text { exoskeletons }\end{array}$ & {$[219]$} \\
\hline Keratin & $0.1-5$ & & $60-200$ & $\begin{array}{l}\text { Hagfish } \\
\text { slime, squid } \\
\text { beaks }\end{array}$ & {$[30]$} \\
\hline \multicolumn{6}{|c|}{ Biomineral Constituents } \\
\hline Hydroxyapatite & $50-112$ & $30-115$ & & Fish scales & $\begin{array}{c}{[217,218,} \\
220]\end{array}$ \\
\hline $\begin{array}{l}\text { Calcium } \\
\text { Carbonate }\end{array}$ & $50-150$ & $100-200$ & & $\begin{array}{l}\text { Mollusk and } \\
\text { crab } \\
\text { exoskeletons, } \\
\text { sea urchin } \\
\text { spines }\end{array}$ & [7] \\
\hline $\begin{array}{l}\text { Amorphous } \\
\text { Silica }\end{array}$ & $60-75$ & & $155-200 *$ & $\begin{array}{l}\text { Sea sponge } \\
\text { spicules, } \\
\text { diatom } \\
\text { exoskeletons }\end{array}$ & {$[221,222]$} \\
\hline Magnetite & 72 & & & Chiton teeth & [223] \\
\hline
\end{tabular}


Table 2. Mechanical properties of selected marine biological materials tested in a quasi-static, hydrated state.

\begin{tabular}{lcccc}
\hline \multicolumn{1}{c}{ Biological Material } & $\begin{array}{c}\text { Elastic Modulus }(\boldsymbol{E}) \\
(\mathbf{G P a})\end{array}$ & $\begin{array}{c}\boldsymbol{U C S}^{1} \\
(\mathbf{M P a})\end{array}$ & $\begin{array}{c}\boldsymbol{U T S}^{2} \\
(\mathbf{M P a})\end{array}$ & \begin{tabular}{c} 
Reference \\
\hline Abalone shell (Nacre)
\end{tabular} \\
Crab exoskeleton (leg) & $0.47-0.52$ & $235-540$ & 140 & {$[102,224]$} \\
& & 57 & $30-31.5$ & {$[133,143$,} \\
Crab exoskeleton (claw) & 4.9 & & & $144]$ \\
Mantis shrimp dactyl club & 75 & & & {$[142]$} \\
Fish scale (Pagrus major) & 2.2 & & 93 & {$[204]$} \\
Diatom exoskeleton & 22.4 & $330-680$ & $155-560$ & {$[64]$} \\
Sea urchin spines & 21 & $42-49$ & & {$[121]$} \\
Conch shell & 30 & $180-310$ & & {$[103,168]$} \\
Hagfish slime & 0.006 & & 180 & {$[225]$} \\
Sea sponge spicules & $36-38$ & & $593-880^{*}$ & {$[221,222]$} \\
\hline
\end{tabular}

${ }^{1}$ Ultimate Compressive Strength

${ }^{2}$ Ultimate Tensile Strength

* Values taken in 3-point bending mode. 
Table 3. Relative weight proportions of biomineral and biopolymer constituents for marine organisms.

\begin{tabular}{lcc}
\hline \multicolumn{1}{c}{ Organism (sample type) } & Ratio of biomineral:biopolymer (by weight) & Reference \\
\hline Snow Crab (claw) & $3.8: 1$ & {$[133]$} \\
Snow Crab (carapace) & $1.6: 1$ & {$[133]$} \\
American Lobster (carapace) & $1.7: 1$ & {$[226]$} \\
Cod (clythrum bone) & $6.4: 1$ & {$[227]$} \\
Seahorse (bony plates) & $1.5: 1$ & {$[150]$} \\
Red Abalone (shell) & $19: 1$ & {$[96]$} \\
Sea Sponge (spicules) & $3: 1$ & {$[82]$} \\
Red Seabream (fish scales) & $1: 1.2$ & {$[64]$} \\
Barramundi (fish scales) & $1: 1.5$ & {$[228]$} \\
Longhorn cowfish (fish scales) & $1: 2$ & {$[12]$} \\
Cow (femur bone) & $2.6: 1$ & {$[52]$} \\
Human (dentin) & $1.8: 1$ & {$[4]$} \\
\hline
\end{tabular}




\section{Figures}

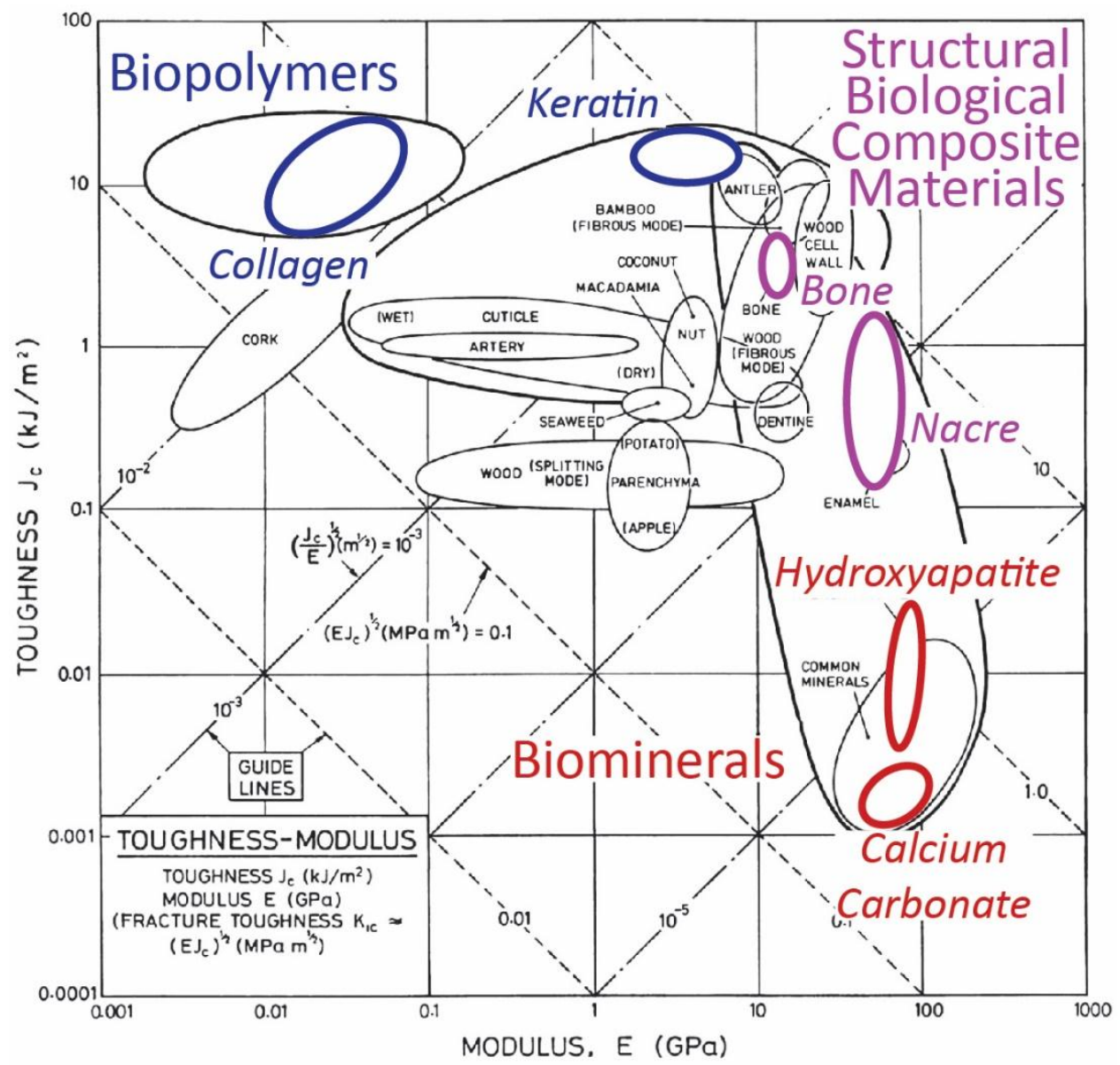

Figure 1. Toughness as a function of elastic modulus for biological materials. Adapted from [7]. 
(a)

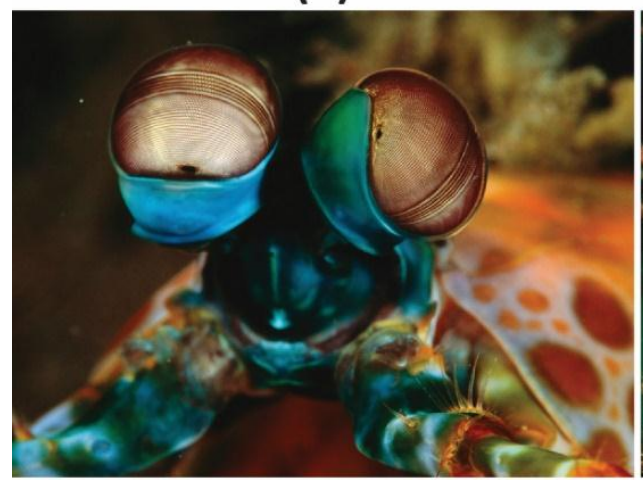

(c)

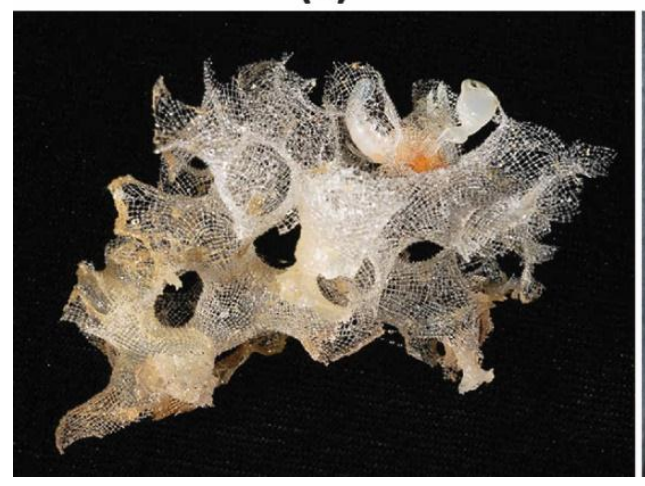

(b)

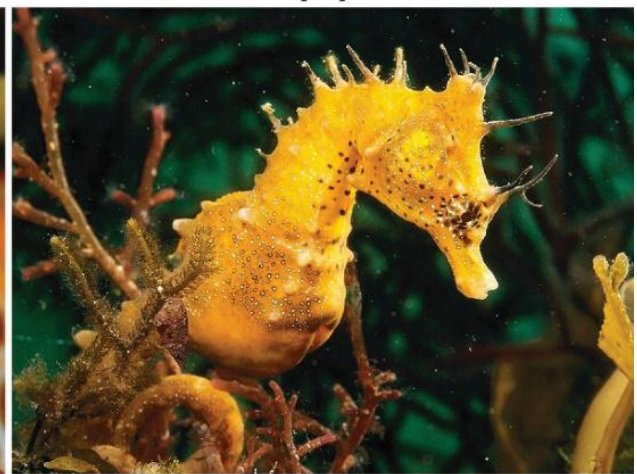

(d)

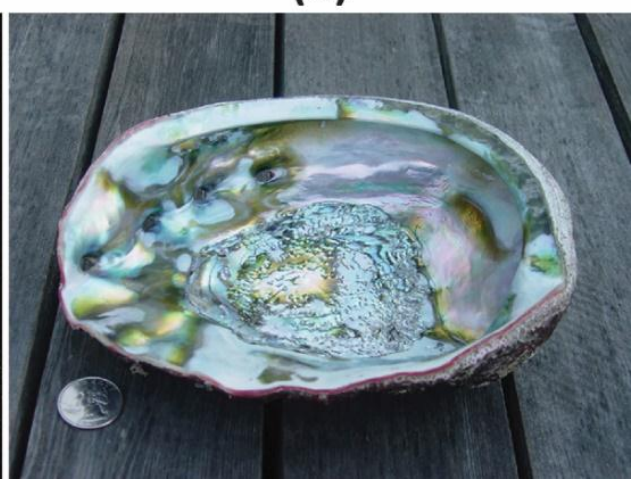

Figure 2. Examples of some spectacular marine organisms. (a) Odontodactylus (mantis shrimp); (b) Hippocampus (seahorse); (c) Farrea (honeycomb glass sponge); (d) Haliotis (abalone). Adapted from: (a) - (c) nationalgeographic.com, (d) wikipedia.com. 


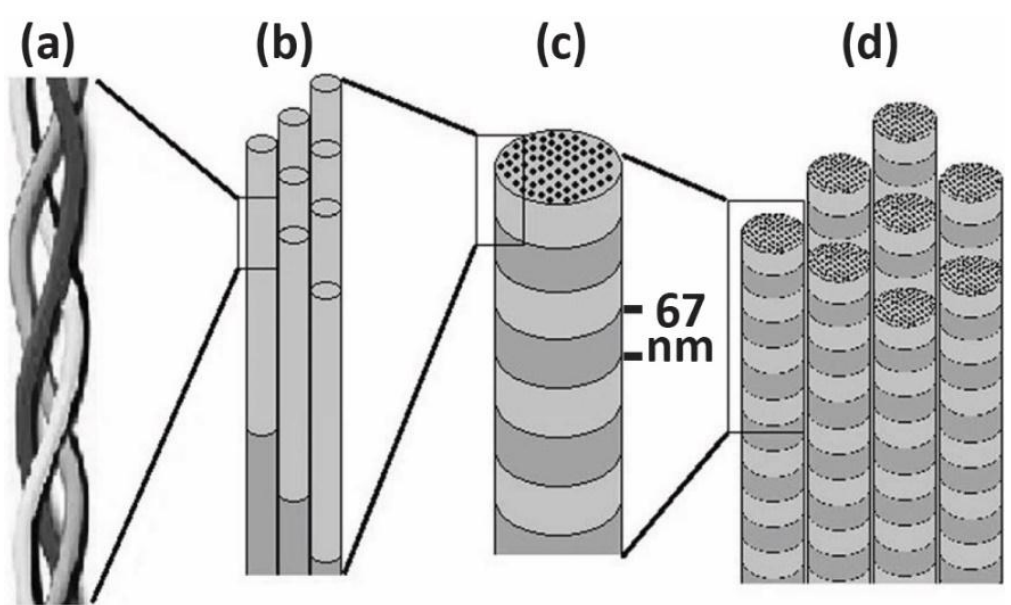

(e)

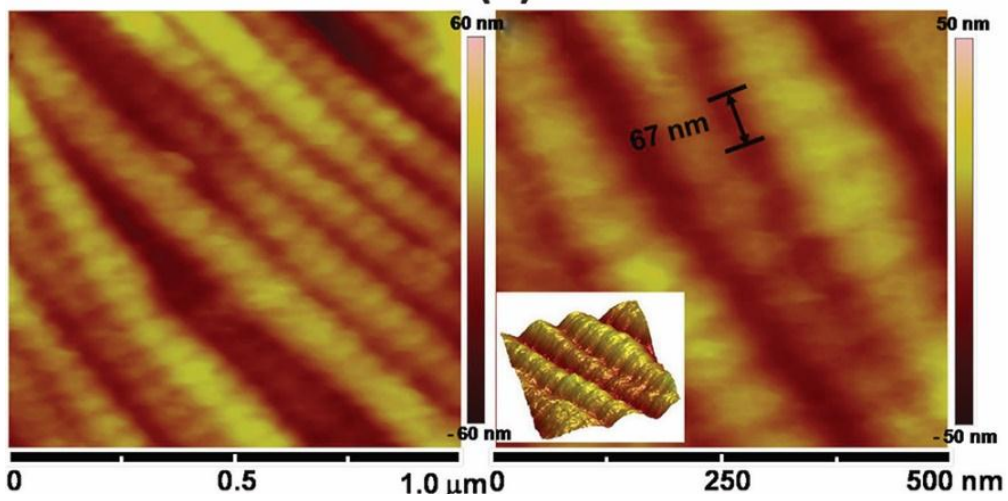

Figure 3. Diagram of the hierarchical structure of collagen fibers. (a) triple helix segments; (b) Tropocollagen molecules; (c) Assembled collagen fibrils with the characteristic periodic $67 \mathrm{~nm}$ spacing highlighted; (d) Collagen fibers assembled from multiple collagen fibrils; (e) Atomic force micrograph of a collagen fibril from fish scales with the characteristic spacing highlighted. Adapted from: (a) - (d) [16], (e) [29]. 
(a)

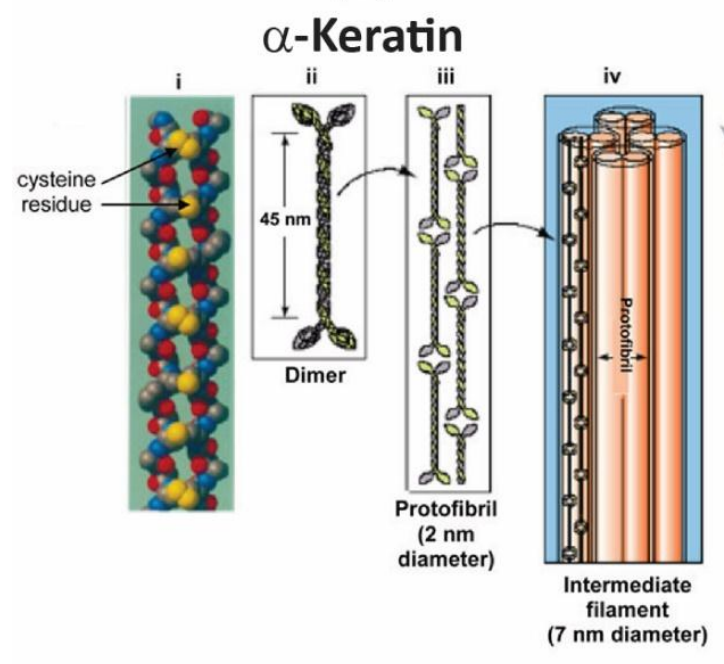

(b)

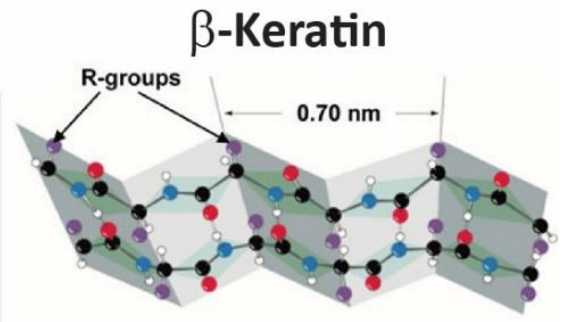

(c)

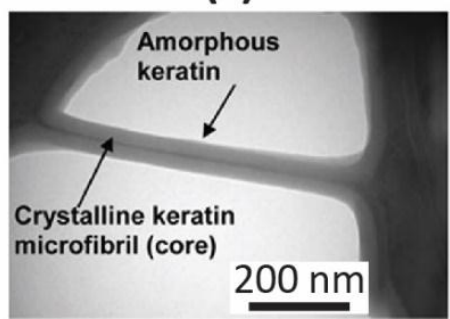

Figure 4. Structure of keratin. (a) Hierarchy of $\alpha$-keratin showing the assembly from two polypeptide chains (i) to a fibrous structure (iv); (b) $\beta$-keratin that shows a pleated sheet shape that consists of antiparallel chains with R-groups that extend between sheets; (c) TEM micrograph of $\alpha$-keratin from a sheep horn that displays the composite structure of a crystalline keratin core within an amorphous keratin matrix. Adapted from: (a) [30, 209], (b) [30], (c) [30, 210]. 
(a)

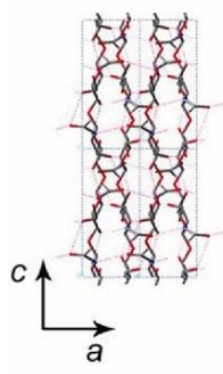

$\alpha$-Chitin

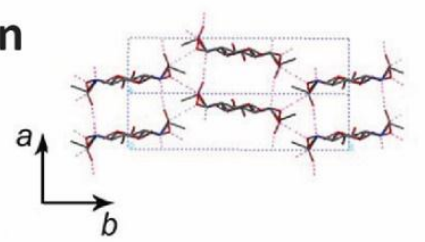

(c)

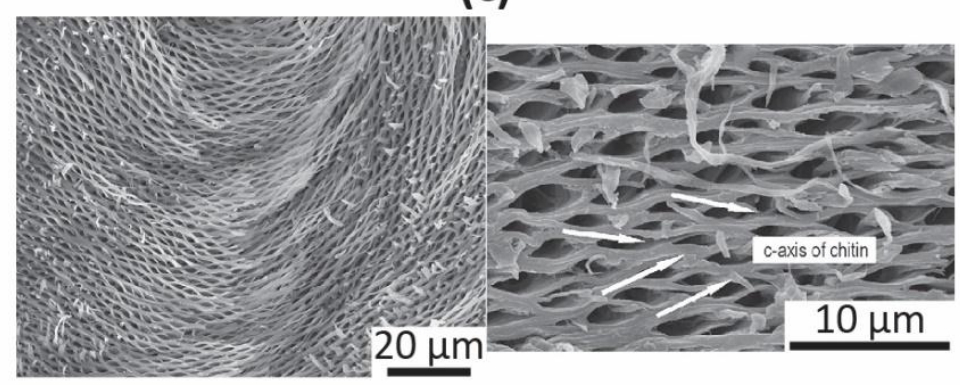

(b)

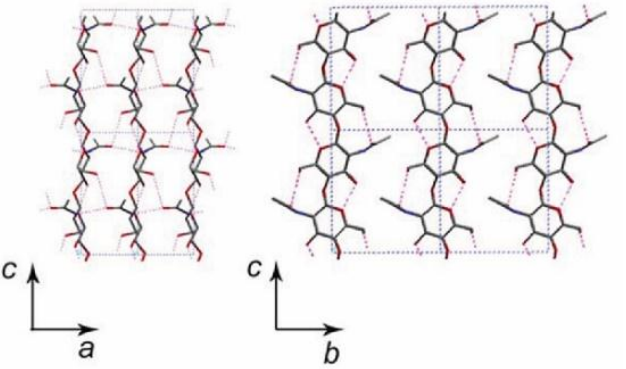

$\beta$-Chitin

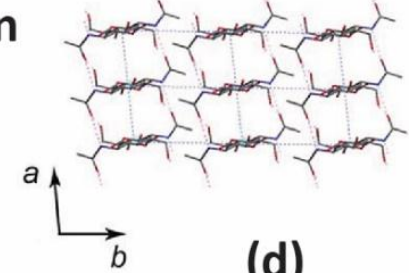

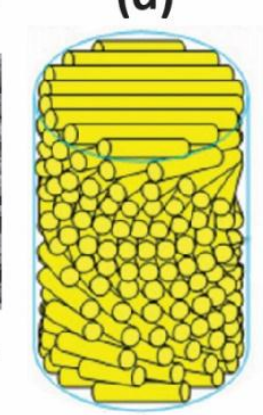

Figure 5. Diagram of the structure of chitin. (a) The molecular structure of $\alpha$-chitin viewed from three different directions; (b) The molecular structure of $\beta$-chitin viewed from three different directions; (c) Aligned microstructure of mineralized $\alpha$-chitin fibers from the exoskeleton of a lobster; (d) Diagram of the helical Bouligand structure of many chitin materials, such as crustacean exoskeletons. Adapted from: (a) and (b) [41], (c) [211], (d) [4]. 
(a)

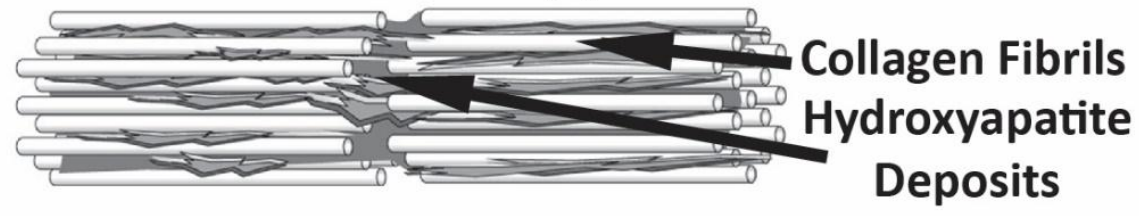

(b)

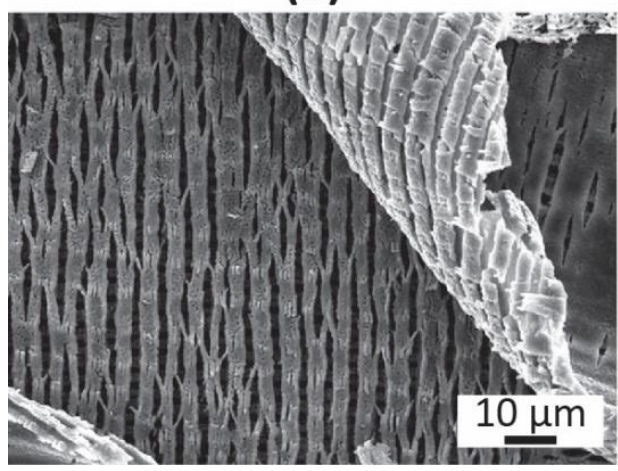

(c)

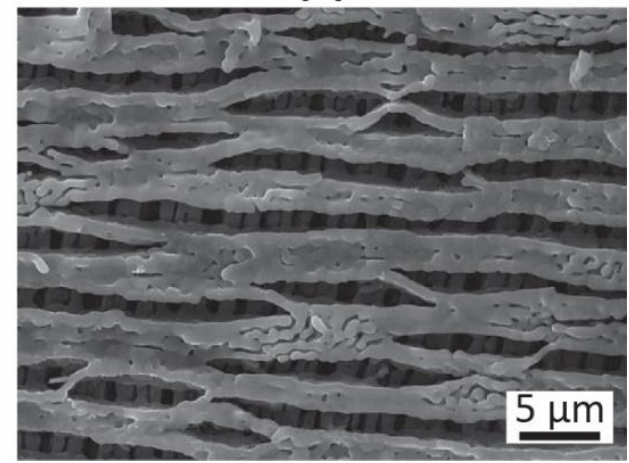

Figure 6. Growth and structure of hydroxyapatite and, in the case of bone, carbonated hydroxyapatite. (a) A diagram of the biomineralization of hydroxyapatite where collagen (or other biopolymer) fibrils template hydroxyapatite crystal growth; Deproteinized tissue (by heating at $1473 \mathrm{~K}$, images of tissue from a sea bream, (Pagrus major) at (b) low and (c) high magnification. While these samples consist of only mineral, they still show a preferential orientation to their original collagen template. Adapted from: (a) [62], (b) and (c) [64]. 
(a)

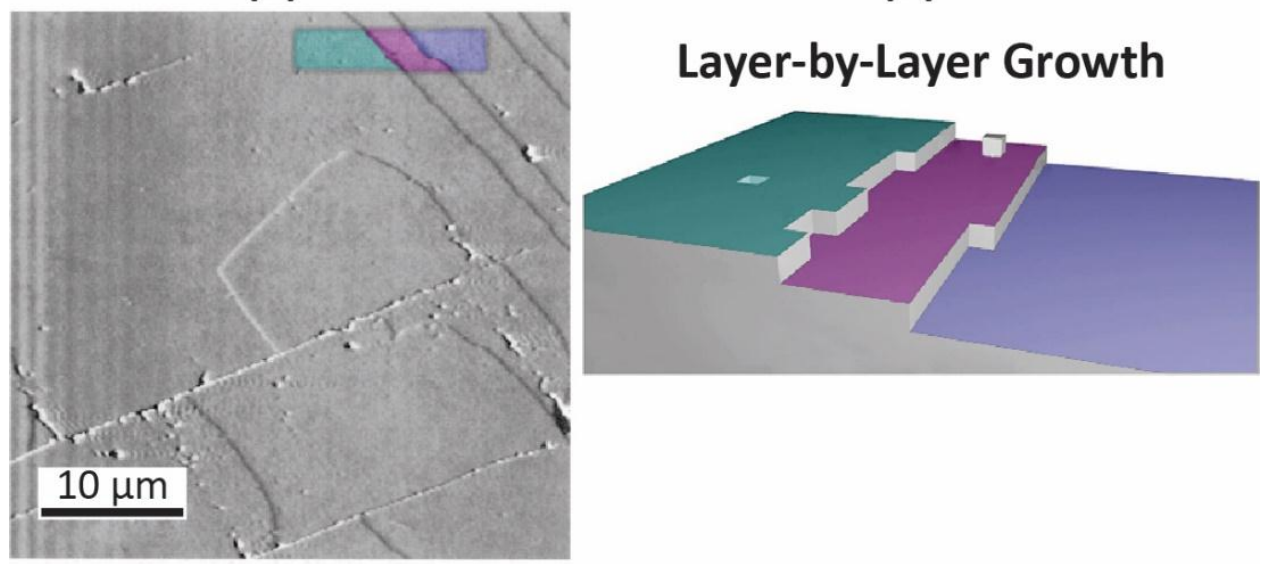

(c)

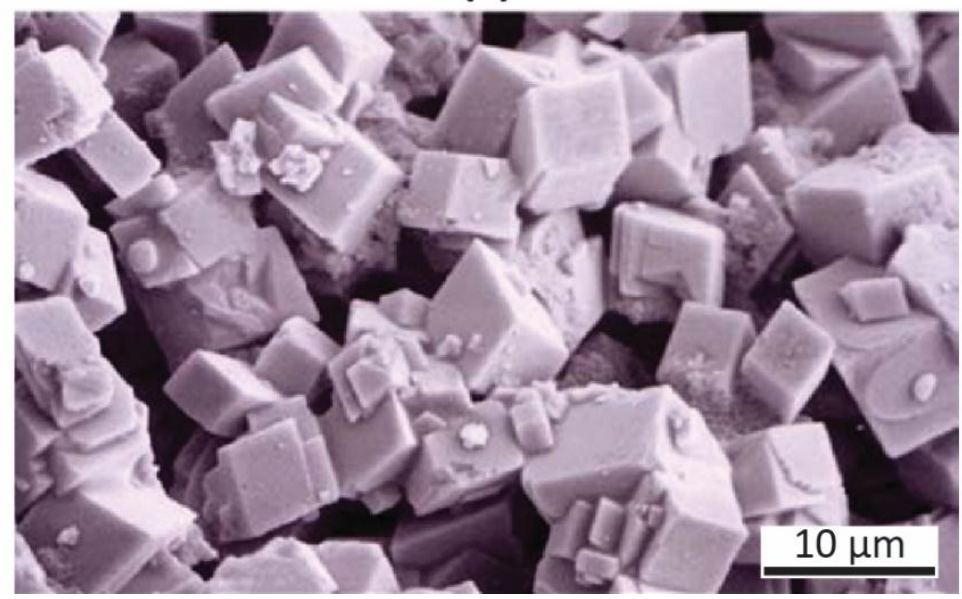

Figure 7. Crystalline calcium carbonate structure. (a) Calcite showing the characteristic layered structure of crystallized calcium carbonate. Layers are colored coordinated with (b); (b) This characteristic structure is caused by layer-by-layer growth as dictated by the diagramed Kossel model; (c) Particles of calcium carbonate (calcite) showing a faceted structure. Adapted from: (a) and (b) [68], (c) [212]. 


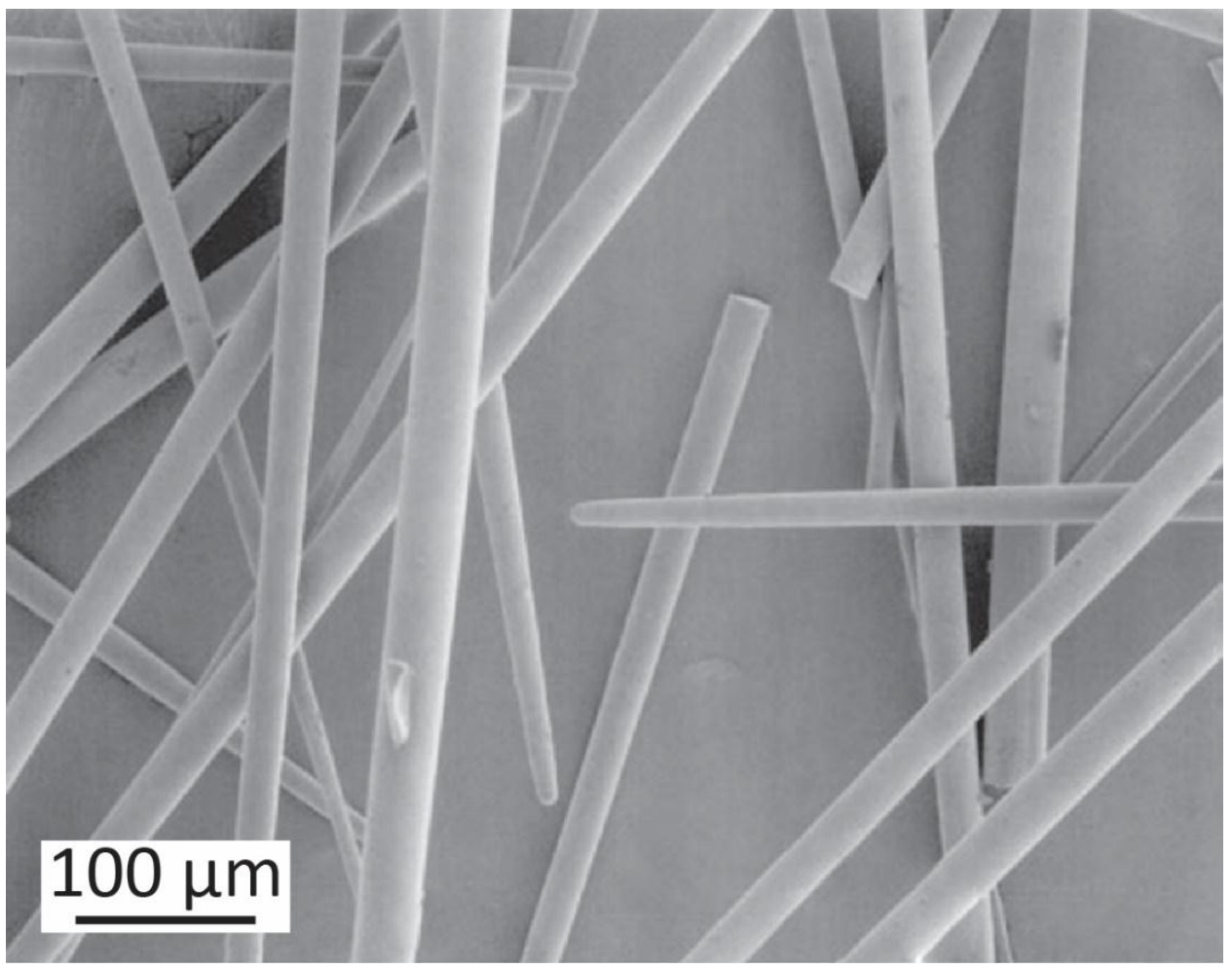

Figure 8. Example spicule structures of amorphous silica employed in sponges and diatoms. Adapted from [82]. 
(a)

(b)

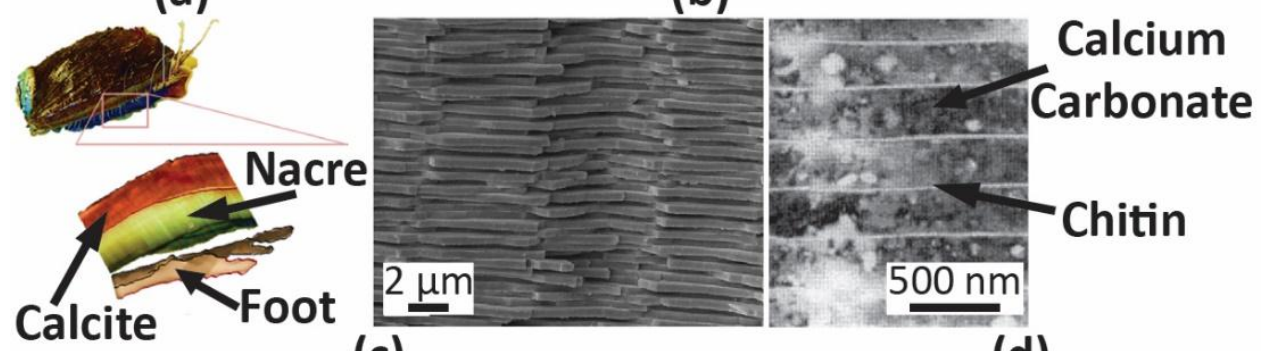

(c)

(d)

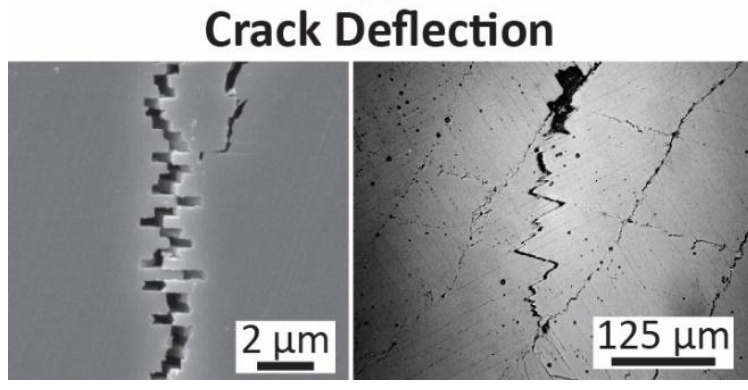

Microbuckling

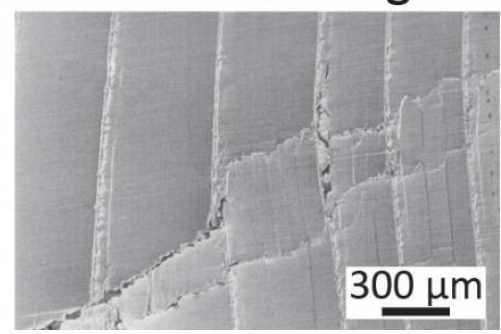

Figure 9. Structure and toughening mechanisms of marine mollusk nacre (imaged species: Haliotis Rufescens and Strombus gigas). (a) Cross-section of the abalone shell displaying the calcitic and aragonitic (nacre) layers; (b) The brick-and-mortar structure of nacre displaying calcium carbonate plates with mortar-like chitin layers; (c) Crack deflection toughening mechanism that causes a more tortuous crack path; (d) Microbuckling toughening mechanism of the calcium carbonate plates that creates significant additional surface area. Adapted from: (a) [213], (b) [93, 102], (c) [96], (d) [102]. 
(a)

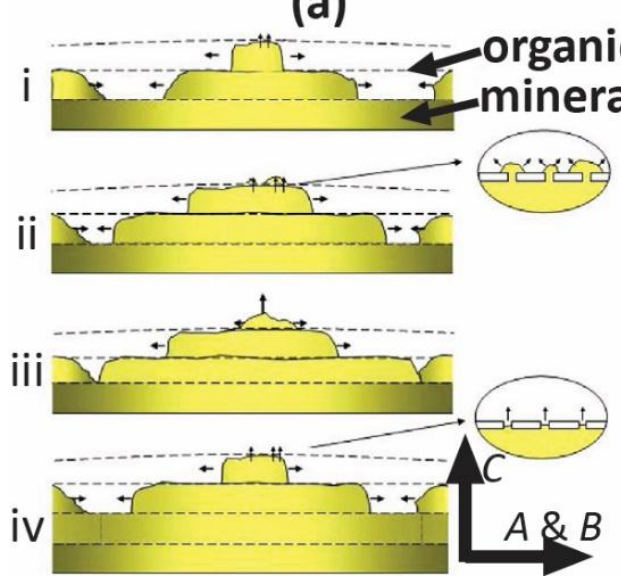

(b)

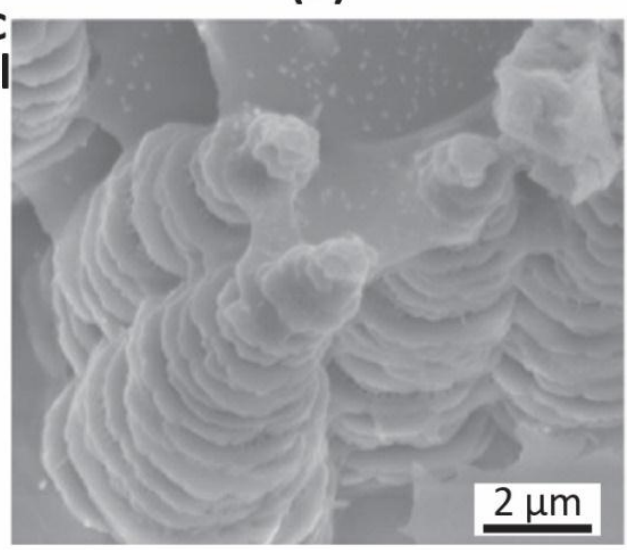

Figure 10. Process of nacre growth in the shell of abalone (Haliotis rufescens). (a) Diagram of the process of nacre growth (progressing from top to bottom) where calcium carbonate mineral shelves assemble through an organic membrane. Growth occurs laterally ( $A$ and $B$ directions) while it is retarded longitudinally ( $C$ direction) by deposition of a porous organic layer (dashed lines); (b) SEM image of nacre displaying the growth peaks. Adapted from: (a) [97], (b) [99]. 


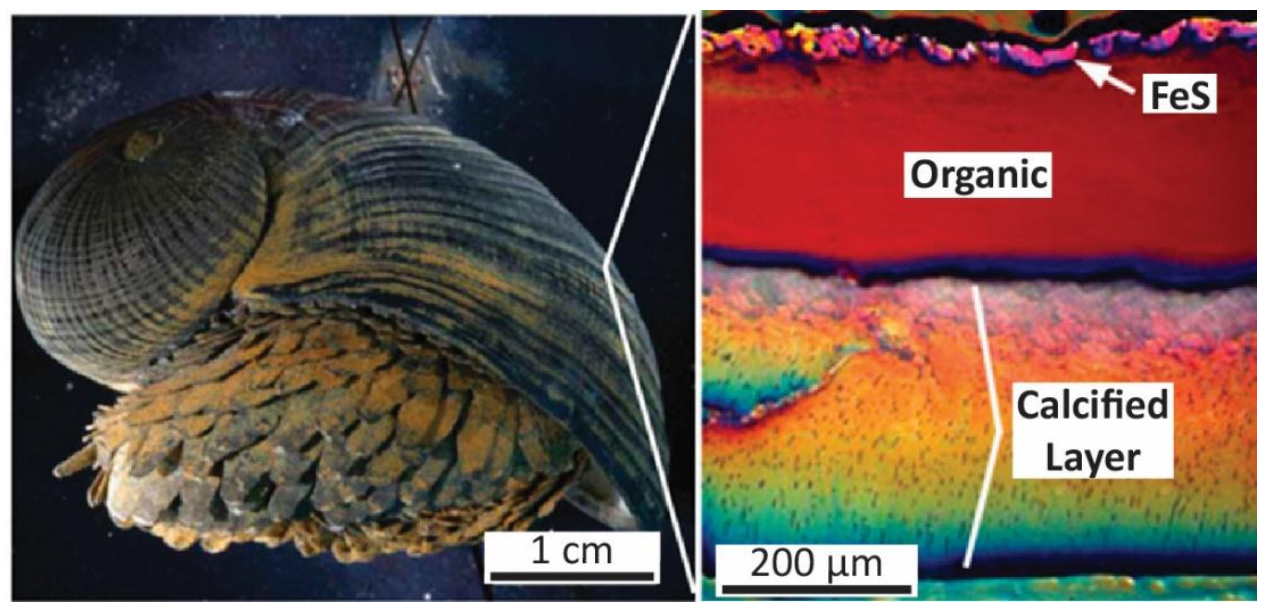

Figure 11. Deep sea scaly-foot gastropod (Crysomallon squamiferum) that employs a three part shell with an iron-sulfide based outer layer (FeS), an organic intermediate layer (Organic) and an aragonite inner layer (Calcified Layer). Adapted from [109]. 
(a)

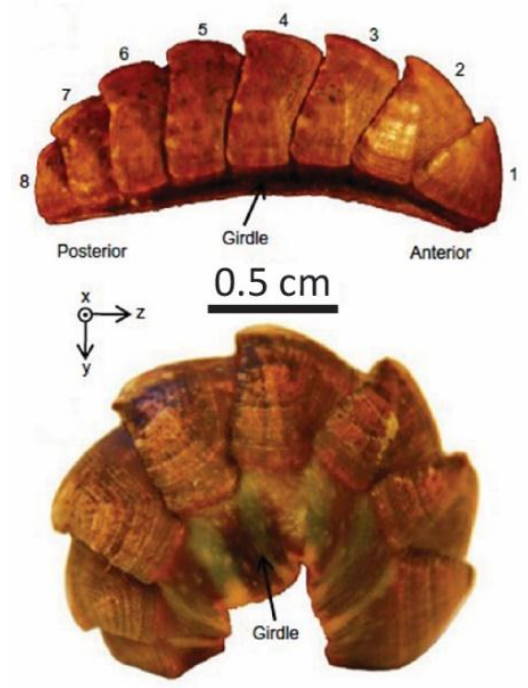

(b)
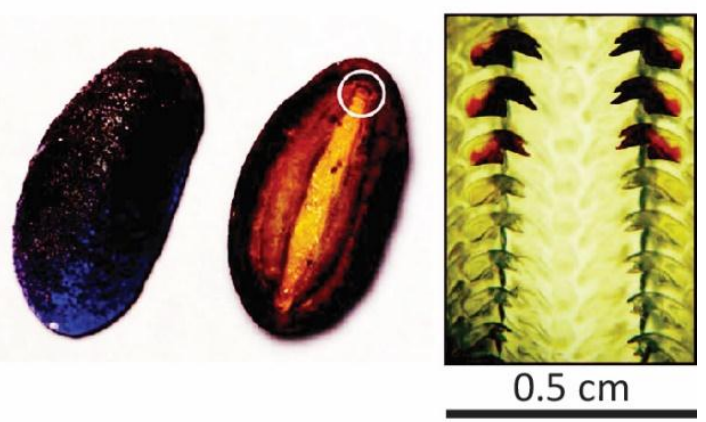

Figure 12. (a) Side-view photographs of a chiton (Tonicella marmorea) showing the eight plates that can curl up into a defensive position; (b) Another chiton species (Cryptochiton stelleri) displaying their characteristic mineralized teeth that are made of magnetite at the leading and trailing edges and iron-phosphate in the core. Adapted from: (a) [113], (b) [89]. 
(a)
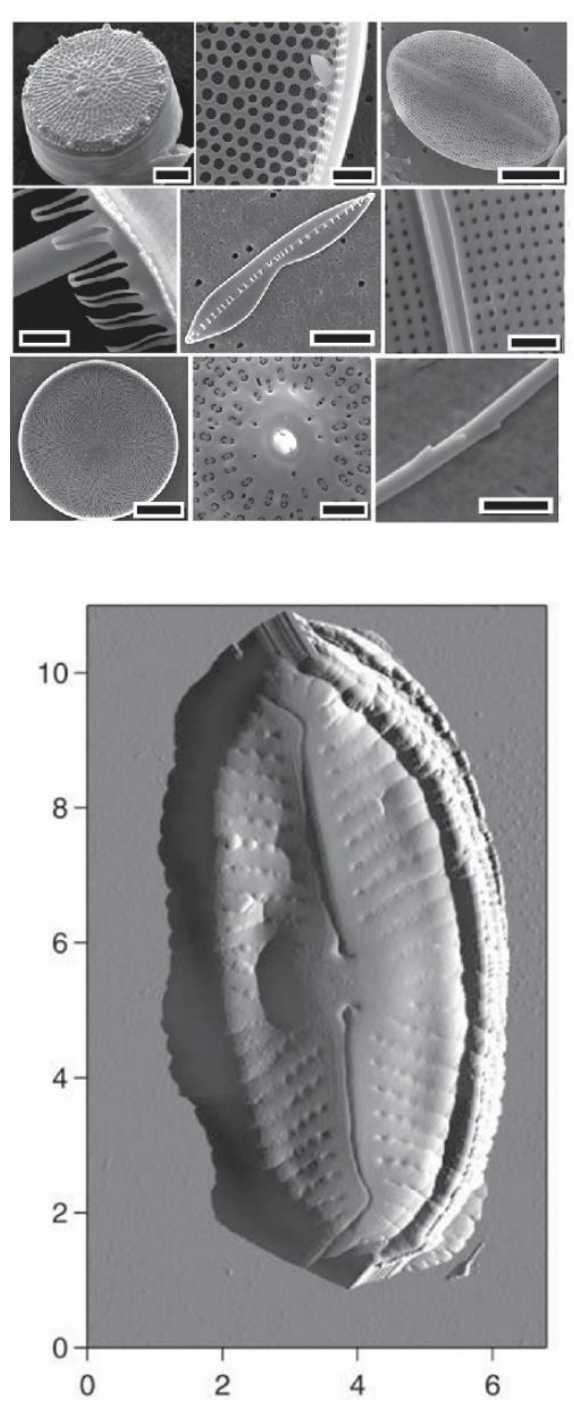

(b)

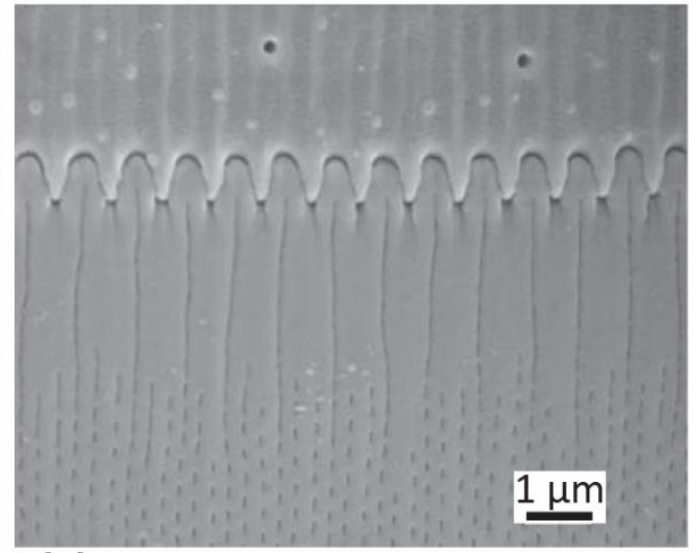

(c)

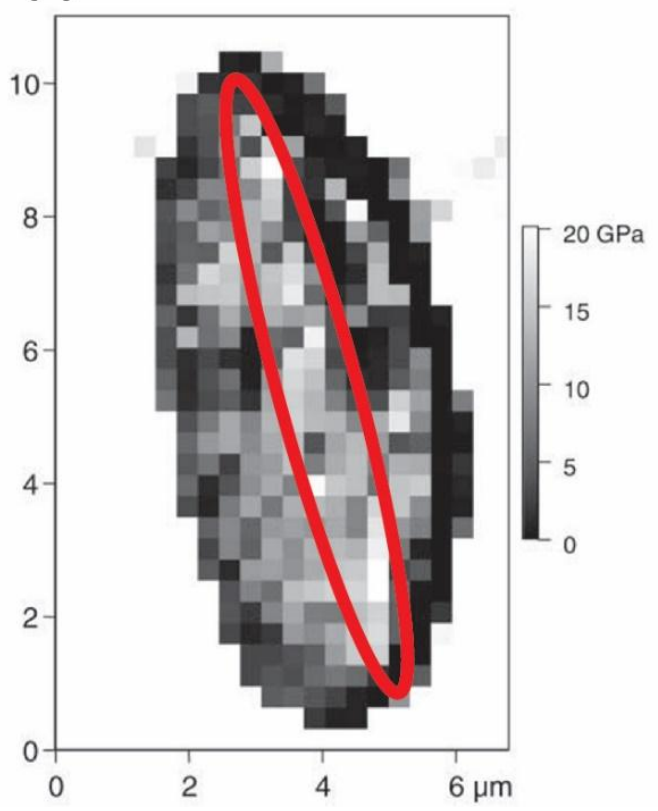

Figure 13. (a) Diatoms displaying a wide variety in exoskeleton shape (scale bars range from 1 - $50 \mu \mathrm{m}$ ); (b) Example of the intricate designs of diatom frustules; (c) Elastic modulus results of atomic force microscopy mapping of a diatom exoskeleton showing the beam-like formation of stronger material (circled) that runs along the center of the body. Adapted from: (a) [118], (b) [79], (c) [124]. 
(a)

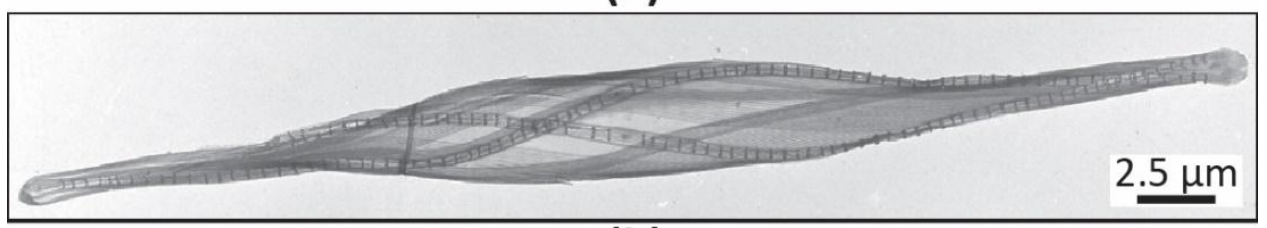

(b)

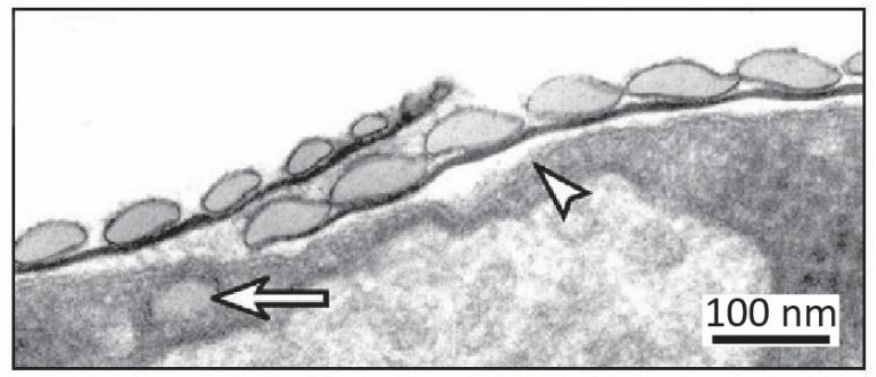

(c)
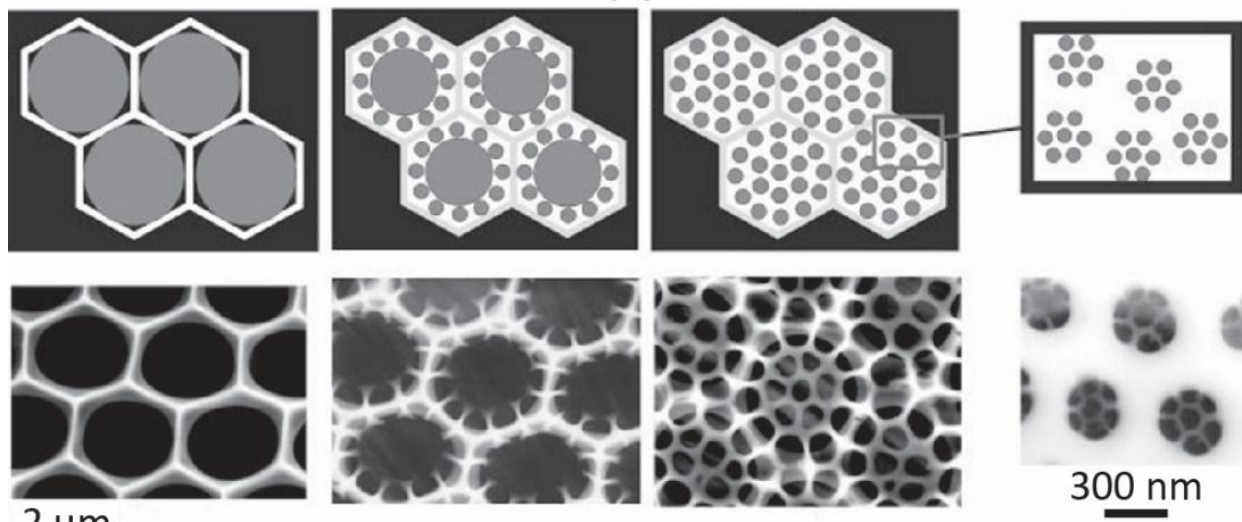

$2 \mu \mathrm{m}$

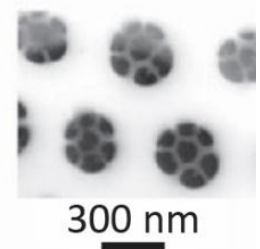

Figure 14. (a) Diatom (Cylindrotheca fusiformis); (b) Cross-section of the diatom showing the silica spheres (marked with arrows) being deposited on the surface of the diatom; (c) The proposed mechanism for the formation of the frustule of diatoms through continuous segregation of a silica phase (light grey) from a water phase (dark grey), steps diagramed (top) and in scanning electron imagery (bottom). Adapted from: (a) and (b) [127], (c) [128]. 
(a)

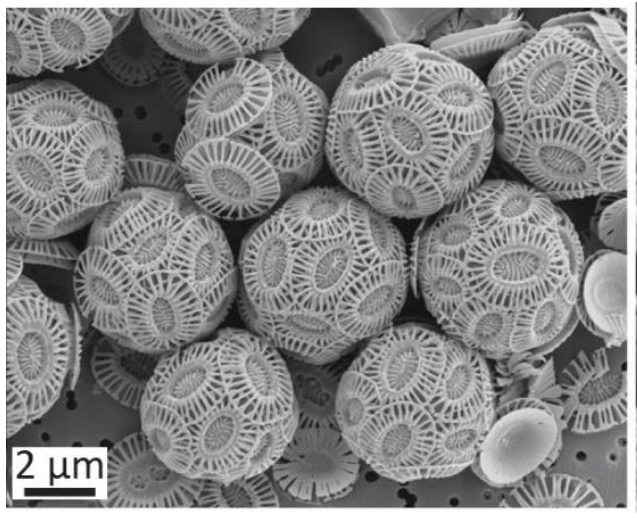

(b)

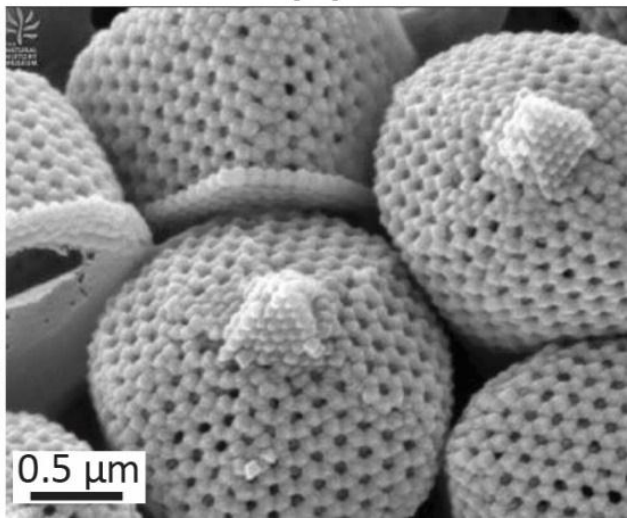

Figure 15. Scanning electron microscopy images of coccolithophores. (a) Heterococcolith (Emiliania huxleyi). The unicellular organism is surrounded by calcite plates whose elements are composed of single crystals; (b) Holococcolith (Syracosphaera pulchra). The unicellular organism is surrounded by a shell composed of small, uniform single crystals. Adapted from [214]. 
(a)

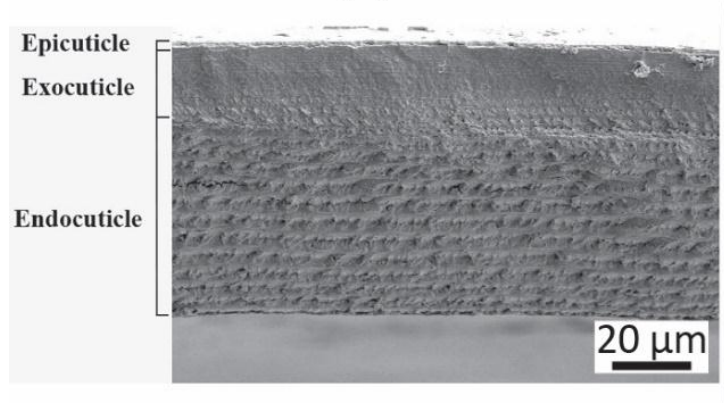

(b)

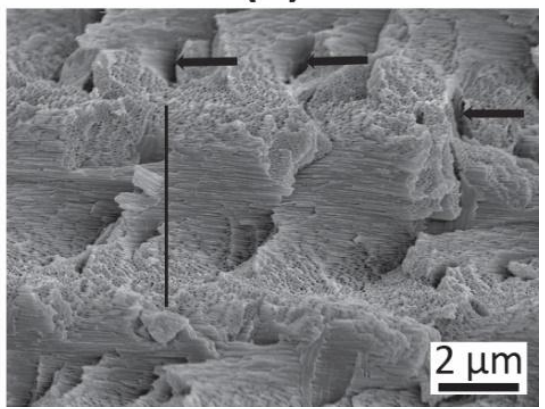

Figure 16. Crustacean exoskeletons (Pachygrapsus crassipes). Images are scanning electron microscopy micrographs showing fractured cross-sections of crab cuticle: (a) The epicuticle, exocuticle and endocuticle of the cross section. There is a change in stacking density of the Bouligand layer at the interface between the exocuticle and endocuticle. The exocuticle has a greater stacking density; (b) Magnified view of Bouligand layer of the endocuticle. Vertical line depicts single Bouligand layers, black arrows indicate pore canals. Unpublished works provided by Jennifer Taylor. 
(a)

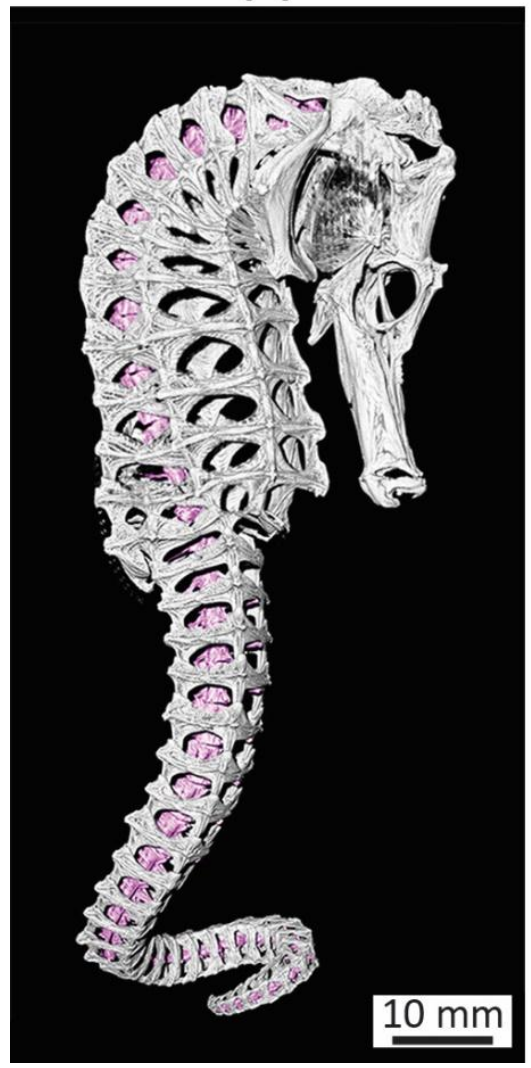

(b)

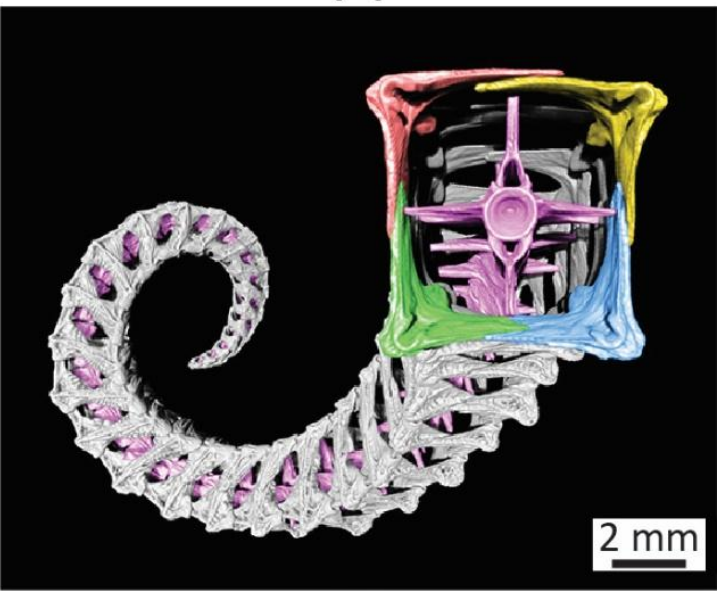

(c)

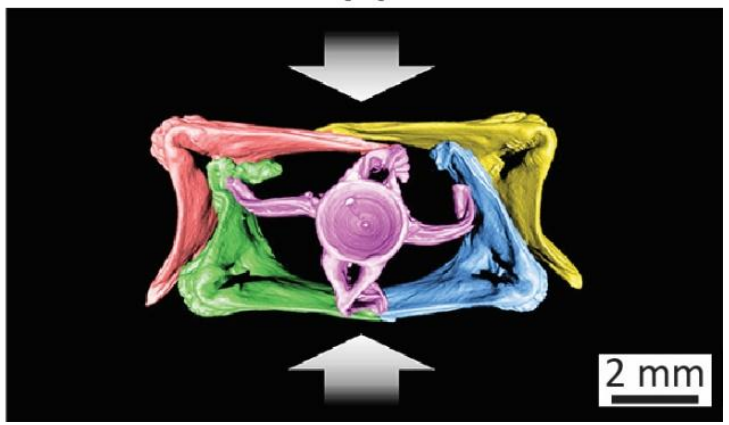

Figure 17. (a) A micro-computed tomography image of the skeletal system of a seahorse (imaged species: Hippocampus reidi and Hippocampus kuda); (b) A micro-computed tomography image of the square seahorse tail displaying four overlapping bony segments and the central vertebrae; (c) The tail cross-section subjected to compression. The skeletal armor buckles and deforms to protect the central vertebral column. Adapted from [154]. 


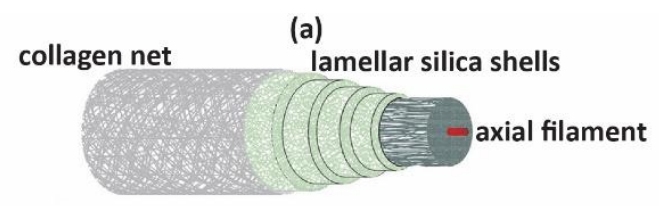

(b)

Structure

(c)

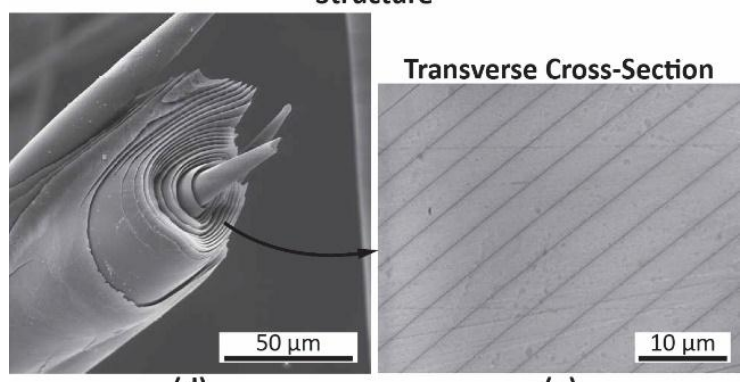

(d) Toughening Mechanisms (e)

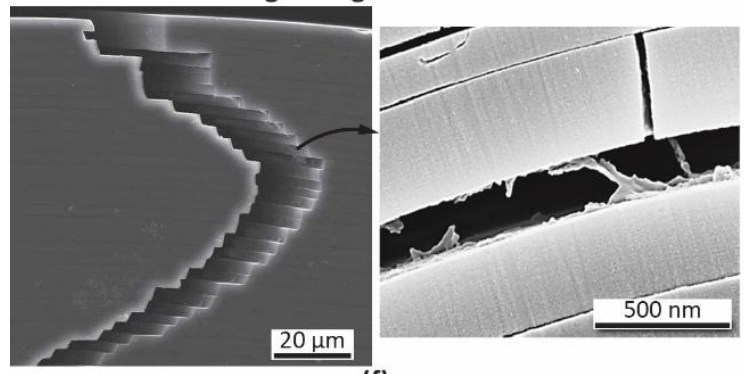

(f)

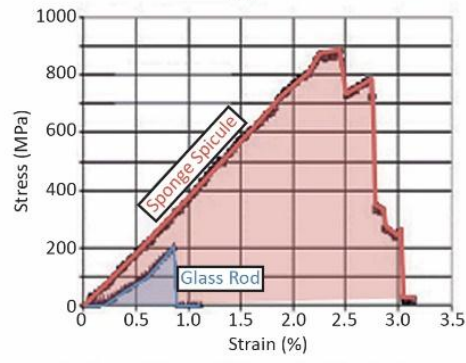

Figure 18. (a) Diagram of the structure of a sea sponge (imaged species: Euplectella aspergillum and Monorhaphis chuni) spicule showing the axial filament (silicatein), the surrounding silica shells and exterior collagen net; (b) Etched microstructure of a sea sponge spicule showing the concentric silica rings (shells); (c) Transverse cross-section of a silica spicule showing the concentric tree-like rings; (d) Fracture of a spicule showing significant deflection of a crack passing through the silica rings; (e) Magnified fracture displaying the thin layer of silicatein (protein) between the silica rings; (f) Mechanical data displaying the significant increase in toughness of a sponge spicule over a sample of similar geometry made up of the spicule's main constituent, silica glass. Adapted from: (a) [156], (b) - (d) [161], (e) [158], (f) [215]. 
(a)

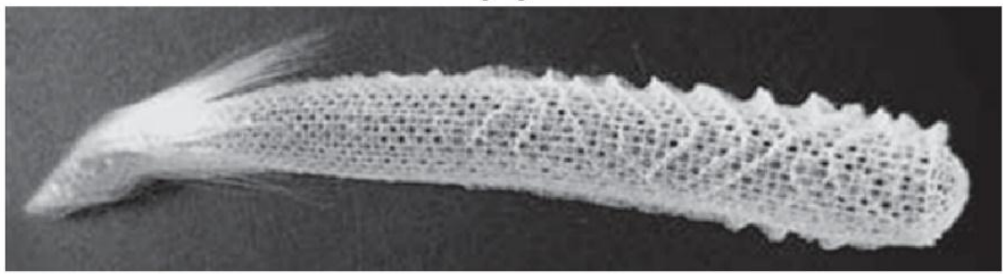

(b)

(c)

(d)

\section{Spiraling Ridges Horizontal-Vertical Struts Diagonal Struts}
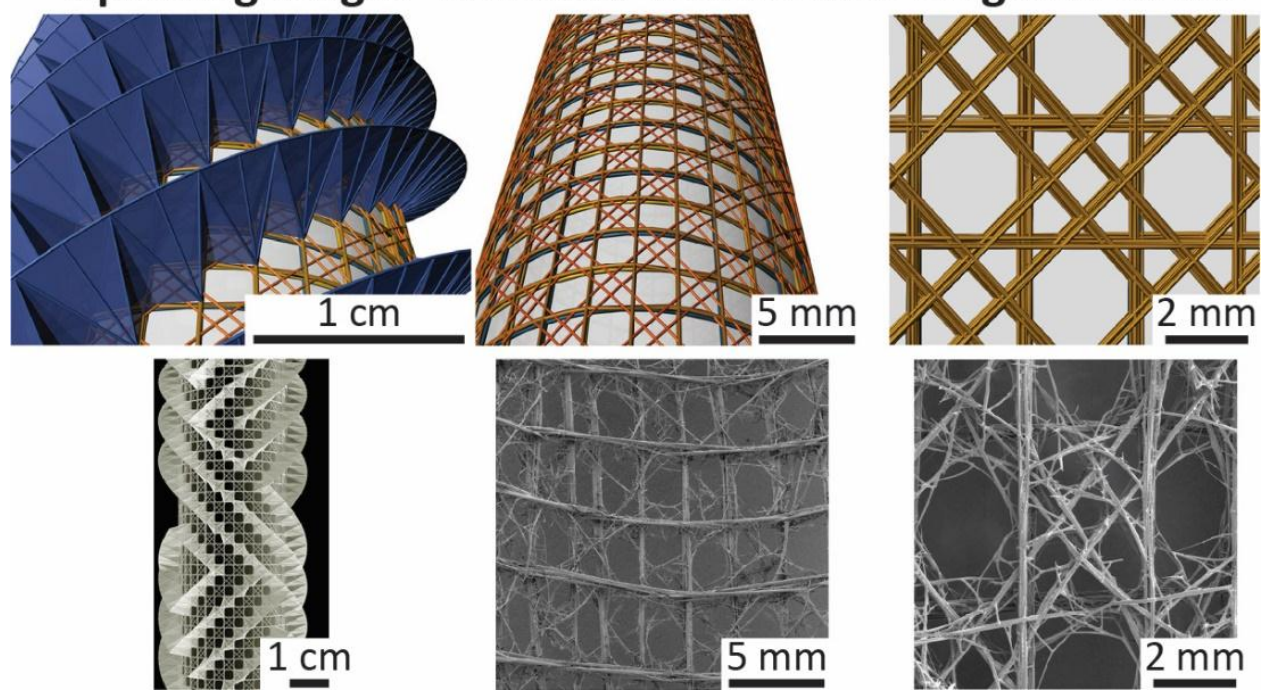

Figure 19. (a) Hierarchical skeleton macrostructure of the Venus' flower basket sponge (Euplectella aspergillum). Examples of the complex structure of struts that Euplectella aspergillum employs with diagrams, optical microscopy and scanning electron microscopy images: (b) Exterior spiraling ridges; (c) Horizontal and vertical struts where the horizontal struts are predominately on the interior of the lattice and the vertical struts are predominately on the exterior of the lattice; (d) Diagonal struts. Adapted from: (a) [158], (b) - (d) [157]. 
(a)

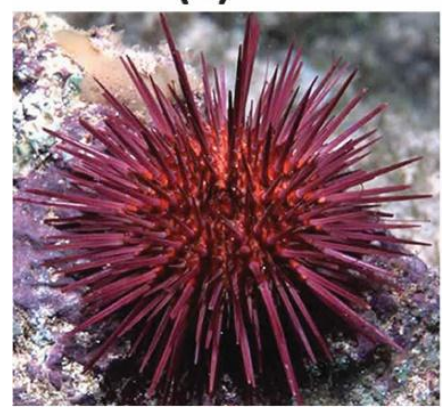

(b)

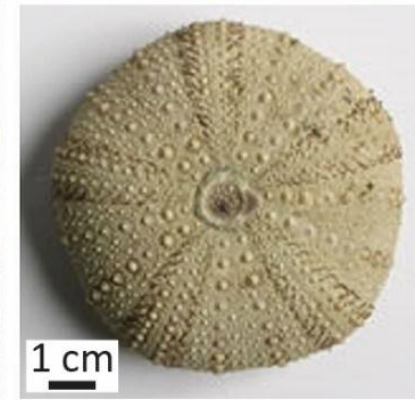

(c)

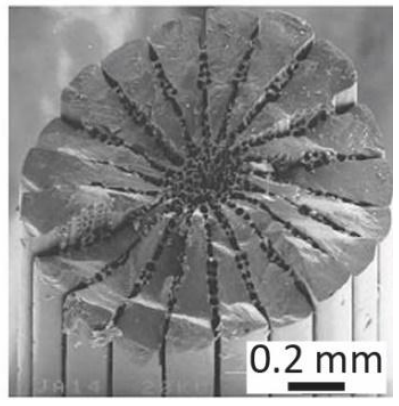

Figure 20. (a) Photographs of a common sea urchin (Paracentrotus lividus); (b) the sea urchin test; (c) SEM image of the fracture surface of a spine. Adapted from: (a) www.puntacampanella.org, (b) www. aeonwebtechnology.com, (c) [216]. 
(a)

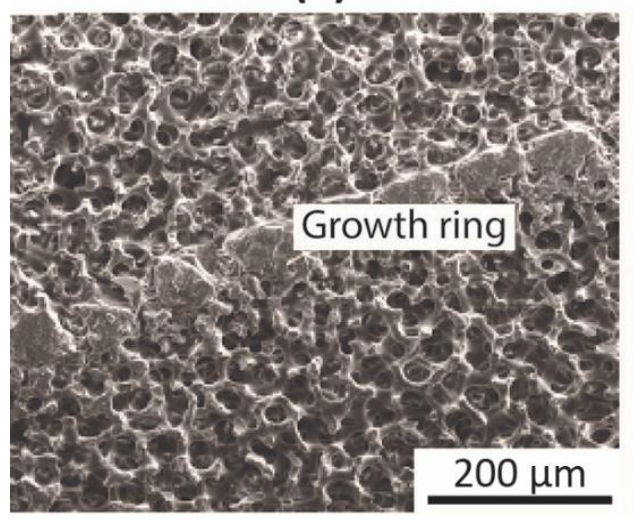

(b)

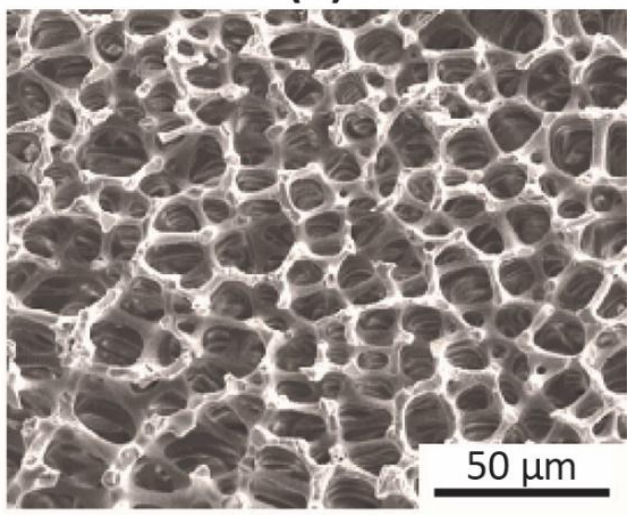

Figure 21. Scanning electron micrographs at varying magnifications of a cross-section from a spine from the sea urchin, Heterocentrotus mammillatus, displaying the porous bulk and dense growth rings. The growth rings likely result from former exoskeleton surfaces. Adapted from [163]. 
(a)
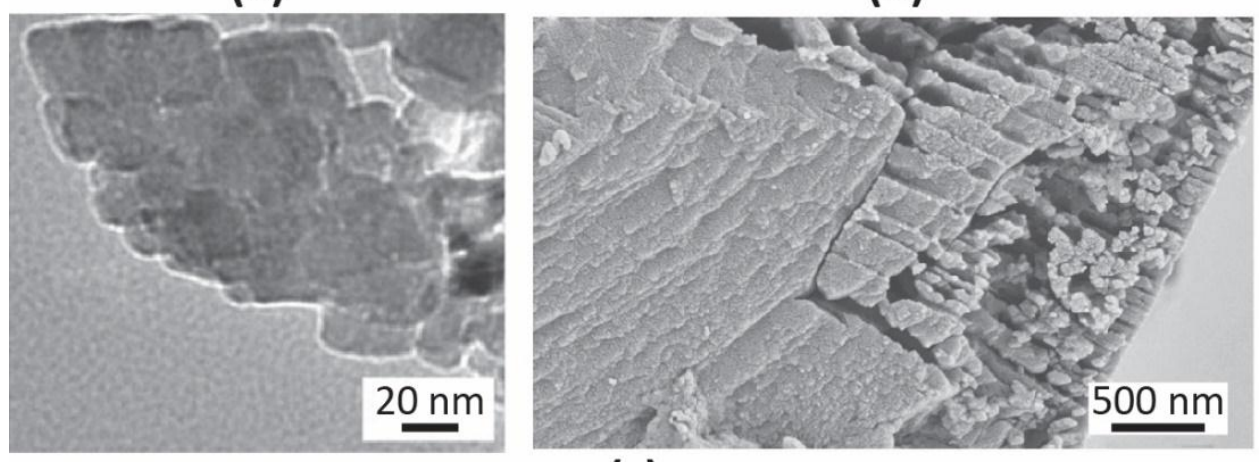

(c)

(b)

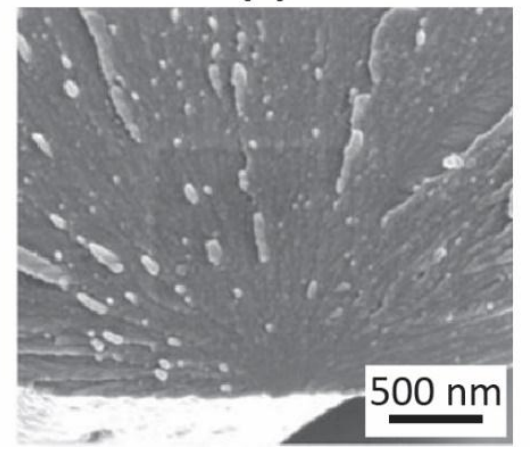

Figure 22. Structural features of sea urchin (imaged species: Echinometra mathaei, Anthocidaris crassispina and Authoeidaris erassispina) spines. (a) Transmission electron microscopy image of the nanocrystals from spines; (b) Etched transmission electron microscopy image of the mesocrystal structure of spines; (c) Scanning electron microscopy image of the spine fracture surface displaying a similar structure to glass fracture surfaces. Adapted from: (a) and (c) [165], (b) [164]. 


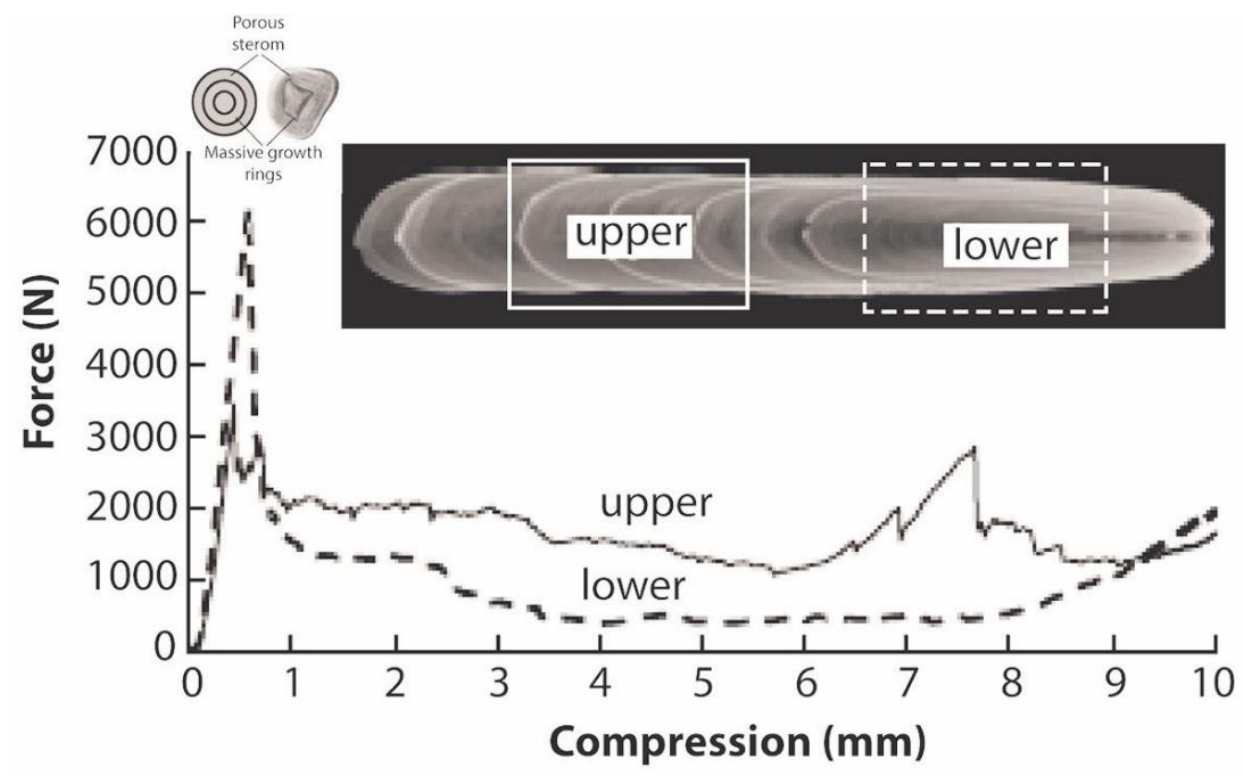

Figure 23. Force-deflection curve for a spine from the slate pencil urchin (Heterocentrotus mammillatus) showing a graceful failure mode. Top left image is a diagram showing the growth rings and porous interior (sterom). Top right image is an X-ray computed tomography image showing higher (lighter) and lower (darker) density regions. Adapted from [163]. 


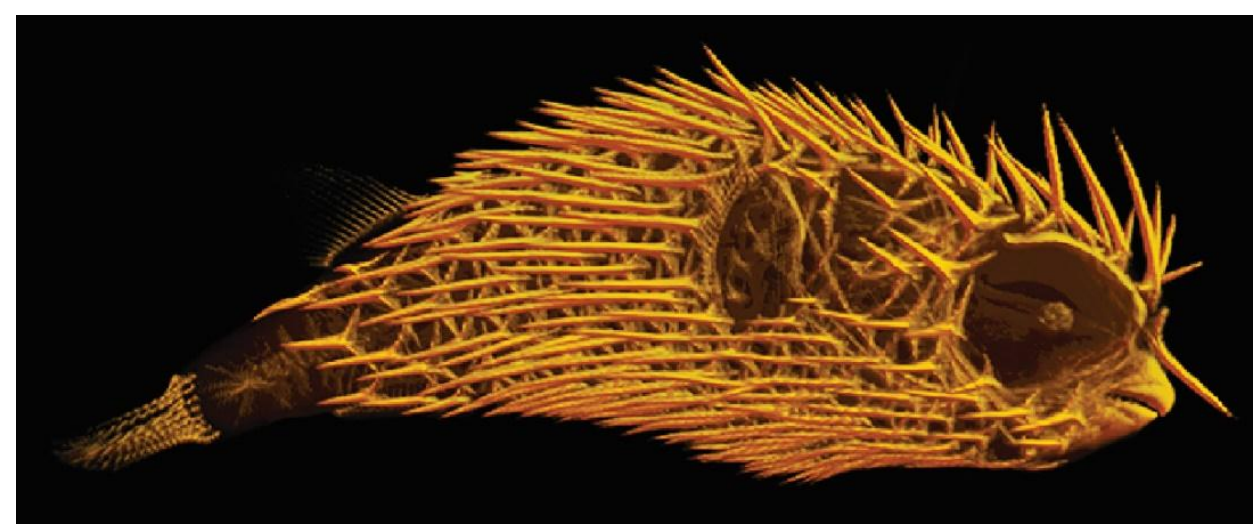

Figure 24. Micro computed tomography image of a porcupine fish (Diodon holocanthus) displaying the long spines embedded within the skin of the fish. Unpublished work provided by Frances Su (UCSD). 
(a)

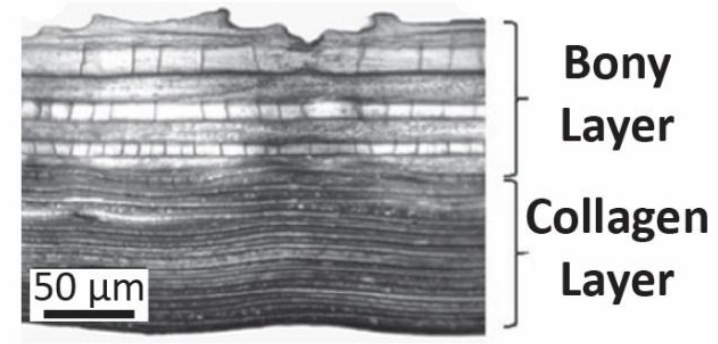

(b)

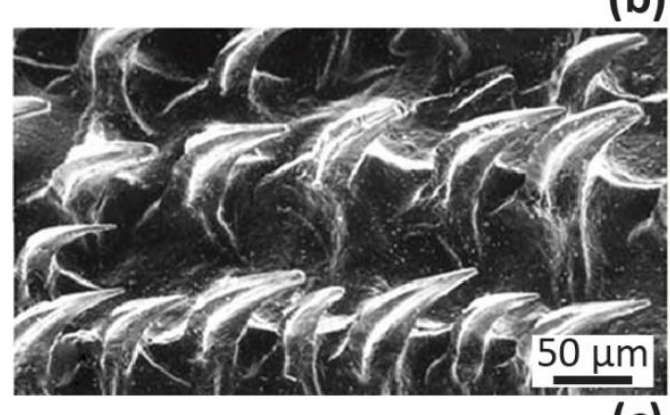

(c)
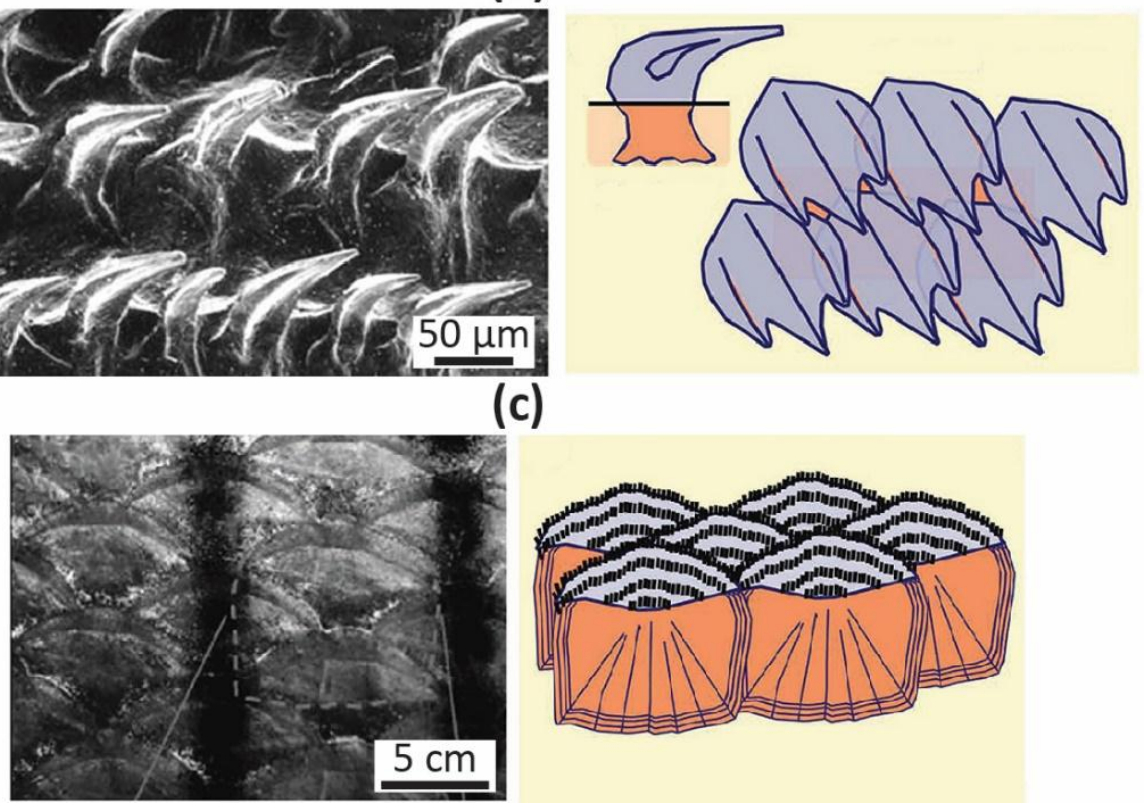

)

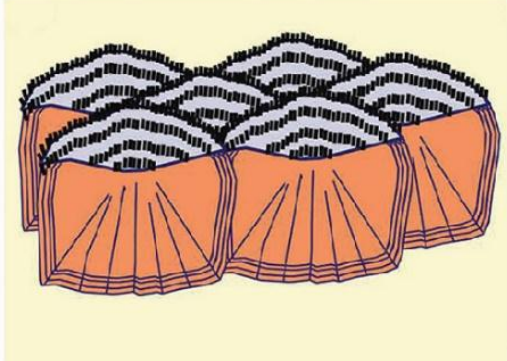

Figure 25. Marine fish scales. (a) Cross section of an elasmoid scale (from a striped sea bass, Morone saxatilis) displaying bone and collagen layers. Major marine fish scale groups: (b) Scanning electron microscopy image and diagram of a placoid scale (from a catshark, Scyliorhinus canicula); (c) Image and diagram of an elasmoid scale (ctenoid, from a striped sea bass). Adapted from: (a) [180], (b) [13, 188], (c) [13]. 
(a)

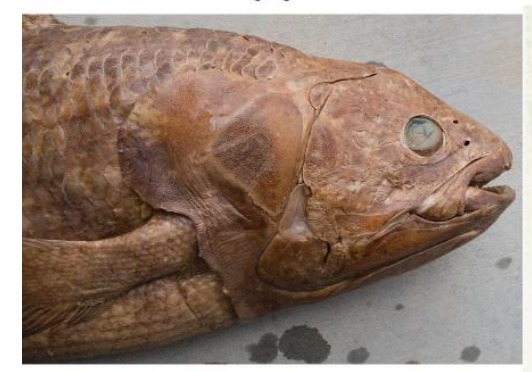

(b)

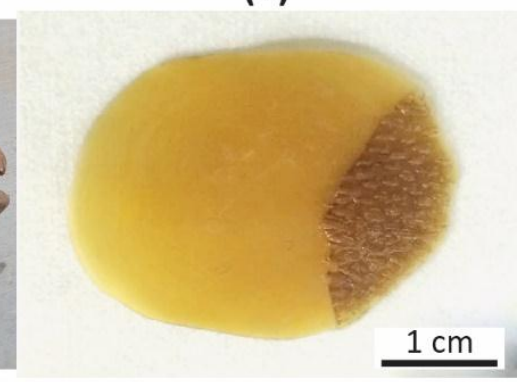

(c)

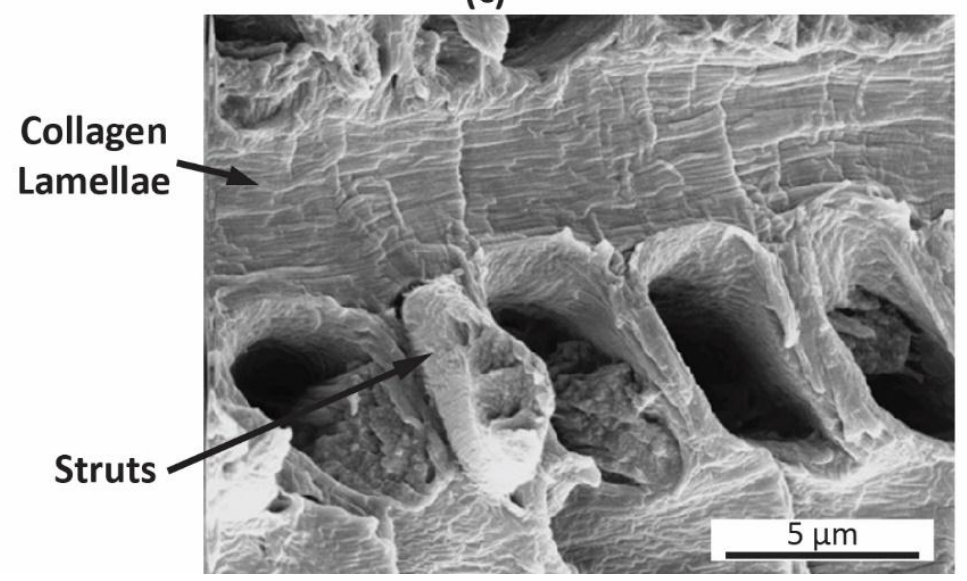

Figure 26. Cosmoid scales from a coelacanth (Latimeria chalumnae). (a) Coelacanth; (b) Cosmoid scale; (c) Micrograph of the cross-section of the cosmoid scale displaying the distinctive struts that bridge between collagen lamellae and provide additional strength. (a) is unpublished work provided by Haochan Quan (UCSD), (b) - (c) are adapted from [196]. 
(a)

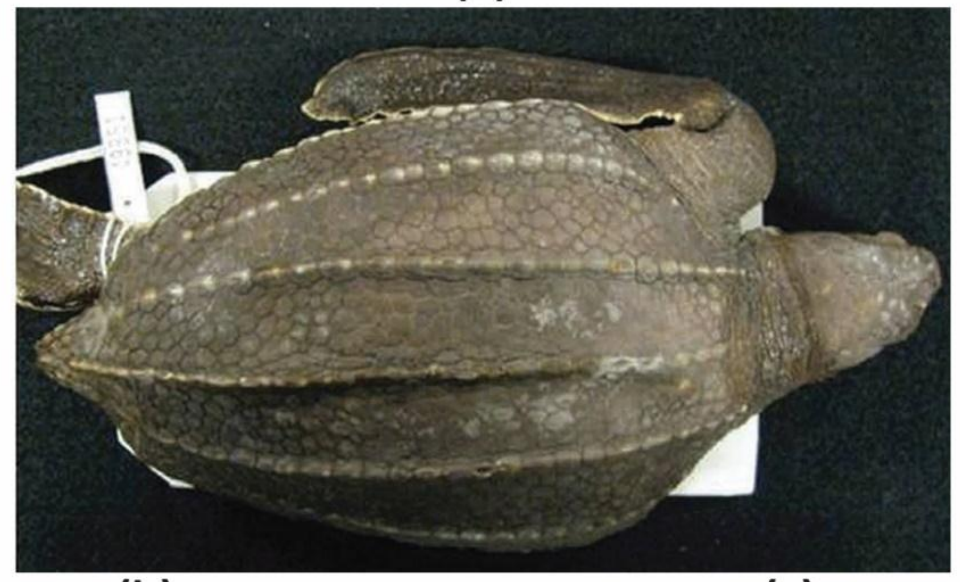

(b)

(c)

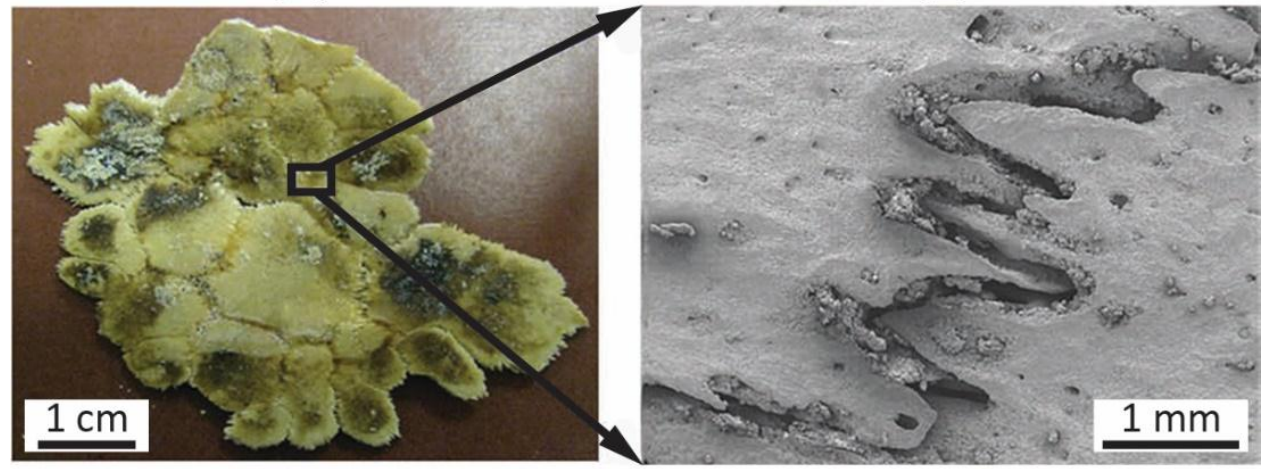

(d)

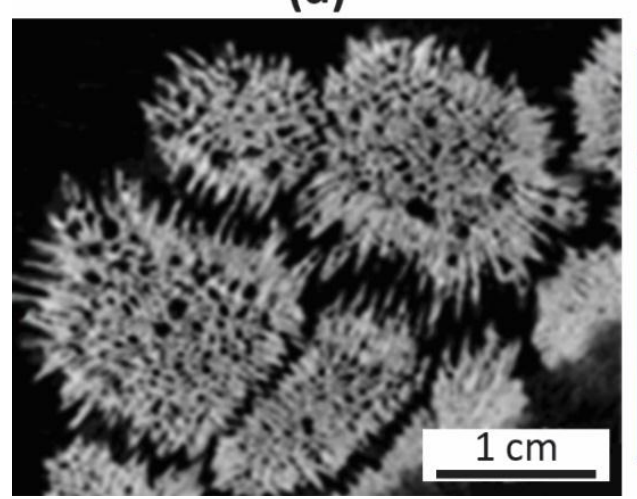

(e)

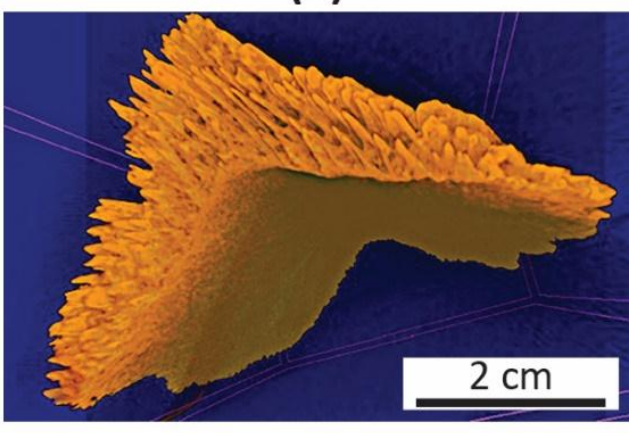

Figure 27. Carapace of the leatherback sea turtle (Dermochelys coriacea). (a) Leatherback sea turtle; (b) A section of carapace displaying osteoderms connected by sutured interfaces; (c) Scanning electron microscopy micrograph of the sutured interface of two osteoderms; (d) Micro-computed tomography image displaying a highly random porous morphology and gap between osteoderms that enable flexing; (e) Micro-computed tomography image of a single osteoderm showing a 3D arrangement of sutures. Adapted from: (a) - (c) [13], (d) and (e) [200]. 
(a)

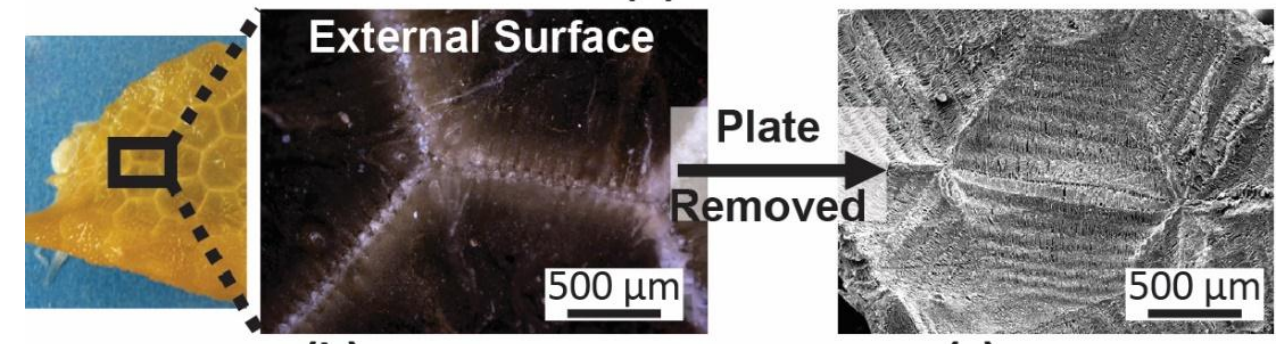

(b)

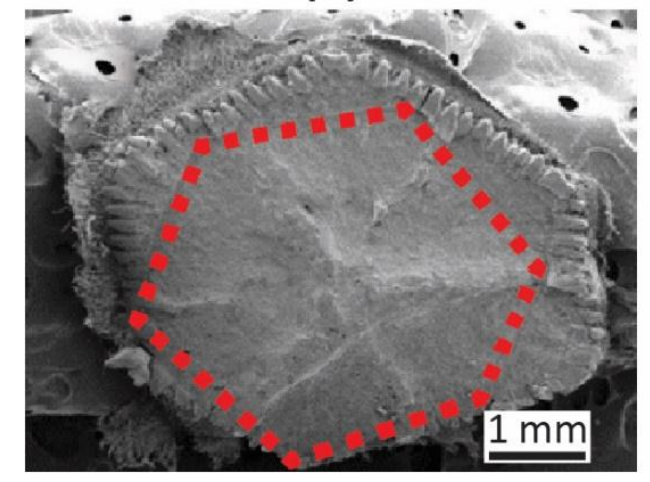

(c)

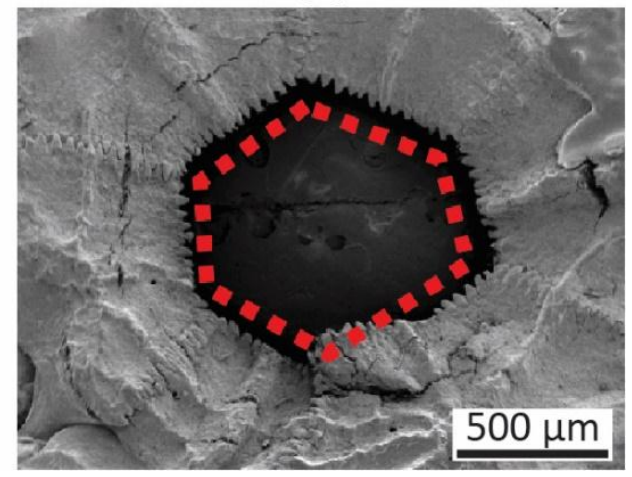

Figure 28. (a) Structure of the lateral scutes of the boxfish (Lactoria cornuta), the external surface is mineralized and rigid, but if removed, a base of aligned collagen fibers is revealed; (b) Fracture of a scute tested in a punching mode by a hexagonal punch (highlighted); (c) Fracture of the surrounding scutes. In both cases, the facture occurs primarily within the collagen base while the mineral remains relatively intact. Adapted from [12]. 
(a)

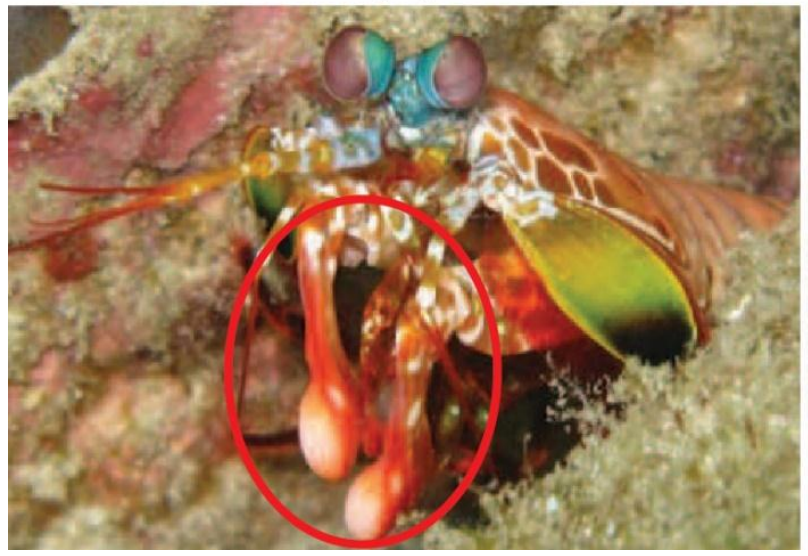

(b)

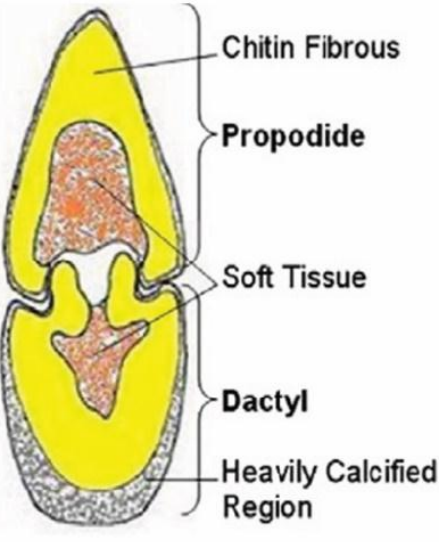

Figure 29. Mantis shrimp (Gonodactylus chiragra) dactyl club. (a) A mantis shrimp with the dactyl clubs circled; (b) Diagram of the cross-section of the dactyl club showing the heavily calcified surface, the fibrous chitin in the interior and soft tissue at the core. (a) adapted from [205], (b) adapted from [4]. 
(a)

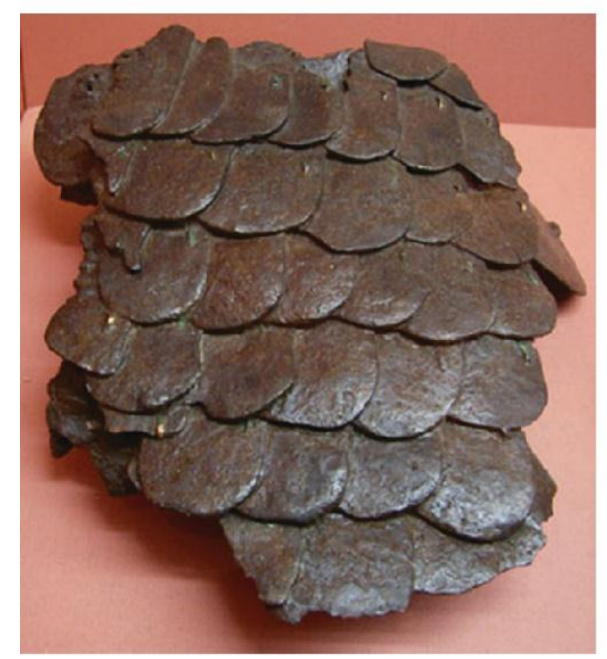

(b)

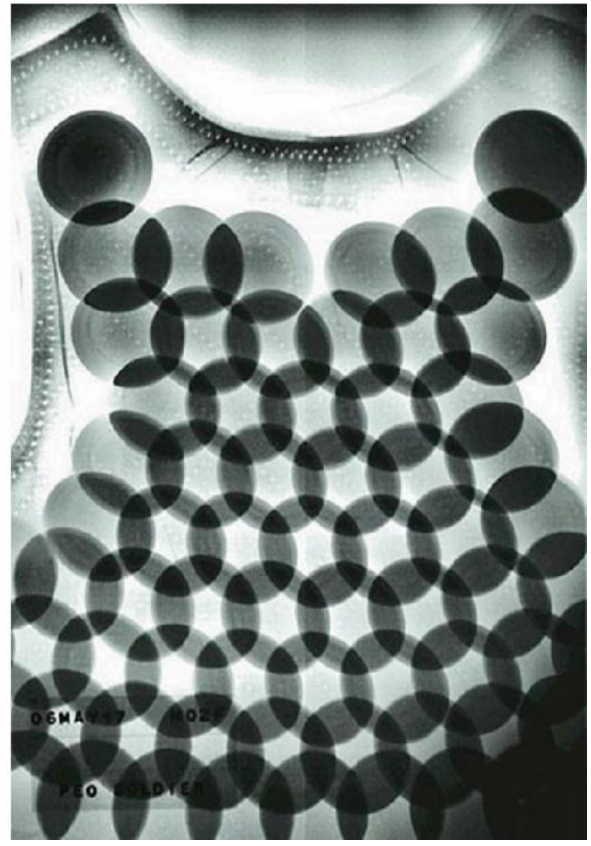

Figure 30. Bioinspired armor designs based upon fish scales. (a) Ancient Roman "Lorica Squamata" armor designed with metal overlapping scales over a leather shirt; (b) Modern "Dragon Skin" armor designed with ceramic, bulletproof and overlapping plates. Adapted from [48]. 